\title{
SOWING THE SEEDS OF RESILIENCE: COMMUNITY PERSPECTIVES
}

by

\author{
Tui Marina Arona
}

A 120 point thesis submitted to Victoria University of Wellington as partial fulfilment of requirements for the degree of Masters of Environmental Studies

School of Geography, Environment and Earth Sciences

Victoria University

July 2015 


\section{Abstract}

The term sustainability is one that has been critiqued as a buzzword which, although popular, holds very little meaning. The same is now being claimed with regard to the term resilience. This research seeks to understand community members' interpretations of the terms resilience and community resilience in response to the Wellington City Council's adoption of a resilience focused outlook. These plans assert that building the city's resilience is a collaborative responsibility, inclusive of both the community and Council. With a wealth of meanings connected to the term resilience, it is important to understand the communities' understandings and expectations of the resilience building process.

Joseph (2013) has critiqued the resilience literature, highlighting that it may be used as a way for governing institutions to reduce their responsibilities and instead put the responsibility of community resilience onto community members. As a second research focus, this study explores participants expectations of both their and the Council's roles in this process. Using a case study of Wellington City community gardens, this research looks at how the current community led initiatives influence community resilience.

Corroborating lessons learnt from pre-existing literature, participants drew from a range of meanings to define the word resilience. Understandings of the term community resilience were much more cohesive. Participants highlighted an appetite for driving the process of community resilience while designating a role characterised by support for the Wellington City Council. The case study of Wellington City community gardens exposed that the initiatives contribute to community resilience through the enhancement of bridging and linking social capital as well as through providing access to human resources, such as skills, knowledge and networks. Although community gardens also provided some physical resources i.e. produce, land, buildings, tools, etc., this area still requires further development. 


\section{Acknowledgements}

The focus of this thesis has been on the role and importance of community, and it is clear that without my own community of people, this thesis would not have been possible.

Firstly, to my Mum, thank you for your love, support, unwavering faith in me, and patience with my late night phone calls full of panic and stress. Without your support and advice this thesis would never have seen the light of day. Thank you for always reminding me of the importance of having a sense of humour when things don't go my way, and that with a little more persistence l'll always work it out.

To my supervisor, Bethany Haalboom, thank you for your enduring patience, advice and guidance. This has most certainly been a learning process and I feel very lucky to have had you by my side for the journey.

Also, a big thank you to Wokje Abrahamse who stepped in as a secondary supervisor. Your council and encouragement was invaluable.

Thank you to Camilla Chaplow, Rachel Elliot, and Steve Mahy for being my home away from home, listening to my complaints and worries, and ensuring I got at least one home cooked meal a week.

To Jerome Cameron, Samantha Morris, and Pattern Reid, what luck that I had the opportunity to share an office with you and with it the highs and lows of the research process. Thank you for keeping me sane, putting up with my chatter and ramblings, offering compassion and advice, sharing your treats, and bringing some fun and hilarity into every day.

Special thanks to Sophia Murphy for her creative title suggestions and also to Avril Macfarlane and Kelly Agassiz for tirelessly proof-reading my drafts and providing kind yet constructive criticism.

Many thanks to Te Ropu Awhina for your support throughout my time at Victoria University, without your encouragement and suggestion, I would not have even considered undertaking a thesis. Thank you for pushing me in my aspirations and achievements. 


\section{Contents}

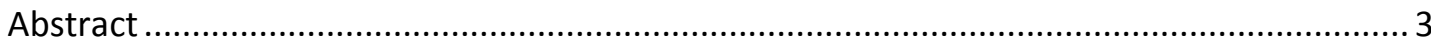

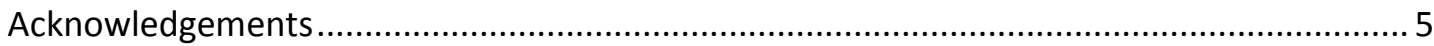

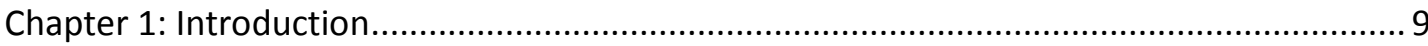

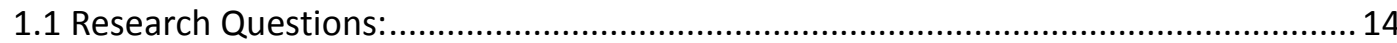

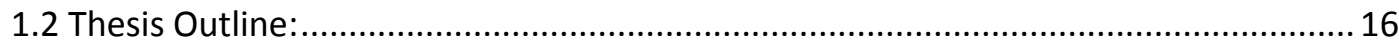

Chapter 2: Understanding Resilience and Change ................................................................ 19

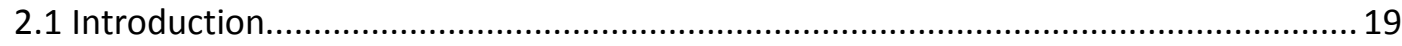

2.2 Traditional Resilience or The Roots of Resilience ........................................................ 20

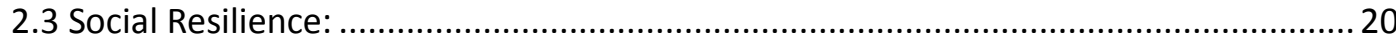

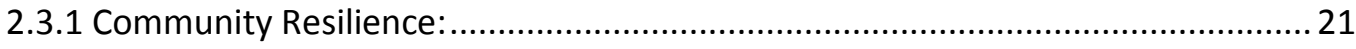

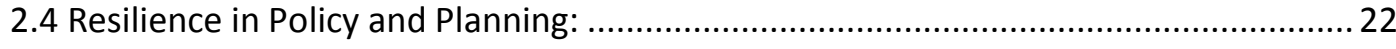

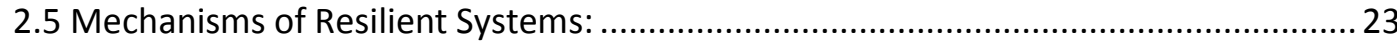

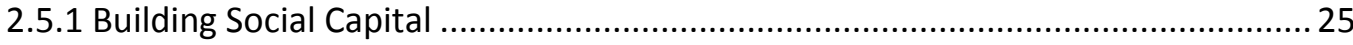

2.6 Resilience Critiques and Contemporary Understandings: ...........................................2 28

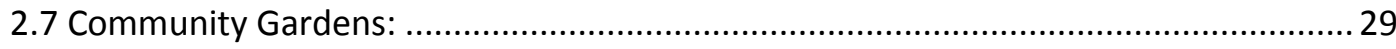

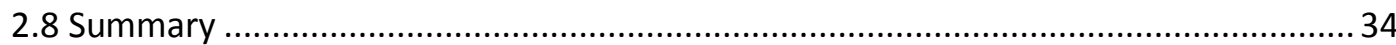

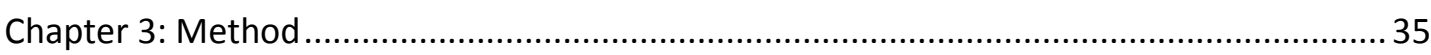

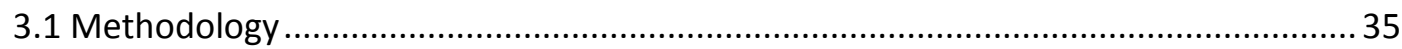

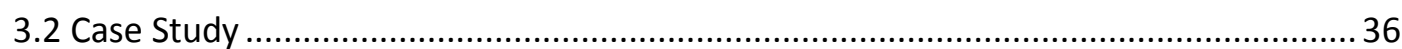

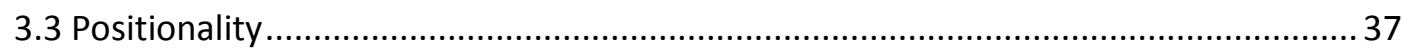

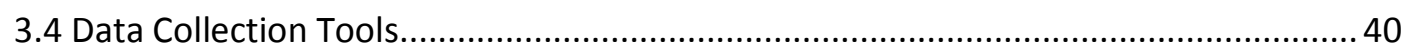

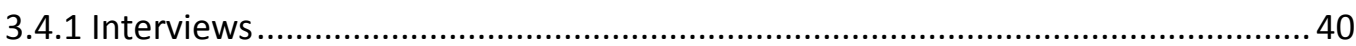

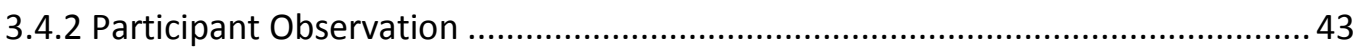

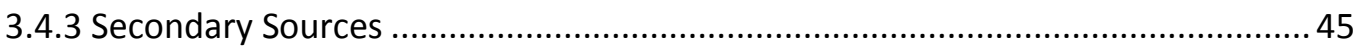

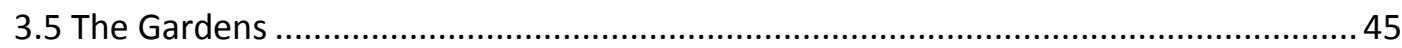

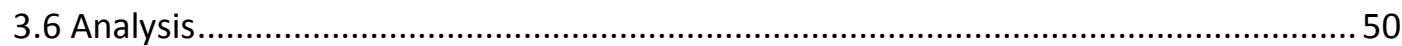

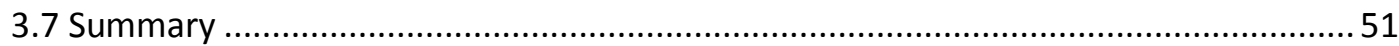

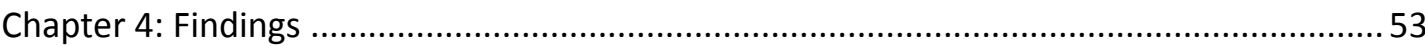

4.1 A Community Understanding of Community Resilience ..............................................54

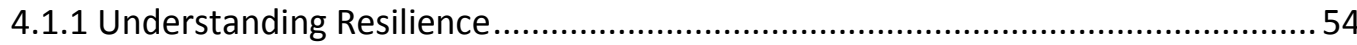

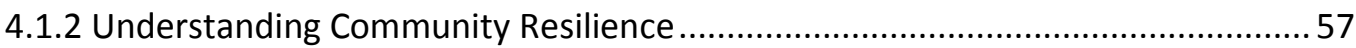

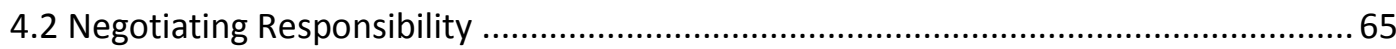

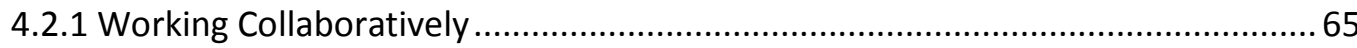

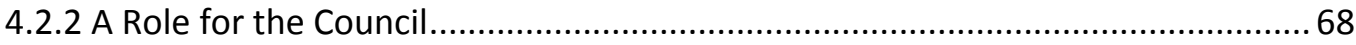

4.2.3 A Role for Communities .................................................................................. 71 


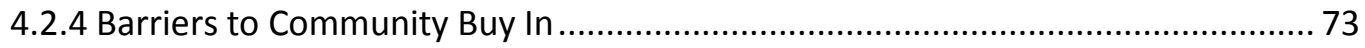

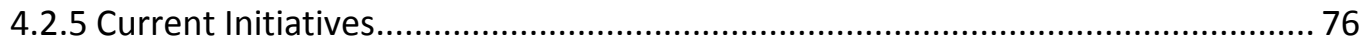

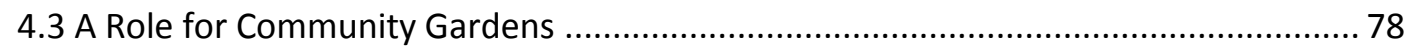

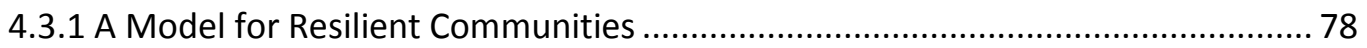

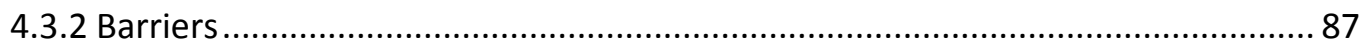

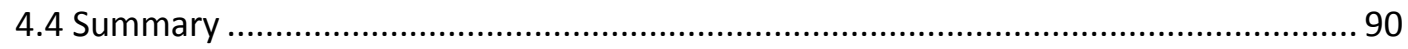

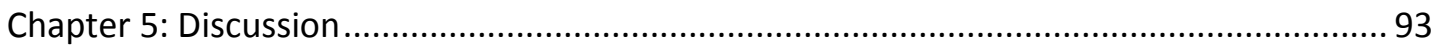

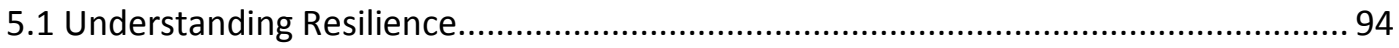

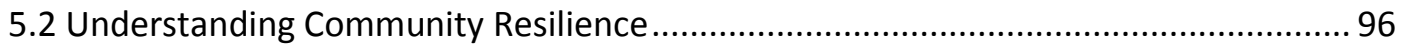

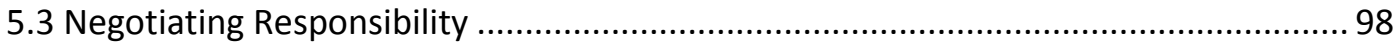

5.4 Community Gardens - A Vector for Community Resilience? ................................... 100

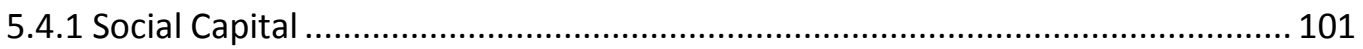

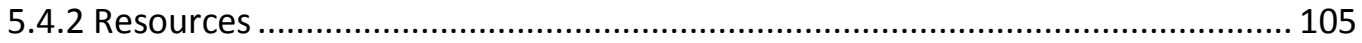

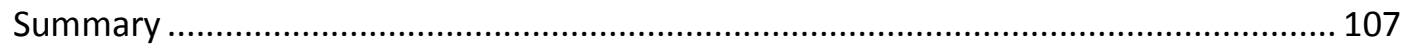

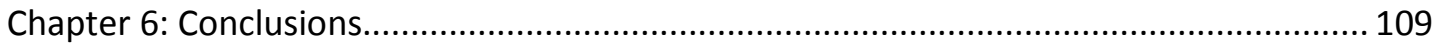

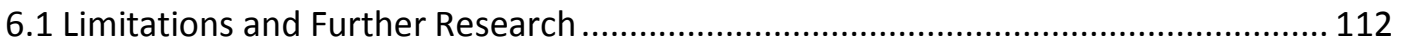

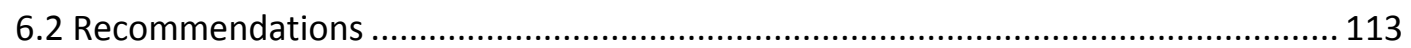

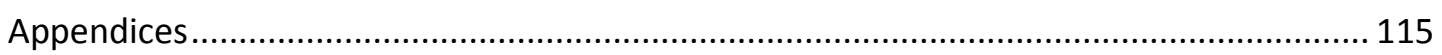

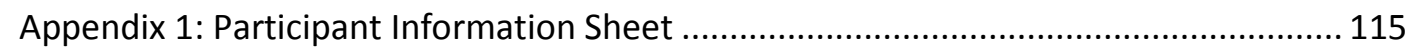

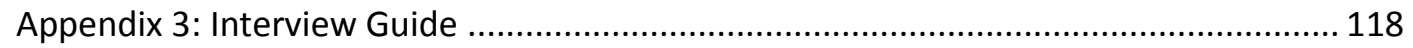

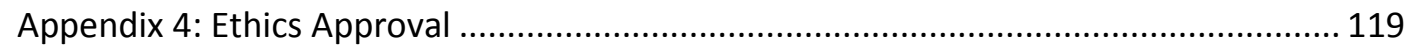

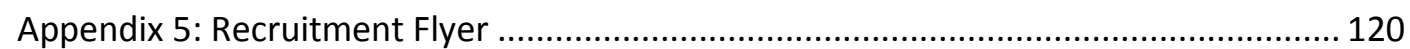

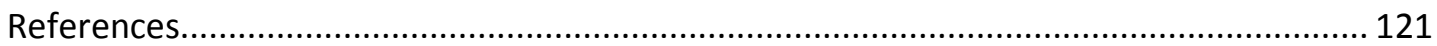

Figures:

Figure 1: Map displaying the location of Community Gardens .......................................... 45

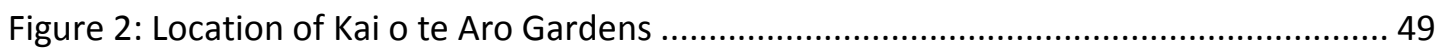

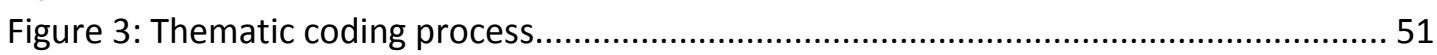

Tables:

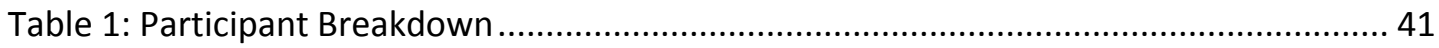




\section{Chapter 1: Introduction}

The term sustainability has been criticised widely in the literature. Often cited as a buzzword or megatrend, its over use in a wide range of disciplines has seen the term lose its meaning (Graedel \& Klee, 2002; Lubin \& Esty, 2010; McMichael, Butler, \& Folke, 2003). Through providing no agreed upon process for which to measure sustainability, the transparency of this word has been further clouded (Graedel \& Klee, 2002). Stumpp (2013) questions whether we are seeing a similar pattern with the increasing use of the word "resilience". The term resilience is derived from two main disciplines, ecology and engineering, and therefore holds multiple meanings and is considered by Strunz (2012) to be a boundary object ${ }^{1}$. The term is often used to describe how a system responds (positively) to an unexpected disturbance (Gunderson \& Holling, 2002; Peterson, Allen, \& Holling, 1998). However, this response may be characterised in many different ways i.e. displaying stability, resistance to change, adaptation to change, or perseverance. Concurrently, resilience may also refer to the status of a system prior to disturbance, i.e. preparedness, robustness, etc. which identifies a systems potential to react positively to change.

The popularity of this term has increased rapidly over the last decade. In particular, its use in the planning arena has become an expectation. The incorporation of this term is logical as both resilience and city planning share a focus on managing unexpected changes (Davoudi et al., 2012). Stumpp (2013) suggests that in order to avoid the same pathway of "sustainability", with the term "resilience" we need to take greater care and refrain from diving into a new concept head first.

Strunz (2012) highlights how the presence or absence of precision in the term resilience could be perceived as either a strength or a weakness, depending on the context and objectives of the research or programme being conducted. Precision is favourably viewed, especially in discourses requiring 'hard science', as it allows for measurability and quantifiability. The issue with using an ambiguous term is that a lack of solid parameters result in it being difficult to measure. This in turn makes it

\footnotetext{
${ }^{1}$ Boundary objects are terms which can be used across multiple disciplines (Strunz, 2012)
} 
hard to quantify progress. Here Strunz (2012) highlights that "very broad concepts may tempt researchers to believe the concepts could explain everything" (p. 114). Absence of an agreed upon definition results in the term being applied loosely by users, which gives the term no significant meaning. Contrary to this, Strunz also explores the strength that conceptual vagueness provides for boundary objects. Conceptual vagueness is necessary for boundary objects which fuse ideas across multiple disciplines. Vagueness allows for a wider scope when approaching a problem which needs to be solved. It allows for creativity and out-of-the-box thinking. This openness encourages participation by a broader selection of stakeholders. Strunz (2012) highlights that different research objectives and contexts requires differing degrees of vagueness and that it is the prerogative of those conducting the project to decide what balance of precision or vagueness is utilised in defining resilience within the intended research.

Wellington City Council provides a prime example of the trending use of this term in local city management policies. The term has been integrated into many aspects of local planning papers. The increasing use of this term is likely a reflection of Wellington City's physical vulnerability. The geographical placement of Wellington City, straddling two converging plate boundaries, brings strong focus to the issue of security and hazards based management. In the event of an earthquake or other severe natural hazard, it is well publicised that the city would be faced with severe challenges in regards to infrastructure and accessibility. This focus on New Zealand's resilience and hazard management has only grown following the destructive earthquakes experienced in Christchurch on 22nd February 2010.

In 2011, the Wellington City Council released "Wellington Towards 2040: A Smart Capital", a report outlining the future vision for the city. Central to this report was the notion of natural, social and technological changes that would see the City develop in new ways over time, creating both new opportunities as well as new challenges (Wellington City Council, 2011c). In response to these shifting challenges and opportunities, the report advocates for greater focus on resilience building for the city. Despite a heavy focus on the topic, this report fails to explicitly define the term resilience. Instead of defining the term, it is discussed in a way that links it to 
the idea of adapting to change. The report encompasses both social resilience i.e. population diversity, social cohesion, social networks and connectedness, as well as resilience focusing on resources and physical assets i.e. urban development and infrastructure.

Within this report is a marked division between the Council's and the community's responsibilities. Attention is brought to the complexity of responsibility in outlining that the Council is "just one player" (p. 4) amongst a wider network of actors. Though vague, this language use shifts the focus of responsibility away from solely the Council, instead highlighting a shared responsibility for "shared action" (p. 41) which is required for successful resilience building within the city. Further discussions of responsibility in relation to resilience reflect a role for the Council in building Wellington's physical and economic resilience. Explicit relationships between these categories are outlined with reference to hazards discourse and economic growth. Though support for community led initiatives is offered, void from discussions regarding the Council's responsibilities is any precise mention of what specifically the Council's role is in building community resilience and social capital initiatives.

In 2012 the Wellington City Council released the "Long Term Plan 2012/22", which was developed out of the "Wellington Towards 2040: A Smart Capital" report. This plan outlined the steps the Council plans to take in order to fulfil the vision outlined the previous year. Within this plan, focus is given to the infrastructural response to hazards i.e. the ability of the city's infrastructure to cope with or absorb shocks from earthquakes and other natural disasters, and also to community resilience with a focus on homelessness and the aging population. Again, no defined explanation of these terms is outlined in the document. Under plans for social resilience the Council identifies their role as supporting communities in their attempts to build resilience through providing support in the shape of services, facilities and grants where appropriate and available. From this, the plan states that the "Community Preparedness Grant" be subsumed by the "Social and Recreation Grant" (Wellington City Council, 2012b). The Community Preparedness Grant originally provided funds for community groups who needed financial assistance for the creation of events or projects that built community resilience (Wellington City Council, 2012a). Established 
in 2011, this Grant was made available for only two years (Wellington City Council Representative, July, 2014). To combat this change, the Social and Recreation Grant's budget was increased by $\$ 25,000$ with additional criteria for funding developed (Wellington City Council, 2012b). This additional criteria outlines that applicants need to consider how their project can contribute to building resilient neighbourhoods or communities, with the aim being to encourage social connectedness and support.

In 2013, Wellington City was selected to take part in the UN-Habitat City Resilience Profiling Programme (Wellington City Council, 2013e). This programme is primarily focused on hazard based resilience and community preparedness as a response to potential hazards (UN-Habitat, n.d-b). Wellington's position above two active and converging plate boundaries, provides a good case study for situating the development of these plans and forming the City as a leader in hazards based resilience planning (UN-Habitat, n.d-b). The programme is scheduled to take between 4-5 years with the aim to achieve five goals (UN-Habitat, n.d-a), these include:

1. Create an "urban systems model" adaptable to locales around the world.

2. Provide a basis of measurements for resilience.

3. Create tools and software to analyse resilience.

4. Produce an international standard for urban resilience.

5. Implement a global resilience monitoring system.

Most recently, the Wellington City Council successfully submitted a proposal to join the 100 Resilient Cities programme hosted by the Rockefeller Foundation at the end of 2014. The 100 Resilient Cities Programme is financially supported by the Rockefeller Foundation and is an international programme formulated with the aim to create a network of cities working together to achieving resilience (100 Resilient Cities, 2014). Although hazard based resilience is a key focus, emphasis is also given to social aspects of resilience. In earning a place amongst the 100 Resilient Cities projects, participants will be able to access a network of support from other participants as well as receiving support from public, private and NGO based service providers to help find solutions to local problems. Central to this, a position will be 
created in the Wellington City Council for a Chief Resilience Officer (CRO) who will be implement a "resilience strategy".

Across these broad and diverse projects is a common display of a heavy focus on hazard based resilience and the response of the physical infrastructure. In reality a city is not a city without its people. As identified by the Wellington City Council the success of any of these projects comes from the ability of the community and council to work together. Despite this, the council fails to 1 ) clearly identify what resilience means and 2) provides only vague reference to both their own and the communities' expected roles in this process. This research aims to address the issue of community members' understanding of the term resilience, and their perceptions of the Council's role in building resilience, in order to help create a foundation of understanding between these two stakeholders that can be used to enhance community resilience. According to the Department of Internal Affairs (2011) role of local council is to "[enable] democratic decision-making by and for local communities." (p.1), thereby community members' understandings should be a formative concept for the development of the council's understanding and the council's actions should be manifest in response to community members' needs.

This research also aims to contribute to the existing literature as it gives further insight into the complexities of the term and its usage. Use of the term by the public is growing in popularity, it is important to establish how members of the public are interpreting these terms as involvement and support from the public body is cited by the Wellington City Council as being required for the implementation of their plans. In addition to this, Brown (2014) critiques the concept of resilience stating that it does not consider that there may be multiple outcomes or 'desired states' envisioned by the users of the term. This research seeks to examine whether participants have similar expectations of the resilience building process within Wellington City communities.

The use and perception of the term 'resilience', by Wellington community members will be explored from the perspectives of community garden members from community gardens located within Wellington City. This research has been grounded 
within the context of community gardens as they are often used to build community resilience through the creation and support of social capital, advanced social networks/connectedness, and increased access to physical resources i.e. food supplies, tools, water collection etc. (Kingsley \& Townsend, 2006; Krasny \& Tidball, 2009; Pudup, 2008).

The Wellington City Council (n.d-b) defines a community garden as "a small-scale, low-investment neighbourhood communal gardening venture, where the primary purpose is growing vegetables or fruit" (p. 1). Wellington City plays host to over 30 different, volunteer operated, Community Gardens (Wellington City Council, n.d-a). The types of gardens in the area include: community gardens on public property; gardens established on City Housing sites primarily for the residents of these buildings; private garden groups; and collective gardening through institutions such as schools and churches. This study focuses on gardens located on public grounds which are open to any members of the public for either collective gardening or the establishment of plot gardening. Plot gardens are a large communal space where members are allotted a section which they can work on independently and have agency and ownership of both the process and the produce grown in this space. Unlike community plot gardens, communal gardens are characterised by a collective attitude to work in the gardens with the resulting produce being shared between participants.

\subsection{Research Questions:}

The overarching goal of this research is to investigate how community gardens members in Wellington understand and build resilience. This research addresses community members' perceptions of both the process and outcome of community resilience building. This cannot be achieved without first grasping how communities understand and use the word "resilience". As such, the following research question is addressed:

How are the terms "resilience" and "community resilience" perceived by community garden members from Wellington City communities? 
In "building resilience" we are actively working towards creating an envisaged state (Brown, 2014). This question explores the multiple meanings behind the use of the term. In moving resilience into a social field we need to understand what this translation of the term implies and how it is interpreted by its users. With issues such as resource constraints becoming ever more apparent, the negotiation of stability or transformation to a new state is crucial.

This question seeks to contribute to the existing literature as it gives further insight into understanding how the term is used by the public. It is important to establish how members of the public understand these terms as the Wellington City Council frame resilience building as collaborative process requiring involvement from the Wellington City communities. Material from the Wellington City Council plans and strategies, as well as interviews with Community Garden participants were used to answer this question.

The Wellington City Council has identified that building community resilience should be a collaborative process between the communities in question and the Wellington City Council. However they fail to explicitly identify what this responsibility will look like for either player. In response to this, this research explores expectations the community has of themselves and of the Wellington City Council in this process. Joseph (2013) argues that governmental institutions utilise the term resilience to divest their own responsibility for providing the public with stability and growth and instead encourage communities to take this responsibility upon themselves. Drawing from this literature, this claim is investigated through interviews with members from community gardens by addressing the following research question:

Who do participants from community gardens identify as being responsible for driving community resilience initiatives, and how are these participants responsible?

Resilience is a product of multiple factors (Leach, 2008; Lewis \& Conaty, 2013; Sherrieb, Norris, \& Galea, 2010), and the final research question explores the presence or absence of these factors within Wellington City Community Gardens in 
order to assess their potential use as a tool for building resilience within these communities.

How do members from Wellington City community gardens use these gardens to enhance community resilience?

The findings from this question contribute to the literature by moving the idea of resilience out of the abstract and academic world, as identified by Leach (2008), through highlighting practical initiatives that currently contribute to the enhancement of community resilience. Furthermore, this question aims to build a case for the increase of support and recognition of local community gardens by the Wellington City Council. Observations and interviews with participants from Wellington City Community Gardens form the data for this component of the research.

\subsection{Thesis Outline:}

This introductory chapter has introduced the core concepts central to this thesis, outlined the context for the research, as well as proposed research questions, and highlighted the relevancy of using Wellington City community gardens as a case study to explore resilience in the following chapters. Chapter Two will provide an overview of the literature that focuses on resilience, community resilience, and community gardens. The incorporation of these works have aided the formation and direction that this research takes and has helped to inform data analysis. Chapter Three discusses the qualitative case study approach applied to this research and gives insight into the process of data collection and analysis. Chapter Four is divided into three main segments which outline the results and findings of this research in response to the three research questions posed. The first section of Chapter Four focuses primarily on how participants from Wellington City Community Gardens understand and perceive the terms 'resilience' and 'community resilience'. The second section of Chapter Four explores respondent's perceptions of responsibility over creating 'community resilience' in Wellington City should be negotiated between the community and local government. The role of community gardens is addressed in the final section of Chapter Four, which highlights how community 
gardens are currently used by local participants to enhance community resilience. Chapter Five provides a discussion while Chapter Six provides the final conclusions derived from the findings of this research and presents recommendations based upon these findings. 


\section{Chapter 2: Understanding Resilience and Change}

\subsection{Introduction}

Resilience theory is multi-disciplinary in nature and can be applied broadly over different sectors. Due to its broad use it also has a wide range of definitions, which are complex and differ depending on which frameworks are used in its description. This chapter reviews the origins of the term resilience and describes the term's translation from scientific disciplines into social disciplines. Within the framing of social resilience, this review also explores the concept of community resilience which is currently gaining traction in academia.

This chapter further explores the incorporation of the term resilience into policy construction and the dissemination of the term throughout the public realm. Resilience building has been criticised as an attempt to encourage the public to govern themselves while lessening the responsibility of the governing power. Drawing from the literature on governmentality, this section of the review addresses the second research question which investigates how roles and responsibilities should be divided between the Council and Communities in the community resilience building process.

Leach (2008) has critiqued the use of the term resilience as being a concept which is often sustained in the abstract world of academia, but requires a more tangible link to practical measures for constructive use in policy generation. In response to this, the following section reviews common concepts from the available literature to assess which components make up a resilient system. Within this section, focus is given to the development of social capital, as this concept is one of the strongest indicators of a resilient community, identified throughout the literature.

The final section of this chapter will examine how community gardens have been studied as contributors to community resilience. As critiqued by Leach (2008), resilience should be linked to practical and tangible action. This section evaluates the potential for community gardens to enhance community resilience. 


\subsection{Traditional Resilience or The Roots of Resilience}

Gunderson and Holling (2002) state that from its origins, resilience took upon dual meanings stemming from engineering and ecological frameworks. Traditional conceptualisations often describe resilience in relation to a system's capacity to bounce back to its original state after experiencing a period of distress (Peterson et al., 1998). As referred to by Gunderson and Holling (2002), this is known as engineering resilience. Engineering resilience can be described as the capacity of a system to manage shocks and retain its original identity through negative feedback loops (Berkes \& Folke, 1998; Gunderson \& Holling, 2002; Rotarangi, 2012).

An alternative definition is the amount of disruption required to change a system from one stable state to another (Peterson et al., 1998). This can be termed as ecological resilience, which gives greater reference to the issue of transformations in these systems (Gunderson \& Holling, 2002). Holling's work (1973) on ecological resilience is one of the foundational works on resilience and is among the most cited papers currently available on the topic. Holling (1973) discusses resilience as an ecological concept to explain the persistence of a species to exist through periods of destabilising change. As a concept, resilience has evolved from a focus on stability, to emphasising and understanding the complexity of ecological systems (Lele, 1998). Holling (1973) elucidates the importance of feedback networks which influence these systems. The interaction with feedback loops allows for multiple states of stability to exist within a single system (Holling, 1973). Theories stemming from both of these lines of thought tend to deal with topics such as tipping points and critical threshholds (Lewis \& Conaty, 2013). A lack of resilience is identifiable in the collapse or adaptation of ecosystems brought about due to severe change or increased stress (Lewis \& Conaty, 2013).

\subsection{Social Resilience:}

The transition of resilience to the social sphere was predicated on the growing awareness of societal impacts on eco-system health and the damage this creates 
which in turn, impacts societal well-being (Lewis \& Conaty, 2013). In contrast with ecological resilience, social resilience applies more specifically to communities. As defined by Adger (2000, p. 374), social resilience is the "ability of groups or communities to cope with external stresses and disturbances as a result of social, political and environmental change". The influence of politics, power relations, psychological and moral norms is often absent in literature dealing with ecological resilience, yet is a focal point in the discussion of social resilience (Wilson, 2012). Social resilience recognises these influences as strong factors which contribute to, not only relationships between people within society, but also society's relationship with the environment. It is these relationships which contribute to human well-being (Wilson, 2012). A crucial difference between social and ecological resilience is that unlike ecological resilience, social resilience can never truly bounce back to an original state (Wilson, 2012). This is due to the human capacity for social learning, and because of this, human systems are not stable, but always in a state of change (Wilson, 2012).

\subsubsection{Community Resilience:}

Scholars are also now looking towards communities and their ability to inspire environmental and social change at a local scale (Wilson, 2012). Community resilience, as a sub-form of social resilience, requires the understanding that although communities do not control all conditions which affect them, they can to some extent manage the way in which they respond to these changes (Berkes \& Ross, 2013). Community resilience, which can be of either a preventative or reconstructive nature (Wilson, 2012), is defined by Magis (2010) as "the existence, development, and engagement of community resources by community members to thrive in an environment characterized by change, uncertainty, unpredictability, and surprise" ( $p$. 402). Resilient communities are constructed on trust, social cohesion, strong interconnections, regular and positive interactions, and by members who are socially invested in the place and space (Zautra, Hall, \& Murray, 2008). Magis (2010) echoes this and additionally proclaims that availability, engagement with and development of community resources, collective action, active agency, strategic action, equity and planned impact are all crucial components of community resilience. 
Community resilience has emerged from the convergence of ecological resilience and psychological resilience (Berkes \& Ross, 2013). Community resilience combines systems orientated thinking with disaster based theory. In doing so, this combination deals with adversity and the way individuals cope, giving insight as to how individuals in communities interact to cope during times of change (Berkes \& Ross, 2013). In using a social-ecological lens in understanding community resilience, it is possible to apply a "richer set of analytical concepts" to the term, whereas a psychological perspective provides a greater understanding of the social science processes involved (Berkes \& Ross, 2013, p. 16).

One reason why community resilience is becoming a popular topic is due to urban and economic growth which puts pressure on resource availability (Melnick, 2005). Due to the coupling of GDP growth and consumption levels it is recognised that areas with higher economic inputs are greater resource consumers (Melnick, 2005). A growing urban population has incited a move toward developing urban agriculture as a way to support local populations (Chaplowe, 1998). Urban agriculture has the potential to lower threats to food security and aid income generation (Bhattarya, 2005). Furthermore, urban agriculture can minimise waste and importation expenses due to recycling and reduction of transportation needed for perishables, creating a follow through effect in reducing transport emissions (Chaplowe, 1998). Chaplowe (1998) purports that urban agriculture may increase the efficiency of urban land use, and reduce the vulnerability of people to economic and food security shocks.

\subsection{Resilience in Policy and Planning:}

In policy, the term resilience is prominent, but the context and language in which it is used is integral to how it is received (Hayward, 2013). Davoudi et al. (2012) state that within governmental institutions, much of the discourse surrounding resilience stems from an engineering approach to resilience. Documents published from these institutions are based on the potential for a system to bounce-back after a disturbance, preventing the system's collapse. Unlike traditional conceptualisations of social resilience which focus heavily on disaster based disturbances in the context of natural hazards, Lorenz (2013) reconceptualises disaster, stating that disaster is 
simply when a community of people "fail to receive expected conditions of life" ( $p$. 11). This reframes disaster, moving the concept away from connotations of simply hazard based resilience theory, and increasing the potential for the inclusion of other "disaster" based issues such as political, economic and social upheavals.

Another focus of resilience theory in policy is often applied to promote economic resilience above all else to create a strong foundation with which to address other shocks (Hayward, 2013). Market growth is not a new focus within policy discourse, however by applying market growth to a resilience discourse, the language used in association of these terms enhances the importance of the market (Hayward, 2013). Hayward (2013) states this entrenched line of economic thinking can be counterproductive in relation to resilience, as it assumes that current dominant discourses which support economic growth are sufficient and does not allow for the development of non-growth orientated alternative trajectories.

The incorporation of resilience focused thinking in planning is an easy alignment, as both resilience and planning encompass core principles of flexibility and adaption to change (Davoudi et al., 2012). Joseph (2013) poses the theory that this natural alignment comes down to the neo-liberal principles that are embedded within resilience theory, which makes it a desirable tool for planning and community management. This includes aspects such as reflexivity, individual responsibility, the ability to bounce-back, and self-reliance. Together these factors provide a foundation for a framework that encourages people to self-govern, reducing government responsibility for planning and community management.

\subsection{Mechanisms of Resilient Systems:}

Although resilience and community resilience are becoming more popular amongst academics, professionals and the public alike, as stated by Leach (2008), the term must be bound to something tangible and not purely sustained in the abstract world of academic discussion. This section explores the main concepts which make up a resilient system, allowing for the term to transverse the abstract of academia into 
tangible use for policy creation. The following section examines how resilient social systems are created.

Despite variability in the application and meaning of resilience, similar concepts which constitute a resilient system are evident within the literature available. The following section will discuss the factors that influence the strength of resilience as applied to social systems. Table 1 outlines several concepts that have been discussed in the literature as components of resilient systems. Although individually these concepts enhance systems, when applied in tandem, they create robust and enduring systems.

\begin{tabular}{|c|c|c|}
\hline Concept & Application & Authors \\
\hline $\begin{array}{l}\text { Access to } \\
\text { resources }\end{array}$ & $\begin{array}{l}\text { Economic stability and the removal of restrictions to } \\
\text { access resources enhances the capacity of } \\
\text { stakeholders to respond to disturbance. }\end{array}$ & $\begin{array}{l}\text { Lewis and Conaty, } \\
\text { (2013), Sherrieb et al., } \\
\text { (2010) }\end{array}$ \\
\hline Diversity & $\begin{array}{l}\text { Relates to flexibility. Lowers the potential of large } \\
\text { scale disruption stemming from a single event. } \\
\text { Although diversity may improve resilience alone it } \\
\text { does not necessarily reduce vulnerability. }\end{array}$ & $\begin{array}{l}\text { Lewis and Conaty } \\
\text { (2013), Leach (2008) }\end{array}$ \\
\hline $\begin{array}{l}\text { Feedback } \\
\text { Loops }\end{array}$ & $\begin{array}{l}\text { High functioning communication networks allow for } \\
\text { information to be relayed, providing a } \\
\text { comprehensive database of information which } \\
\text { improves the identification of future threats and } \\
\text { thresholds. }\end{array}$ & $\begin{array}{l}\text { Lewis and Conaty, } \\
\text { (2013) }\end{array}$ \\
\hline Innovation & $\begin{array}{l}\text { Space for learning and experimentation enhances } \\
\text { adaptive capacity. }\end{array}$ & $\begin{array}{l}\text { Lewis and Conaty, } \\
\text { (2013) }\end{array}$ \\
\hline Modularity & $\begin{array}{l}\text { System components work individually which reduces } \\
\text { the potential of passing on shocks throughout the } \\
\text { system }\end{array}$ & $\begin{array}{l}\text { Lewis and Conaty, } \\
\text { (2013) }\end{array}$ \\
\hline Overlap & $\begin{array}{l}\text { Roles are filled by multiple actors/components. By } \\
\text { encouraging overlap and reducing streamlined } \\
\text { efficiency the loss of a single actor/component will } \\
\text { not derail the system in entirety. }\end{array}$ & $\begin{array}{l}\text { Lewis and Conaty, } \\
\text { (2013) }\end{array}$ \\
\hline $\begin{array}{l}\text { Social } \\
\text { Capital }\end{array}$ & $\begin{array}{l}\text { Collaboration of actors allows for effective and } \\
\text { efficient responses to disturbances and larger } \\
\text { resource pools to draw from. }\end{array}$ & $\begin{array}{l}\text { Gunderson and Holling } \\
\text { (2002), Lewis and } \\
\text { Conaty (2013), Sherrieb } \\
\text { et al. (2010) }\end{array}$ \\
\hline
\end{tabular}

Table 1: Components for creating resilient systems 


\subsubsection{Building Social Capital}

Aldrich and Meyer (2015) cite social capital as being the greatest contributor to community resilience. Physical improvements to resilience i.e. infrastructure development, can only reduce risk to a certain degree. As highlighted in Table 1, social capital is repeatedly mentioned in the discussion of resilience for its contribution in constructing robust and resilient social systems (Gunderson \& Holling, 2002; Lewis \& Conaty, 2013; Norris \& Stevens, 2007; Sherrieb et al., 2010). Social capital refers to the links or networks that exist between individuals within a community (Gunderson \& Holling, 2002; Norris \& Stevens, 2007). As highlighted by Aldrich and Meyer (2015), following a disaster it is individuals within the community who are the first to react, not social service units or professionals. Assistance through personal relationships in these situations vary from immediate medical response, information sharing, financial support, familial support and care, and stress management.

Social capital increases access to different resources and streams of information and is considered critical for the development of further features of resilient communities, as the development of strong relationships are a starting point for tapping into the other elements of resilience i.e. resource sharing, information feedback, innovation, diversity etc. (Aldrich \& Meyer, 2015). Sherrieb et al. (2010) discuss two factors that help to cultivate social capital. The first is building structural social capital, which refers to the organisations and networks which are in place that contribute to communication between both individuals and groups alike. The diversity and strength of these interconnections allows for the sharing of both knowledge and resources between individuals, which in turn provides a foundation for collectivism (Gunderson \& Holling, 2002). The second component of social capital refers to cognitive social capital, which comprises the social norms and perceptions that allow for cooperation, such as trust and reciprocity (Sherrieb et al., 2010). Helliwell and Putnam (2004) highlight the importance of social trust stating that many researchers consider social trust to be a foundational aspect of social capital. Other characteristics which would come under the branch of cognitive social capital as discussed by Norris and Stevens (2007) include place-based attachment and an instinctual drive for community. Although these two components can operate as 
individual components, used together, they enhance the strength of social capital (Sherrieb et al., 2010).

Within the concept of social capital there are three different types of relationships that can be formed. These are bonding social capital, bridging social capital and linking social capital. Although all three are concerned with creating networks of people, each involves different "players", and has different outcomes and degrees of strength in terms of relationships formed. The cultivation of all three types are necessary in creating well-rounded, resilient communities.

Bonding social capital refers to the networks and relationships present within socially homogenous groups (Coffé \& Geys, 2007; Hawkins \& Maurer, 2010; Poortinga, 2012). Bonding social capital, in particular, cultivates assets such as support and cohesion within groups (Poortinga, 2012). Relationships within groups characterised by homogenous identities i.e. race, ethnicity, religion, family, etc., are considered to be stronger than other forms of social capital (Hawkins \& Maurer, 2010).

Despite the strength of relationships between individuals within the group, for personal development, homogenous group interaction alone is not sufficient (Poortinga, 2012). Strong interaction between members cultivates a streamlined understanding of the world. If these groups remain isolated within their interactions, there is a risk that individuals can become socially disconnected from the wider world, which impedes both mental health and the ability to access wider networks for support and information (Poortinga, 2012). This can inhibit open-mindedness, preventing innovation within the community (Poortinga, 2012). These tight knit groups may also exclude the introduction of new individuals to the group, creating an atmosphere of exclusivity and external distrust (Coffé \& Geys, 2007; Steinfield, Ellison, \& Lampe, 2008). The internal focus of these groups can also be problematic if the group is characterised by negative traits i.e. poverty, as it can compound problems and prevent access to outside resources (Poortinga, 2012). Helliwell and Putnam (2004) further critique the concept in response to its pliable nature, which allows it to be used for many different reasons. As an example, they highlight the 
potential use of bonding social capital in supporting negative actions, such as acts of terror.

Bridging Social Capital refers to the strength of networks between groups of differing characterisations within a community. Unlike bonding social capital, which is related to social cohesion, bridging social capital focuses on encouraging diversity (Poortinga, 2012). Although ties between groups of dissimilar backgrounds are more difficult to broach and are weaker than those formed through bonding social capital, success with bridging social capital provides a higher return on investment as it creates intergroup respect and trust. Developing these qualities are necessary in order to stimulate resilience within a community as it opens up access to information, resources and innovation (Lewis \& Conaty, 2013).

Determining bridging from bonding social capital can be difficult in practice. Coffé and Geys (2007) draw attention to this by highlighting the difficulty of creating defined borders of a group. Identifying groups through characterisations such as religion or ethnicity are problematic as many of these groups can be sub-divided into smaller assemblages, each of which have differences, whether obvious or nuanced. Furthermore, it is important not to forget that individuals hold multiple identities and may subscribe to a number of different communities at one time, or even transition between communities over time.

Linking Social Capital is a newer concept within the theory of social capital, and is perhaps considered the most important of the three when discussing community resilience. Linking social capital describes the strength of the relationships and networks between a community and governmental institutions (Poortinga, 2012). Although this concept is still being developed within the literature, it has been identified as being linked to political capital and political participation. Strong linking social capital is characterised by mutual respect and trust between the community and institutions of power or authority. This trust and respect allows for communities to have access to resources and information with greater ease, enhancing risk communication and preparedness, as well as civic participation (Poortinga, 2012). 
The development of social capital is frequently cited within the literature as being a key component of building community resilience. The presence and role of social capital in participants' understandings of community resilience will be explored in this research as well as how community gardens my aid in developing social capital.

\subsection{Resilience Critiques and Contemporary Understandings:}

Resilience theory has evolved and expanded over time. Rotarangi (2012) argues that contemporary resilience pertains less to the idea of resistance to a disturbance and is more regarded as the system's ability to change to a desired state, thereby improving its position (Rotarangi, 2012). In response to such ideas, Brown (2014) writes that a common critique of resilience theory is the issue of needing a "desired state" (p. 109). Where resilience refers to bouncing back to a state of balance, this notion assumes that there is a desired state that actually exists. In reality, there may exist multiple desired states, depending on the stakeholder's perspectives. This brings into question the issue of system politics and power relations in relation to "who" controls/determines which state is to be desired, what exactly we want to bounce back to, and whose responsibility it is to achieve this (Brown, 2014; Leach, 2008). Following from this idea of power relations, Brown (2014) states that resilience often excludes the social context and circumstances surrounding resilience thinking. The idea of resilience is discussed more often as a system or an object rather than a process. In doing so, these discussions fail to identify the interactive nature of the concept. Furthermore, in using the term resilience, users often refrain from explicitly identifying the issue of "resilience for whom" (p. 109) and more often focus on external disturbance rather than internal systemic disruption.

There is a need for goal orientated progressive focus, which encompasses capacity building, planning and collective vision, which enhances community health, wellbeing and vibrancy. Magis (2010) further extends on this, stating that members of resilient communities act with intention to stimulate change, in order to create a progressive positive shift for the collectives' future. Resilience as a system, is not 
always beneficial or desirable, although it is often used in positive terms, it can also be used to describe the persistence of deficit conditions i.e. poverty cycles (Berkes \& Ross, 2013). In response to this, the occurrence of transformative change becomes desirable, in order to create positive, resilient communities (Berkes \& Ross, 2013). Berkes and Ross (2013) state that transformative change of a system at community level can enhance a community's overall resilience, which can then pass on further benefits to wider systems i.e. regional and national conditions. Zautra et al. (2008) advocate the necessity to expand the idea of resilience past simple definitions, which infer connections to trauma or disturbances, to include conceptualisations of resilience as a transformative process.

Until recently the integration of resilience and transformation has been absent in the literature (Ferguson, Brown, \& Deletic, 2013; Haxeltine \& Seyfang, 2009). Commonly, resilience is understood in engineering terms as persistence or resistance to change, as opposed to a process of evolving with change. Changing a system drastically is often seen as a disturbance or negative process for communities or individuals (Brown, 2014). Brown (2014) suggests that this does not allow room for development of the systems, and instead reflects ecological conceptions that involve the key concepts of adaption and change. Change, however, should be approached with the intention of maintaining the core identity of the system (Brown, 2014). Despite the apparently opposing natures of resilience and transformation, parallels can be drawn in reference to explaining and understanding complex adaptive systems. In combining the two frameworks, focus is instead given to "Transform[ing] system structures [with the goal to create] sustainability and resilience in context of [an] uncertain future" (Ferguson et al., 2013, p. 57). This creates a "resilient system, [instead of simply] a resilient regime" (Ferguson et al., 2013, p. 57).

\subsection{Community Gardens:}

In response to Leach's (2008) critique this thesis grounds the study of resilience within a case study of Wellington City community gardens. There have been few studies done on community gardens outside of the Americas. Guitart, Pickering, and Byrne (2012) note that New Zealand, although abundant in community gardens, is 
understudied in the area, and this study aims to address this gap. Today, community gardens are growing in recognition as a popular form of urban agriculture and as one way to reduce food security shocks. Community gardens are communal property spaces where shared access, ownership or usage is permitted for the public with the general intention of creating a shared resource (Ferris, Norman, \& Sempik, 2001). The intentions, goals, constraints or guidelines associated with community gardens differ from one example to the next, depending on the needs of the community (Ferris et al., 2001). Most of these gardens rely on a sense of democracy for the development and organised running of the space (Ferris et al., 2001).

Krasny and Tidball (2009) categorise community gardens under the umbrella of urban ecological stewardship or civic ecology. Through this, citizens can enhance and improve both the urban natural environment and social capital within the community, leading to greater community well-being. For example, following the Christchurch Earthquake in 2011, the community gardens of Project Lyttleton played a significant role in food security and the strengthening of social relationships in the community (Cretney, 2013). Peoples' sense of belonging is often reinforced through their connections to natural surroundings and familiar flora. Gardening may help link peoples' identity to place as they feel a connection with something they are familiar with or helped create which, in turn, may help to inspire stewardship and care over the resource (Brook, 2003).

Krasny and Tidball (2009) highlight how community gardens can be used to enhance and improve food security, the urban natural environment, and the social relationships within the community. This can lead to greater community well-being. A case study in Melbourne, Australia showed how a local community garden was established in order to diminish negative emotions residents had about the impacts of an increasing urban population and a changing built environment (Kingsley \& Townsend, 2006). The study revealed that participation in community gardening activities, especially "working bees", enhanced social capital, creating networks, support systems and the transfer of information and advice (Kingsley \& Townsend, 2006). Glover, Parry, and Shinew (2005) echoes these findings, drawing attention to 
the potential of community gardens to act as facilitators of social capital development. The networks developed allow individuals to access skills and resources from a wider pool i.e. equipment and labour (Glover, 2005).

An alternative take on community gardens explores their use in opposition to current food systems, which are linked to globalised and industrial systems (Allen, FitzSimmons, Goodman, \& Warner, 2003; Hassanein, 2003). Community gardens are commonly perceived as a way to connect community members to cheap and easily accessible forms of food production (Gottlieb \& Fisher, 1996). Although these gardens do not necessarily provide complete food security, they can be used to supplement households food requirements (Gottlieb \& Fisher, 1996). As Rocha (2001) argues, food security is not a lack of food issue, but an issue of unequal distribution of safe, high quality food. By reframing access to food as a right, this not only ensures governmental support, but also defines people "first and foremost [as] citizens rather than [as] consumers" (Rocha, 2001, p. 43). In doing so this redirects the traditional market-based framing of food, which is one of the main causes of food insecurity. Rocha (2001) highlights that although food security is a public good, the food itself is a private good, and private goods are controlled by market forces, which not only restricts output and accessibility to resources, but can also transfer costs to consumers. By reframing food security as a human right, it becomes a political issue rather than an economic issue. Community gardens as hubs of publically available food, which are 'paid for' based upon a collective commitment of time and energy, work separate from the economic realm and instead can be viewed as a political commentary or movement against the commodification of food. Another way in which community gardens deviate from the neo-liberal production of food is that they allow for local production and aid in the development of economically resilient local communities (Allen et al., 2003; Hassanein, 2003). Through community gardening, participants also build strong civic responsibility and develop the tools necessary to engage in strategy building for overcoming challenges the community faces. Through creating self-reliance, participants are able to move away from industrialised hegemonies of sufficiency (Levkoe, 2006). 
Community gardens can also serve as a vehicle for larger social change. Pudup (2008), highlights that the surge in community gardens throughout history has correlated with large scale social change i.e. WW1, WW2, Urban Social Movements, and the Great Depression. During such times of change, community gardens have acted to build resilience in terms of economic and food security. Surpassing such achievements, these initiatives generated positive change through improving social equality, empowering communities and enhancing social capital.

Gerlach and Hine (1970) refer to change in two ways. They categorise social change as either developmental or radical/fundamental. Developmental change refers to small changes made to current systems, which allow for systems to retain their original identity. This process of change aligns with Geels and Kemp (2006) who identify reproduction as a process of change that stimulates only minor alterations and projects fundamentally the same regime. This is referred to by Geels and Kemp (2006) as a stable state regime, although this does not mean that systems reject change, but that minor innovations do not undermine, detract or defer from the current system. This type of change is important as it creates minor improvements over time, which ultimately result in a more effective and efficient system (Geels \& Kemp, 2006). This approach is similar to Haxeltine and Seyfang (2009) of replication, which consists of small incremental changes to slowly alter and shape a new system. In contrast, radical or transformative change, works to alter social systems and structures in a way that overhauls its current identity e.g. the Agricultural Revolution. Ferguson et al. (2013) cite transformative change as a holistic shift in a systems structure and function. Haxeltine and Seyfang (2009) work uses the term translation to describe radical change. This is the direct translation of new ideas into hegemonic settings. Haxeltine and Seyfang (2009) state that this is potentially challenging if the proposed changes are discrete from current regimes. Transformational change in societies is experienced through members of society questioning social norms and behaviours, extending past these traditional concepts to embrace a new way of living (Brown, 2014). 
In order for this new way of living to become a transformational change it must be embraced across many aspects of society both in terms of cultural and social acceptance, and formal and organised processes i.e. through law and politics (Brown, 2014). However, the balance of society tends to favour that of the status quo, meaning that opposition often is felt to such proposed changes. To ensure against such an outcome it is necessary to enhance processes of change by being inclusive of different stakeholders, as different focal points allow for greater understanding of the holistic and complex issues involved (Brown, 2014). They note that a gap exists within research in identifying how transformative change is integrated into policy planning and action, which in turn has hindered progress in planning processes. Current approaches to transforming society through policy support linear change rather than transformative or unexpected change. In part, this is a determinant of short term policy goals which reflect electoral cycles. Ferguson et al. (2013) argue that this is insubstantial in regards to transformative changes, which occur on a 2050 year long span.

Although Pudap (2008) identifies a link between community gardens and social change, he also critiques community gardens as an extension of neo-liberal governance, whereby despite self-perceived independence, communities are developing constructed trajectories. In effect, the State is merely absolving responsibility for provisioning support by encouraging communities to be selfgoverning bodies. This argument aligns with neoliberal governmentality framings of resilience posed by Joseph (2013). Yet, the successful functioning of urban agricultural initiatives is dependent on access to infrastructure and services; institutional support; facilitative urban policies and regulations; and access to resources and land, amongst other criteria (Armar-Klemesu, 2000; Jacobi et al., in Bhattarya, 2005). Considering these criteria, it seems clear that the role of the State is critical. In order to address the role of government institutions, this research will explore community garden member perceptions of their roles and responsibilities in creating a resilient community, as well as their expectations of the Wellington City Council in this regard. 


\subsection{Summary}

The notion of resilience has risen quickly over the past 50 years, being continuously altered and added to along the way, and being applied to a wide range of topics. Hollings work on ecological resilience saw the term bought into popularity. With this popularity, the term began to be added to and adapted across a range of disciplines. Its conversion from the disciplines of physical science in to social science has seen the term transformed even more so. As a sub-form of social resilience, the concept of community resilience has also become a popular concept. Unlike general resilience, community resilience reflects more specifically upon a community's ability to withstand shocks.

With the adoption of the term resilience across different disciplines has come the issue of measuring resilience. Across the literature, an array of concepts have been identified which contribute a resilient system. Of these, the concept of social capital appears to be the greatest contributor to community resilience and will be explored in this thesis. The development of social capital acts as a starting point to enhance other aspects within the community which builds further resilience i.e. transfer of skills and knowledge, increased access to resources, social and emotional support and wellbeing etc.

Community gardens have been recognised as one way in which to build community resilience. Community gardens are shared spaces where members can work either collectively or independently on a garden. Community gardens are often cited as a way for individuals to reduce financial burden through supplementing purchased groceries. However, beyond this, community gardens may be thought of as a way to reduce reliance on traditional food production systems and empower members. Despite this, the focus on self-reliance and empowerment through community gardening has been critiqued as a characteristic of governmentality. 


\section{Chapter 3: Method}

The purpose of this chapter is to guide the reader through the process conducted in carrying out this research. The following sections will introduce the factors that have led to the creation and direction of this research, introduce the gardens that were represented in this study, as well as describe the analytical process employed. This research was conducted utilising a case study approach which focused on participants from community gardens within Wellington City.

\subsection{Methodology}

A post-structural epistemological approach describes the implicit relationship between reality and the use of language. This theory states that the way language is constructed and reproduced is integral to the way reality, i.e. actions, ideas, beliefs, are manifest within society (Kitchin \& Tate, 2000). Thereby, the world is constructed by the way it is discussed. Rather than words being used to describe society, society is a reflection of the language we use. The interpretation and meaning behind the words which people use to describe society need to be deconstructed in order to expose the many meanings these discussions encompass. Through understanding the way in which we use language to describe society we can actively reframe these discussions. The discourses, and interpretation of these discourses evolve throughout time (King \& Horrocks, 2010), revealing how transformations in society are manifest through language.

A post-structural epistemological approach is appropriate for this research, as it deals with multiple understandings of resilience. This theoretical approach allows for the critique of society and institutions while providing a path in which transformation can occur (Creswell, 2012). In particular, this research aims to provide insight into how communities understand the discourse of resilience, and outlines their expectations of what a resilient community entails. Through identifying these bottom up, multiple understandings and expectations, this research may be utilised to help both communities and the Council identify parameters and needs within future plans.

This research uses a qualitative methodological approach. Qualitative methods, as discussed by Limb and Dwyer (2001) embrace the notion that the world is shaped by 
human processes. These processes, i.e. economic, political, cultural or social, are dynamic and continually influence the way the world appears. This presentation of the world is received, interpreted, and perceived in different ways based upon an individual's own experiences. Qualitative methodologies seek to understand how these perceptions are constructed within a certain context (Limb \& Dwyer, 2001). Qualitative methodologies in this research allow for participants to express their perceptions of resilience and provide for the extended discussion of their experiences, viewpoints and motivations (Hay, 2010).

\subsection{Case Study}

This research lends itself to a case study approach. A case study approach focuses on contemporary issues or events that are given meaning through real life contexts (Yin, 2014). Yin (2014) frames this approach as a way to interpret a decision or a process. Moore, Lapan, and Quartaroli (2012) use this approach to explore important issues within social or political spheres. Swanborn (2012) also identifies case study research as an appropriate approach for analysing the "implementation processes of governmental policy" (p. 5).

This method allows a researcher to examine both reasoning and process with phenomena (Yin, 2014). It allows for the examination of how community members think about resilience; how their actions contribute to resilience; why these actions are important, and how can we enhance community resilience. In addition this method allows exploration of how responsibilities should be divided up and what constraints exist in creating a resilient future for the communities in question. Understanding these perceptions are an important segment of the process as it analyses the potential (or lack thereof) for collaboration between the community and Wellington City Council.

Yin (2014) highlights that often case studies are critiqued as being poor approaches which lack rigor. Although the flexibility that this method provides can be framed as a weakness, it allows for a wider inclusion of data sources which provides the researcher with a deeper understanding of both the context and phenomena. To improve rigor, case study approaches must be constrained by location, a frame of 
time, and an identified context (Moore et al., 2012; Yin, 2014). The research for this thesis is bounded by seven Wellington City community gardens with data that informs this research collected between the months of July and November 2014. The intention of this research is to explore the potential and willingness of these participants to contribute to the Councils current resilience building initiatives.

Within the realm of a case study method this thesis takes on elements of both an instrumental and intrinsic approach. An instrumental approach, although identifying that the case and context are important, primarily focuses on expressing the phenomena at hand (Grandy, 2009). The phenomena being explored here is how resilience is understood by community members. In line with an instrumental technique, the aim of this work is that it may be compared to similar studies in order to inform the different ways in which people talk about the word resilience and the expectations that are manifest in response to its use. Although a primary focus here is understanding the multiple meanings of resilience, this research also includes research stemming from an intrinsic approach. Unlike an instrumental approach, this approach is more invested in the context of the research and the outcomes this may have specific to the phenomenon or event in question (Grandy, 2009).

\subsection{Positionality}

Within qualitative, social research approaches it is important to realise that the researcher and the participants co-produce knowledge (Tarrant, 2013). The researcher's own perspectives and actions influence not only the interpretation of data but also how data is collected (Manderson, Bennett, \& Andajani-Sutjahjo, 2006). Researcher attributes will influence how participants construct and deliver their answers during an interview (Manderson et al., 2006). These interactions are influenced by the perceived differences or commonalities between the interviewer and respondents (Hopkins, 2007). These attributes can either ease the transfer of information or create a barrier preventing the fluid transfer of information (Hopkins, 2007; Manderson et al., 2006).

Coming from a small, rural New Zealand town, the importance of community has always been paramount in my understanding of the world. As an only child in a single 
parent family, this importance has been crucial in both my upbringing and success. The collective identity of the community supported our family, allowing us to build social capital which in turn, from my own perspective, enhanced our family's resilience to cope with shocks. At times, individuals from the community ensured we had a home through providing space in their own places for us. Most important, was the knowledge that no matter the issue, there was always support and assistance available. This community was not confined by the limits of physical space, with the support network enduring despite my relocation to Wellington.

Although I have a deep seated interest in communities, and highly value them for the social support they can provide, I am not unaware of my position as an outsider from these communities which have been formed through gardening practices. My horticultural knowledge is limited and my connections with community members are newly formed. In undertaking this research I am well aware of the limits this has presented. My original intention was to interview 15 participants from community gardens over a two month period, in reality, recruiting took a total of 5 months to find 12 participants. Although I had a handful of initial responses to emails and flyers I had dispersed, many did not follow through on the interviewing process. Had I begun this research as a member of a local Community Garden it is possible that the potential for me to recruit participants may have been enhanced as my access to these networks would have been improved. Although I considered establishing myself as a member prior to commencing this research, I felt as though my participation may have appeared to other members as being motivated by my research rather than through sincere interest. I felt this association could strain any relationships formed prior to commencing my research and therefor may have created a barrier to recruiting participants.

I acknowledge that my identity as a tertiary educated woman conducting research in community gardens may also have influenced the way in which knowledge was produced. Manderson et al., (2006) discusses how the researchers and participants gender can influence the production of knowledge during an interview. The way in which women and men, men and men, or women and women interact during an interview can vary. Manderson et al., (2006) highlights that female participants who 
are interviewed by a female researcher are more likely to be open and conversational in sharing information. In contrast, some men may revert to a more masculine identity and provide information in a technical manner which removes emotional connotations. These characteristics are not a rule however and it is important to realise that multiple factors influence how a participant constructs their own identity which informs how they relate to the researcher (Tarrant, 2013).

The issue of age difference in interviewing has been discussed in depth by Tarrant (2013). As a younger researcher, her work identifies how interviewees from older generations may feel reluctant to share information with the researcher as the age difference may cause the interviewee to perceive the researcher in a nonprofessional way. Tarrant uses the example of interviewees invoking a grandparent/grandchild association between themselves and the researcher. This association can cause participants to feel a need to shelter and protect the researcher from the more controversial topics in the interview. Although during this research I at no time felt uncomfortable or at a disadvantage working across generations, it is possible that this difference was felt by older participants and influenced which knowledge they imparted to me.

The setting where an interaction takes place can influence the way individuals perceive power imbalances. Feelings of ownership over a setting can affect perceptions of power in an interaction. If the interview is held on premises familiar to the researcher this can create an intimidating atmosphere for the participant, whereas having the participant host an interview within their home allows for participants to feel comfortable and in control (Manderson et al., 2006). Elwood and Martin (2000) discuss how place association can influence the richness of content discussed. They highlight that participants are more likely to link their examples to the space they are in. For example, a discussion on neighbourhood activism provided richer data when the interview was conducted in the participant's home.

Furthermore, conducting interviews in a public setting may constrain participants from expressing themselves, whereas a private setting may make the participant feel more comfortable in responding emotively and they may also be less likely to withhold sensitive information (Manderson et al., 2006). In order to ensure 
participants felt a sense of control within this study I gave participants the opportunity to choose the location and time for the interview. As a result, some interviews were held at cafes, some were held in participant's homes, and others were held at Victoria University of Wellington. Elwood and Martin (2000) argue that giving participants control over setting an interview location can also give the researcher insight into which places or institutions are perceived by the participant as important to their experience within a community, or conversely which institutions or spaces may be missing from a community.

\subsection{Data Collection Tools}

The data was collected through in-depth interviews with local community members involved in community garden projects as well as through my observations at meeting and collective gardening days. This was then set against the backdrop of Wellington City Council planning documents and public notifications to allow for an understanding of context. A range of members from community gardens were approached in this study with the aim to gain a wider understanding of participant's viewpoints and perceptions.

\subsubsection{Interviews}

Qualitative data was collected through the use of in-depth interviews. Semistructured interviews allowed for a more conversational flow of information (Hay, 2010). The implementation of this in-depth, semi-structured style was the most suitable method as it allowed for the exploration of converging and diverging perceptions (Schensul, 2012). In line with Hay (2010), questions were used to direct the discussion, however no set rigidity in structure or time allotments were used. This not only gave participants opportunities to voice their experiences on their own terms, but also allowed participants to expand on ideas at length. Interviews with members from community gardens took on a semi-structured format in order for participants to express in their own words their perceptions and constructions of resilience. Furthermore, this semi-structured technique embraced the formation and discussion of new ideas for pathways forward. Questions were open ended allowing for the natural flow of conversation and guided by prompting questions selected from the interview guide (See Appendix 3). Questions were framed using plain 
language, with general definitions provided for participants who found the terms difficult to understand. Participants were informed that they could stop the interview at any time, refuse to answer questions or come back to a question at a later point in the interview. With the exception of one participant asking to come back to a question at a later point in the interview, all participants answered all the questions asked and remained within the study.

I carried out twelve in-depth semi-structured interviews, with participants represented from 7 different community gardens based in Wellington City (See Table 1). Four participants were recruited through previously established personal network connections that we had formed separate to the gardens i.e. through University. Two participants were recruited through word of mouth. Other participants were recruited through communicating with local community garden groups via email and phone call, from the contact details in public records. In addition to this, posters advertising (See Appendix 5) for participants were placed in community spaces such as local notice boards, in Commonsense Organics, on Community Garden notice boards, and in the online community gardening group pages on social media.

\begin{tabular}{|l|l|l|l|l|l|l|}
\hline Participant & Residence & Garden & Location & Sex & Membership & Occupation \\
\hline Participant A & Miramar & Mt Crawford & Miramar & M & $\sim 1$ year & Not stated \\
\hline Participant B & Aro Valley & Kai o te Aro & Aro Valley & M & $4-5$ years & Not stated \\
\hline Participant C & Aro Valley & Kai o te Aro & Aro Valley & F & 7 years & Not stated \\
\hline Participant D & Highbury & Tanera Park & Aro/Brooklyn & F & 5 Months & Carer \\
\hline Participant E & Newtown & University Garden & Aro/Brooklyn & F & $1-2$ Months & Student \\
\hline Participant F & Unspecified & Commonground & Island Bay & F & 3 years & Youth Worker \\
\hline Participant G & Mt Victoria & Innermost & Mt Victoria & F & $2-3$ Months & Student \\
\hline Participant H & Miramar & Innermost & Mt Victoria & M & $4+$ years & Teacher \\
\hline Participant I & $\begin{array}{l}\text { Wellington } \\
\text { CBD }\end{array}$ & Innermost & Mt Victoria & M & 4 years & Not stated \\
\hline Participant J & Evans Bay & Innermost & Mt Victoria & F & $4-5$ Months & Mother \\
\hline Participant K & Newtown & Newtown & Newtown & M & 1.5 years & Student \\
\hline Participant L & Newtown & Newtown & Newtown & F & $\sim 1$ year & Council \\
\hline
\end{tabular}

Table 1: Participant Breakdown 
Surprisingly, the response to the posters and advertisements was limited. Although four people contacted me with an interest in participating, all were unsuitable for the project due to their location outside of the Wellington City. Instead, groups who I had contacted via phone, email or who had come across my advertisements contacted me to invite me along to gardening days and meetings. This proved to be the most successful way of recruiting individuals, as it gave participants a familiar space to hear about the project in a casual and non-committal way. Five participants were recruited through this approach and one participant was recruited through snowball sampling. Snowball sampling is a recruitment method that relies on finding participants through nominations by previous participants (Morgan, 2008). This is best utilised as part of purposeful sampling where specific characteristics are needed (i.e. members of community gardens) but the population is hard to access (Morgan, 2008). This method relies on the networks that the participants have formed in these groups. This was useful in this study as at the time of interviewing it was winter and therefore membership in the garden was not as active. Furthermore, many of the community gardens did not hold membership lists or contact details for members.

Recruitment of participants was difficult despite many individuals taking an interest in the research I was conducting. They often did not feel they were suitable as participants or that they would not be able to give the "correct" answers. Although some participants could be encouraged and assured that they were more than suitable for the study, some members shied away and could not be swayed. This effect may have been enhanced by my "advertising" approach which outlined that I would be researching peoples' knowledge of the term resilience. By using the term "resilience" and asking people to share their knowledge of the term it may have opened individuals up to the fear of "not being smart enough" and thereby less willing to be interviewed.

Constraints around enlisting participants were further tightened due to the time pressures on many individuals. The practice of community gardening is often one that comes secondary to that of life necessities i.e. work, school, childcare. Although the garden may be an important aspect of participants' lives, it is not the most crucial. Extra time is put aside by members to take part in this practice, of which some can 
only manage infrequently. In asking members to take further time out of their schedules, many found it hard to make a commitment. A suggestion to combat this was to have the members complete interviews during a garden "working bee" as there would be a larger pool of members present to draw from. However, prior to this during an observation at an AGM for Commonground Gardens, members expressed that they were resentful of meetings (such as the AGM) on gardening days as they took up time that could have been spent in a more productive way and contributing to the success of the garden itself. Because of this, I decided against requesting interviews during working bee days.

Interviews were carried out during the months of July through November, 2014 in Wellington City at various locations which were suitable and agreed upon by both the researcher and participant. The duration of the interviews ranged from 35 minutes to 1 hour and 45 minutes. Participants ranged from young adults in the early stages of a tertiary education through to retirees. Participants interviewed were from various community garden projects. Of the twelve interviews conducted, two participants were from Kai o te Aro in Aro Valley; one from Tanera Park in Aro Valley/Brooklyn; four from Innermost Gardens in Mt Victoria; one from Commonground gardens in Lyall Bay; 3 from Newtown Community Garden in Newtown (of this two were also from the Victoria University Community Garden); and one from Mt Crawford Gardens in Miramar (Refer to Table 1 and Figure 1).

Informed consent was received in accordance with the Victoria University of Wellington Human Ethics Committee guidelines (see Appendix 4). Interviews were audio recorded with the permission of participants, and were later transcribed. Filler words were removed in transcriptions in order to retain flow in the dialog, however caution was taken to ensure that the meaning of the discussion was not altered. Participant's identities were kept confidential through the use of unique identifiers i.e. Participant A, Participant $B$ etc.

\subsubsection{Participant Observation}

Another method utilised in the collection of data for this research, was participant observation. Participant observation is a tool which draws from the researchers own experiences within the field in observing participants, holding informal conversations 
and drawing from events or emotions that the researcher faced (Di Domenico \& Phillips, 2010). This tool adds rigor to the data collected through other methods, provides context for understanding the knowledge imparted by participants and may help to illuminate new areas for research that would otherwise have been neglected (DeWalt \& DeWalt, 2001). Although not a dominant method used in this research, at times I was presented with the opportunity to sit in on meetings or was invited to "working bees" or gardening days. These events were made up of one Annual General Meeting where I took part as a passive participant ${ }^{2}$; a gardening day at Innermost gardens, where I was an active participant ${ }^{3}$; and a gardening day at Newtown community garden where I also took part as an active participant. During my observation at the Annual General Meeting I was able to take notes from which I was able to construct a reflection write-up on later in the day. During working bees it was inappropriate to be taking notes as this was a place for labour and would have detracted from the experience. Because of this, field notes were written as soon as possible in order to retain an accurate account of the proceedings as possible. The observations I made at these events helped to reinforce or confirm several points made by participants in interviews.

The observations made at the Annual General Meeting at Commonground Community Garden gave me insights into organisational structure and planning processes for the garden which informed findings produced in Chapter Four. During my observations at working bees I was able to take part in the work that was being performed. This allowed me to observe the interactions between individuals as well as understand nuances in leadership and certain roles that were being performed. These observations were particularly useful in cultivating my understanding of features of community resilience that are also discussed in Chapter Four. In particular, I bore witness to examples of skills transferral and active building of bonding and bridging social capital.

\footnotetext{
${ }^{2}$ Passive participation is when a researcher acts purely as an observer and takes no part in the activity or interaction being observed (DeWalt, 2001)

${ }^{3}$ Active participation refers to a researcher taking part in almost all activities or interactions being observed (DeWalt, 2001)
} 


\subsubsection{Secondary Sources}

Finally, this research sourced publicly available information from council documents to help provide context and to give greater depth to analysis of the council's role, views and efforts in relation to building community resilience. The two main documents utilised for this were "Wellington Towards 2040: A Smart Capital" (2011) and "Long Term Plan 2012/22" (2012). These documents reflected Wellington City's current plans and projects for the city.

\subsection{The Gardens}

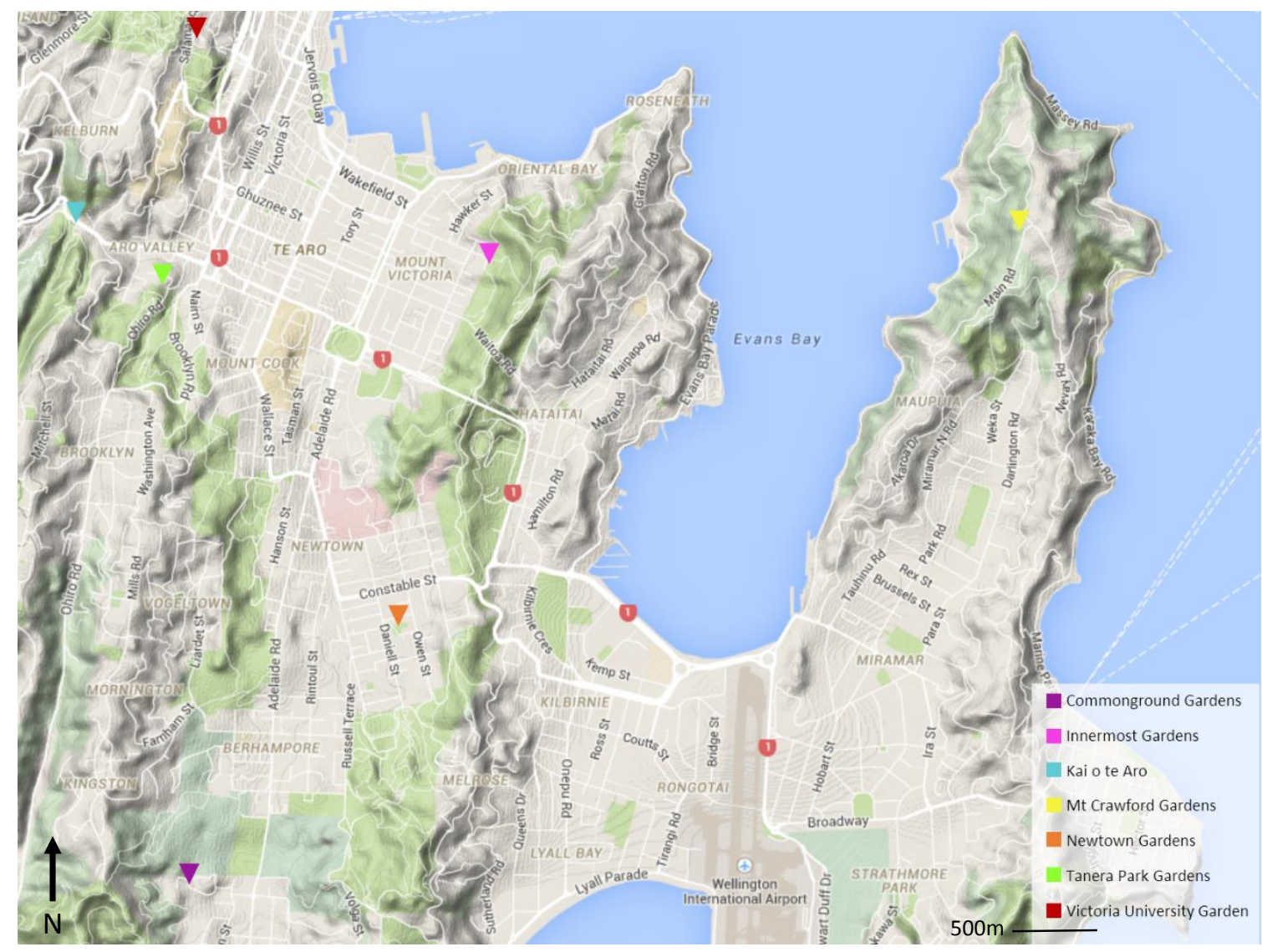

Figure 1: Map displaying the location of Community Gardens. Map adapted from https://koordinates.com/search/?q=wellington+suburbs

The Common Ground Community Garden, is located on The Home of Compassion grounds ${ }^{4}$ in Island Bay. The gardens were established in 2005 by Sister Loyola as a

\footnotetext{
${ }^{4}$ The Home of Compassion in Island Bay opened in 1907, as a headquarters and training centre for the Sisters of Compassion.
} 
way to reintroduce the craft of gardening to younger members of the community and build relationships between the generations (New Zealand Council of Christian Social Services, n.d). Central to the mission of the garden is practicing and teaching sustainable values and enhancing community relationships (Common Ground Community Garden, n.d) The group meets weekly on a Saturday to take part in a working bee. At the time of this research Common Ground Community Gardens was experiencing a period of change. Due to changes at The Home of Compassion, the space dedicated to the gardens was no longer available for long-term occupation by the gardening group. Because of these changes, members from Common Ground were debating the prospects of moving locations, amalgamating with another local community gardening group, or disbanding the group (Common Ground Community Garden, 09/08/2014).

Established in 2006, the Innermost Gardens located on 141 Elizabeth St in Mt Victoria, market themselves as providing opportunities to grow food, participate in community development, develop sustainable lifestyles, and learn (or teach) about Permaculture design, food, ecological restoration and wellness (Innermost Gardens, n.d). This garden provides two main ways to participate. Members who participate in collective gardening (i.e. shared space gardening, where produce is divided between participants) pay a $\$ 20$ annual membership. An organised working bee is held for this group on the $1^{\text {st }}$ and $3^{\text {rd }}$ Sunday of the month, however participation by members throughout the week is also encouraged (Innermost Gardens, n.d). The garden has been developed in order to work on four main issues:

- Encourage social capital and skill transferral

- Practice organic gardening techniques

- Maintain the practise of gardening and food sharing and pass these traditions on to the next generation

- Provide workshops on holistic and sustainable living.

The gardening group leases the land from the Wellington City Council at a fee of \$225 per annum (excl. GST) and the Wellington City Council contribute $\$ 300$ per annum (excl. GST) to the group in order to pay the water rates (Wellington City Council, 
2013a, 2013b) Should water costs exceed this, additional costs must be covered by the group (Wellington City Council, 2013a, 2013b)

The Mt Crawford Community Garden, located on Mt Crawford in Miramar, emerged in response to private land development. Previously the land was owned and utilised by the Mt Crawford Prison, however after the prisons closure in 2012 the process of disposing of the allotment began (Easton, 2013). Under Treaty Settlement agreements, the land parcel was to first be offered to the Port Nicholson Block Settlement Trust before opening up tender to the general market (Easton, 2013). The garden was formed by a small number of local residents in protest of land privatisation and the lack of transparency surrounding this process (Easton, 2013; Scoop Media, 2013). The initiators of the garden were concerned that privatisation of the area may lead to a gated community and would blockade between Shelly Bay and Watts peninsula (Easton, 2013). The occupation of the site by the group resulted in Land Information NZ (LINZ) presenting the group with a "License to Occupy". This lease will last 5 years (Scoop Media, 2014). Further support for this initiative was shown by Wellington City Council who contributed \$2,889.00 of funding in 2014 (Wellington City Council, 2014). This is the first community garden established in the community of Miramar, here members who are involved aim to grow produce, create a nursery, and develop the site for recreation (Poulopoulos, 2013).

Located within the Town Belt on the border of Brooklyn and Aro Valley, the Tanera Park Community Garden is Wellington City's oldest community garden (Mokai Kainga, n.d) (Mokai Kainga, n.d). The garden was opened in 1990 as a way to ease financial burdens that were being experienced at the time (Mokai Kainga, n.d). The garden is managed by Mokai Kainga Maori Centre, a charitable trust and incorporated society who aim to empower Maori and promote the principles of the Treaty of Waitangi (Wellington City Council, 2011a). The purpose of Tanera Park Community Garden is for members, who do not have access to a garden elsewhere, to be able to grow produce and have the opportunity to build networks and skills (Wellington City Council, 2011a). Unlike the other gardens discussed in this research, Tanera Park is an allotment only garden. Thirty eight plots are available on the site for individuals, families or small groups to work (Wellington City Council, 2011a). Although gardening 
may be shared by a small group within each plot, responsibilities are not shared between plots. The Wellington City Council leases the land to Mokai Kainga at a rate of $\$ 1$ per annum (excl. GST) and in addition provides up to $\$ 300$ per annum (excl. GST) to the group in order to pay the water rates, while Mokai Kainga must cover any additional water rate costs (Wellington City Council, 2011b).

The community garden run by students from Victoria University of Wellington located on the property of Weir House, a student housing facility, has only recently been established (Gecko Representative). Initiated by the on-campus environmental club, Gecko, this garden was only started in 2014 and is currently still in its early development phase. This initiative has been supported and funded by the University's Student Wellbeing and Support Centre as the garden has been established as "a space in which students can grow food, take positive time out from study, and meet new people". As the garden develops, the group aspires to provide lessons on urban food systems as well as cooking classes (Lenihan-Ikin, 2014).

The Newtown Community Garden, located in Carrara Park, was developed on the outskirts of an existing park and play area which is owned and managed by the Wellington City Council (Wellington City Council, 2013c, 2013d). The garden in its current location was proposed in 2013 by the Newtown Residents Association Incorporated, in order to enhance community networks, improve safety, enrich local environmental conditions (i.e. biodiversity, organic production), teach gardening skills and grow produce (Newtown Residents Association, 2014; Wellington City Council, 2013d). The initiators of the park aim to increase social capital within the community both with those in the park who garden or choose to use the area for other leisure activities (Wellington City Council, 2013d). The members from this garden encourage those who do not participate in the gardening to pick and enjoy surplus produce while in the park in order to not just benefit those involved but the wider community too (Newtown Residents Association, 2014). The group holds a working bee fortnightly on a Sunday and practise communal gardening (Newtown Residents Association, 2014). In line with Mokai Kainga, the Wellington City Council leases the land to the Newtown Residents Association Incorporated at a rate of $\$ 1$ 
per annum (excl. GST) and in addition provides up to $\$ 300$ per annum (excl. GST) to the group in order to pay the water rates, should water costs exceed this, additional costs must be covered by the group (Wellington City Council, 2013c).

Kai o te Aro, located in Aro Valley, is made up of three gardens spread across Aro Valley (See figure 2). Kai o te Aro started as a network of local gardeners in order to share labour amongst individual's private gardens as well as exchange ideas and skills (Tegg, 2010). A privately owned unused land plot was sourced in 2009 , which then developed into a shared communal garden (The Secret Garden, see Figure 2) (Tegg, 2010). This space has been provided free of charge by the owner (Radio New Zealand, 2014).

The Orchard, sourced from Victoria University of Wellington, was seen as an opportunity to develop an area used as a dumping ground into a productive space (Radio New Zealand, 2014). In 2013, Kai o te Aro announced that The Orchard was to become an allotment garden rather than a communal garden, in order to reach a wider range of local users (Barrie, 2013). Unlike the other gardens discussed in this study, Kai o te Aro are not registered in any formal way and don't have a membership basis, rather the group is informally organised and members participate at their leisure. This appeals to the transient nature of Aro Valley's population base (Radio New Zealand, 2014).

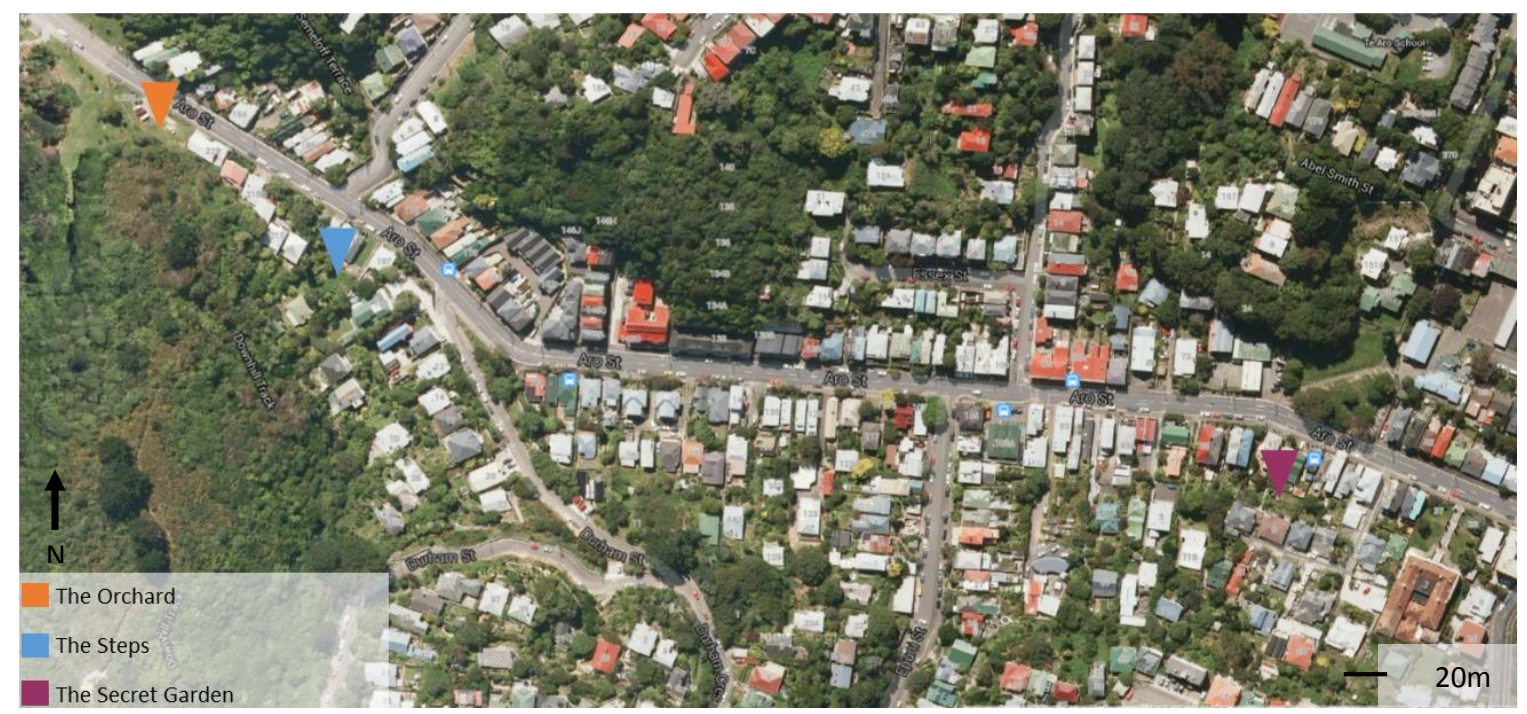

Figure 2: Location of Kai o te Aro Gardens (Map adapted from Koordinates.com) 


\subsection{Analysis}

This research was analysed using a thematic approach. Thematic Analysis was chosen due to its flexible nature which allows for the generation of findings through the collation of similar themes (Braun \& Clarke, 2006). Using this approach requires grouping the collected data into themes and sub-themes. In doing this, patterns and linkages can be highlighted within and across the data which allows for the researcher to elucidate meaning from the results (Braun \& Clarke, 2006). Both an inductive and deductive thematic analysis approach was applied to this research.

A deductive or top-down approach to thematic analysis begins with coding interviews based on pre-determined themes that have been derived from the literature or research questions before interviews were conducted (as expressed in Step 1a and 2a in Figure 3) (Braun \& Clarke, 2006). Themes derived from this method were selected based upon gaps identified in the literature as well as commonalities highlighted throughout the literature. This approach was used in order to examine how previous work either complemented or contradicted the findings presented in this research. An inductive approach is considered a bottom-up approach, in which themes or codes are developed from the data itself (Lower branch of Figure 3) (Braun \& Clarke, 2006). As highlighted in Step 2b (Figure 3), themes are identified through multiple readings of the data in order to find patterns in the data (Fereday \& MuirCochrane, 2006). This highlights commonalities in what participants said in interviews. Braun and Clarke (2006) highlight that thematic analysis is rarely completed using just one of these approaches, as our previous knowledge of a subject cannot be separated from our analysis, and it is hard to ignore unexpected patterns that arise. 


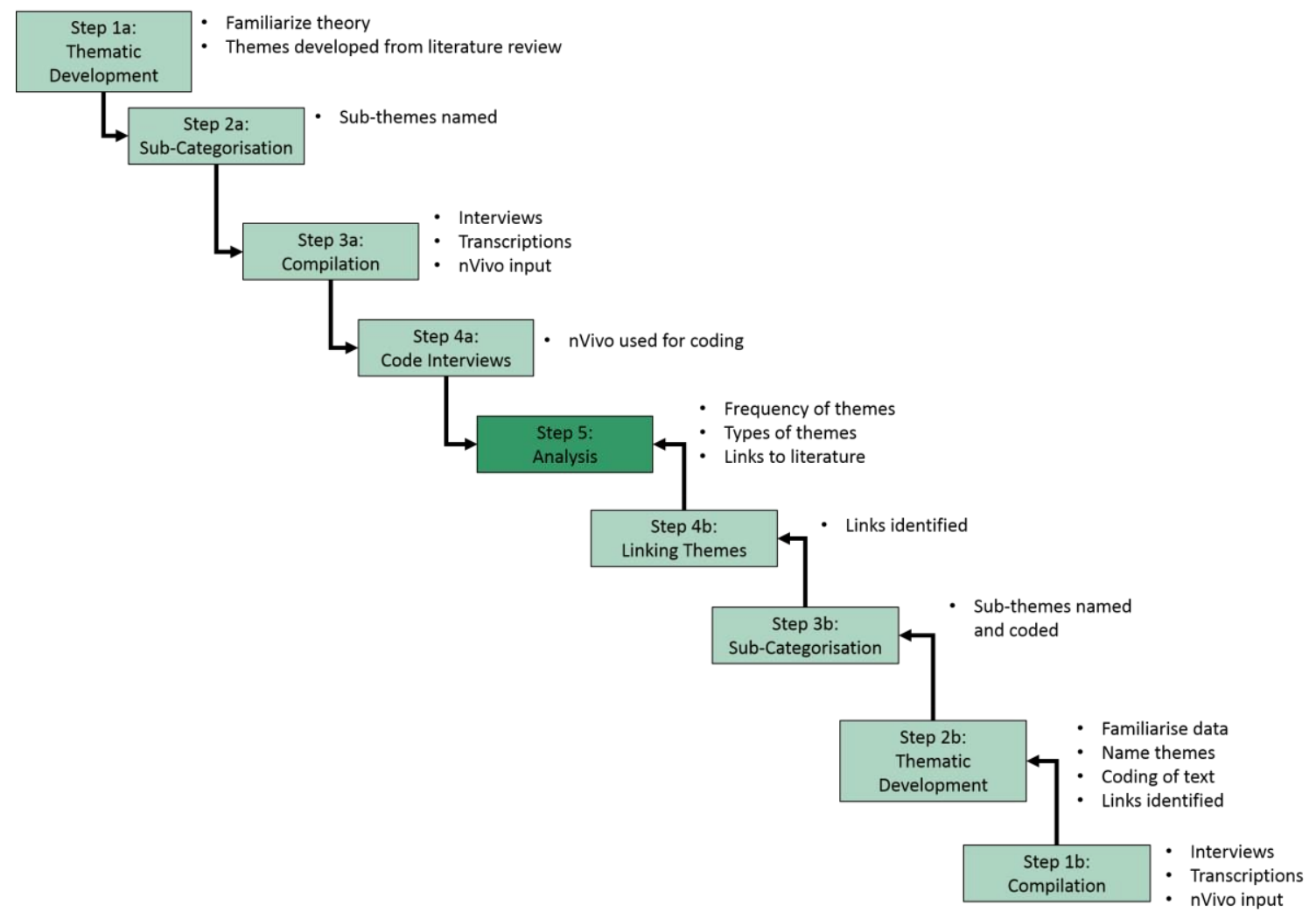

Figure 3: Thematic coding process. Adapted from Braun and Clarke (2006)

The use of nVivo qualitative software is often employed in the collation of data through the use of coding. Transcribed interviews were imported into the programme and manually coded for each individual transcript (as shown in Steps $1 b$ and 3a). In line with Figure 3, initially transcripts were reviewed and coded guided by themes such as responsibility, resilience, and key components forming resilient communities. The inclusion of these themes were derived from the commonalities that were expressed in the literature review. Although the roots of coding this research originally stemmed from a deductive approach, coding was also developed from the data itself using an inductive approach. This helped to make sense of findings as new information or ideas came forth (Fereday \& Muir-Cochrane, 2006). This dual edged approach has allowed for a more comprehensive and in depth analysis of the research.

\subsection{Summary}

The research conducted for this thesis aimed to explore individual's understandings and perspectives of both resilience and community resilience, allowing them to be both self-reflective and outwardly critical of their current situation. These 
characteristics that draw on elements such as feelings, knowledge's, and perspectives required the use of qualitative methods which allow for a greater depth of analysis that cannot be achieved through methods employed using a quantitative study. The use of a post-structural epistemology was employed to bring clarity in understanding the way people vocalise their ideas as reflective of the way in which the both see and act to shape the world around them. The use of interviews and observations fulfilled the role of understanding community members' views of the world in the context of this case study. Thematic analysis was aided with the use of nVivo coding software in order to answer the research questions. 


\section{Chapter 4: Findings}

This chapter explores the findings derived from interviews with members from Wellington City community gardens. This chapter has been broken into three sections which each target one of the research questions posed in this research. Section 4.1 addresses findings relevant to the first research question:

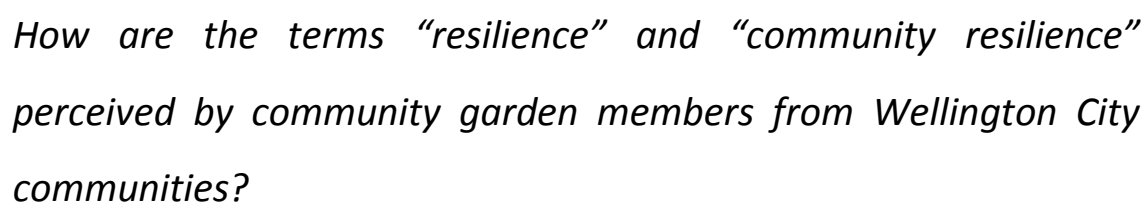

This section discusses aspects of participant's conceptualisations of both the terms resilience and community resilience. The key findings within this section suggest that participants define resilience very loosely, however most definitions included an aspect of "responding to a disturbance" in a constructive way. In defining community resilience participants focused on the theme of a group collectively responding to, or preparing for unwanted change in a positive way.

Section 4.2 explores findings in response to the second research question:

$$
\begin{aligned}
& \text { Who do participants from community gardens identify as being } \\
& \text { responsible for driving community resilience initiatives, and how are } \\
& \text { these participants responsible? }
\end{aligned}
$$

This section revealed that participants view the process of building community resilience as a collaborative approach, in-line with Wellington City Councils suggestions. However, participants felt that community members need to be given greater opportunity to drive the process with the Council taking a role characterised by support rather than leadership.

Finally section 4.3 outlines the findings made in response to the research question:

How do members from Wellington City community gardens use these gardens to enhance community resilience?

Within this section, participants' identified that their community gardens contributed to community resilience through enhancing social networks, and access to human 
and physical resources. However, there is the potential to further enhance these contributions.

\subsection{A Community Understanding of Community Resilience}

One of the major questions this research sought to address was how participants within Wellington City's community gardens used and understood the term resilience and its derivative, community resilience. This interest stemmed from the understanding that the term has been translated from ecological resilience and engineering resilience into the social sphere and is now utilised across a range of disciplines. Over time the term's popularity has increased; this has seen its translation from the academic sector into the public sector. As the word has been employed by Wellington City Council in discussion of local planning and organisation, it is important to understand what expectations the use of this word inspires according to participants of community gardens. Thus, how are the terms resilience and community resilience understood? Within this question, this chapter also aims to answer questions that have been highlighted by Brown (2014), such as; Is resilience discussed in a way that promotes transformation, or in a way that favours stability; and what do community members envisage as being a "desired state" when building resilience?.

\subsubsection{Understanding Resilience}

As discussed in Chapter Two, the use of the term resilience has increased in popularity over the last several decades. Its application by different groups i.e. academics, the public government etc., has exposed an array of different meanings for the term. Even between members within each group, the definition may change from one user to the next. This was highlighted through interviews with community gardening participants, which show that individuals have a range of different meanings for the word.

Comprehension of the word was often reflected in individuals' personal experiences. Participants drew from both their private and professional lives in order to address the question of what the word resilience means. Individuals who had experience 
working with teachers, social workers, and health care personnel described resilience in terms of an individual life skill that is developed in those contexts

"I'm a teacher, so the first thing that jumps to mind is resilience in children in the classroom and building resilience in terms of, as a life skill." - Participant G

Despite the term's origins in ecology, participants who were studying or working within this field did not easily draw any connections between the term resilience and ecological practice.

"I guess possibly when you think of in a nursery sense when you're trying to use less pesticides and make plants more resilient to pests and fungus and this and that. So growing plants from the very beginning that they will be resilient to pests and toxins and things. But yeah not that often, no." - Participant $H$

"That's interesting, not really. I don't think I have ever had that in my lectures, the term resilience." - Participant $E$ [In relation to their study in Biological Sciences]

Common connotations that were used, or alluded to, when defining the term included; perseverance; resistance; bounce back; adaptation; capacity; strength; and preparedness. For example:

"Preparedness, like strength and it's a positive thing but it's sort of being prepared for hard times to come" - Participant $H$

"You have that capacity to take a hit and then bounce back and then grow from whatever happens" - Participant J

This shows that participants tended to describe resilience by drawing on a wide range of conventional terms. Ecologically derived understandings of the term are demonstrated through the use of the words "resistance", "adaptation" and "flexibility". Themes such as "strength", "perseverance" and "bounce back" allude to engineering resilience, which reflects an energizer bunny, whereby the system is 
geared to keep going and going. These connotations associated with engineering resilience, derive conventional associations that lack dynamism i.e. these descriptions favour stability and originality over adaptive capacity or transformation. Although this stability may appear desirable, it is important to question what is being maintained, and whether or not this is a state that should be maintained. Ecological interpretations of the term allow room for improvement and recognise that the current state can never be perfect nor timeless.

Some participants highlighted that although they use the term in conversation, their understanding of the term is incomplete or very general.

"Yeah I guess resilience is quite a large catchall phrase and I haven't necessarily had a look into the pillars that make it up" - Participant $B$

"I don't really know actually how I would describe resilience" Participant $H$

Although Participant $\mathrm{B}$ and Participant $\mathrm{H}$ both demonstrated throughout our interviews that they were comfortable and confident using the term, upon further investigation they both identified that their understanding of the term was limited. This speaks to the work of Graedel and Klee (2002), Lubin and Esty (2010) and McMichael, Butler, and Folke (2003) who explored the poorly defined term sustainability and suggests that participants are using the term resilience in a similar manner. This effect can be further illuminated through some participants' conflation of the term resilience with the term sustainability, which suggests that participants have difficulty distinguishing the term resilience as a distinct concept. As highlighted in Chapter One, the term resilience has embedded itself as being synonymous with the word "sustainable" or as an anti-thesis to "unsustainable". Responses from participants mirrored these findings.

"I think modern street language sort of fuses those sorts of things together, to me there is very little difference. Just life carrying on kind of thing." - Participant I 
As highlighted by Participant I, some participants perceived these terms as being interchangeable. The first quote in particular highlights how they are used interchangeably, and even can be perceived as making one redundant in the presence of the first. The second of these quotes exposes how the term's use within the public realm has blurred the edges of the term "resilience". This quote emphasises the terms malleability which allows it to be used subjectively rather than as a term with a concrete definition and solid parameters.

It is clear from these findings that Wellington City community garden participants interpretations of resilience align with conventional terms found in the existing literature on ecological and engineering resilience. Many participants also linked the term to the idea of sustainability, which suggests that participants are using this term quite loosely and drawing from dominant discourses.

\subsubsection{Understanding Community Resilience}

Unlike the term resilience, participants had a much narrower understanding of the term community resilience. All participants defined the term in relation to a community's ability and willingness to support its members, with focus given to the importance of social networks and social cohesion. Participant H's interpretation of the term is representative of the majority of responses which framed community resilience in relation to feeling within your community there were others who you were able to rely on when needed.

"in rough times or in times when those community members rely on each other or need to rely on each other then there's a feeling that you can go to your community or your neighbours or people in your general community and that you'll have help there or a safe zone I guess. Community resilience, yeah that was my gut instinct" Participant $H$

Participants highlighted that this support within the community extended past responding to conventional disturbances such as natural hazards, to issues such as health, domestic violence, council actions, etc. 
"When I think of community resilience I think it does have more of a focus on how communities work in adverse situations. And it doesn't have to be emergency management sort of stuff. It could be that somebody is ill or there is family violence going on somewhere or we don't agree with what the council are doing in our area. I think community resilience can be a lot of stuff but for me it has more of those connotations of what are a whole group of people doing together about an issue that bothers a lot of them" - Participant $L$

When questioned on what being part of a resilient community entailed, participants' identified two core contributing themes. The first focused on the physical elements of perseverance against external disturbance which may be achieved through reducing reliance on externally sourced resources; food, money, oil, water. The second theme was more inward looking and considered the strength of social connections and the meaning of community.

Participants identified that even though disaster was an important thing to build resilience against, they were equally susceptible to the changes that may occur to resource availability. The issues of climate change, peak oil, food scarcity, water quality and quantity, and financial downturn were commonly discussed by participants in framing community resilience.

"You know it's not just disaster but NZ dependence on oil, you know the price of Fossil Fuels is going to increase overtime and eventually be too expensive for us to get everything we need from other countries or it will be too expensive for anyone to be able to afford. So the idea of resilience and being able to produce stuff locally or manufacture stuff locally is really important and I think that kind of resilience is something we need to build into our future thinking" Participant $B$

"The world is becoming more extreme on the financial side and there is a lot more poor people and people suffering and to have not 
only food but high quality food is something that they can't afford"

- Participant I

These quotes by Participant B and Participant I illustrate that participants are invested in building community resilience against issues that are seemingly predictable, enduring and widespread. This is different to the characterisation of natural disaster which is more often considered to be localised, ephemeral, and unexpected. If a natural disaster were to hit Wellington, it would be possible to draw on assistance from further afield either nationally or internationally. Although devastating, natural disaster is a risk which is understood. Conversely the types of risks participants identified are more complex and newer, meaning that it is harder to predict the outcomes. In response to the unpredictable nature of these threats, participants highlighted the significance of resource availability and development. Having access to physical resources allows communities to be able to reduce their external reliance. By increasing self-sufficiency and reducing over-reliance, participants felt as though their resilience was enhanced.

The second framing of community resilience drew on aspects of social interactions. Socially based understandings of community resilience were understood by participants as having a space where the community shares similar goals and visions for their area and work together as a unit to achieve these goals. This was thought to be dependent on two main attributes: the skills of the individuals in the community, and their ability to work well together.

"I guess a community that works harmoniously together. So people share a similar sort of vision of what they want from their community, of what they expect from their community and what makes them feel safe in that community. Hopefully those voices and opinions can be heard by someone bigger them like the council maybe" - Participant $H$

Most participants expressed that they felt that their communities, along with the wider society, were becoming more insular. This phenomena was defined by participants with terms such as urban isolation or social atomisation. Social 
atomisation here refers to the idea of people becoming insular and having less interaction with the people around them. This fear is what stimulated many of the participants to become involved with community initiatives.

"I don't usually think about emergency situations or natural disasters as much as I do about worrying that kids don't know how to say hello to strangers because we are living in this age with lots of technology and lots of distractions and not as many things centred in and around community anymore because people get most of their food from the grocery store or we mostly drive or things are more spread out then they used to be vs back in the day when everybody just walked everywhere and towns were built around pedestrian streets and what not" - Participant $H$

"I think it's also just that thing of people living in that, I call it urban isolation, where you sort of are separate from everybody else, and you don't have a sense of caring about your neighbours. I think that is a point where this little area could be vulnerable or guilty of" Participant J

The presence of bridging social capital was highlighted in participants' conceptualisations of community resilience. Bridging social capital refers to the connections between groups of differing characterisations within a community which enhances diversity within the community (Poortinga, 2012). The integration and acceptance of diversity was frequently cited as being integral to identifying resilient communities. Participants felt that in encouraging the inclusion of diversity, connections are formed between people who may otherwise be excluded.

"I suppose it means, as opposed to individual or family resilience it's like having a more open, shared spaces or shared projects that can be participated in by anyone and allowing collaboration between different groups. I suppose it can be specific but I guess when I think about community resilience especially in Wellington, it's about just 
providing places where people from different backgrounds can feel comfortable and meet each other" - Participant $D$

"I guess for me community resilience means having ways outside a national structure or an individual person that can help those people feel included in something and feel a sense of connection with the community" - Participant D

Participants also expressed that community resilience had scalar affects. Participant $D$ and Participant $G$ highlighted how small interactions could be utilised to have a large impact. They framed individual issues as community issues and linked this to community responsibility. This emphasised how a community could make an impact on individual member's lives through supporting them in times of need. As an effect of this, larger scale social issues could be minimised. Participants highlighted mental health, unemployment and family violence as examples of this.

"Also I think something that effects young people quite a lot is mental health problems as well so for me that's quite a big thing and I think it's something that's really important within the community as well because it's not something you can cope with by yourself and I think there's a lot of feeling, I get a sense of, that people think it's an individual's responsibility to take care of or find their own solutions but I feel like communities are really important for having support and a space where it's acceptable to talk about this. Also discrimination, I feel like if a community is resilient they allow spaces for people to feel safe. So that idea of having a safe space where people don't feel like they are being offended or oppressed is important" - Participant D

"I took a step back and thought, actually if every household in NZ decided they were going to have a coffee once every 6 months with their neighbours, that would do more to help reduce those horrible statistics than the government spending $\$ 500$ million on a nationwide programme on education for example. It's that 
practical things of let's just say hello to each other. And it's about taking personal responsibility within that" - Participant G

Building up these bridging relationships also allow for a greater transferral of knowledge and provides a foundation for people to work together. Increased social acceptance and cohesion allows for a wider range of community members to contribute different skills and sets of knowledge to the community. Having a wider skill set, as identified by Participant G, enhances a community's resilience as there is a wider pool of people to rely on in times of need.

"I would look at the skills of the people and the ability of them to work together. The connections between them" - Participant $G$

"To me a lot of the resilience of a community depends on the skills of people in the community and the greater the level of skills the more resilient that community is going to be" - Participant $G$

A potential barrier to developing bridging social capital within a geographical community is the transient nature of Wellington's population, as well as the occurrence of communities of interest over-taking the importance of geographical communities. A key theme identified by participants was that the idea of community is not confined by space. Often participants did not identify their geographical community as being their most relevant or most important community. This conflicts with Norris and Stevens (2007) and Zautra et al. (2008), who argue that a sense of belonging and place attachment is key to the idea of maintaining a strong sense of community. These ties to a location allow for individuals to invest resources into building up relationships, networks, and infrastructure in their local communities, which is at the root of building community resilience.

Wellington, as the capital city, is a hub of movement. Work and education are major draw-cards for encouraging migration into the city. Many of the participants interviewed indicated that Wellington was not their town of origin and that they had moved to the city for employment, education or enhancement of lifestyle. This has added to the city's transient characterisation. Of the 12 participants interviewed, 9 indicated that they were not originally from Wellington. Although some found it 
easier to establish a sense of community than others, it was clear that those who had resided in Wellington for a longer period of time had a more defined idea of where they felt they belonged within their communities.

In addition to migration into the city, movement between suburbs is often common, especially for young people. One of the younger participants, who recently transitioned from a life of tertiary education into a working life style, highlighted this mobility. In three years one participant had resided in three different Wellington city suburbs. This participant, along with other younger participants who had moved frequently or recently returned from overseas travel, were amongst those that struggled the most to identify a local community.

"I can see there's a strong sense of community there. I'm not sure what I'm doing next year, if I'm going to move. So also I don't want to settle." - Participant E

When talking about her community, Participant E discussed it as something separate from herself. This quote illustrates that she does not necessarily see herself as being part of, or contributing to, the 'strength' of her community. This lack of investment may be a result of her uncertainty about her future plans. This hesitancy may be driven by a realisation that if she moves on her investment will not be rewarded.

Similarly, others identified Wellington as merely a stop along the way to another destination. Whether this is simply a matter of using Wellington as a resource to build skills and life experience before transitioning to somewhere further afield, or if they have a predefined destination in mind varied amongst individuals.

"I have lived in a lot of places and I am part of those communities and will go back to them at some point" - Participant $L$

This transient nature may be a barrier for encouraging people to invest in their local communities, which could detract from community resilience. The younger participants interviewed in this research struggled to identify a geographical community in Wellington. This may be a result of maintaining an association of 
"community" with their home bases. One past student from Victoria University claimed the university space was still the community she identified with.

However, one participant who had lived in Aro Valley for seven years expressed strong ties to that geographic location. These ties had been strengthened over time, fixing the participants psychological attachment to place. Participant B developed relationships within the area, citing convenience as the main driver.

"I feel the longer I've been here the more I feel that this is where I want to be" - Participant B.

"They're just down the road and you can invite them round for a cup of tea. And it's just easier to have a friendship with someone who's local." - Participant B

Another barrier to developing a sense of community was the notion of "communities of interest". Common to interviews was also the idea of communities that weren't geographically constrained. These sometimes manifested as communities that had formed out of common interests or belief systems. Participants who identified their community as a community of interest also expressed that they didn't necessarily identify with just one type of community, but instead they interacted with many different communities in different ways. The strength of a sense of belonging were at times much stronger in communities of interest, as many participants found it hard to form worthwhile relationships within their immediate neighbourhoods.

"I have one neighbour who sometimes I say hello to her or sometimes she catches the same bus as me to work and sometimes she will just walk past me and just not even acknowledge me and I think "look we have sat down and talked, you live two houses away." I just think sometimes we are just so isolated in our own headspace and I think shyness is an issue for a lot of people." Participant G.

This is in part an effect of globalisation and technological improvements that have seen our society develop new ways in which to communicate. This has opened the 
world up and allowed individuals to explore what truly interests them, allowing them to form connections with people they otherwise may never have met. Without the necessity of needing to form social relationships within our immediate neighbourhoods the latter can break down or can fail to be instigated at all.

The term community resilience was understood widely amongst participants as the way in which a community utilises both physical and social resources to support one another. This support did not encompass responding to natural disturbance alone, but also widespread social and environmental issues i.e. resource constraints, unemployment, a culture of violence etc. Participants focused on how building a safe, inclusive and cohesive community could be beneficial at all times, not just in times of distress, and highlighted how community wellbeing was a reflection of individual wellbeing. Despite this, some participants expressed that their geographical community was not of central importance to their wellbeing, instead identifying ties to multiple locational communities or communities of interest.

\subsection{Negotiating Responsibility}

This chapter seeks to answer the second research question "Who do participants from community gardens identify as being responsible for driving community resilience initiatives?" Participants highlighted that building community resilience requires input from both the community and the Council. Dreier (1996) emphasises that although a collaborative approach may be slower, and at times more difficult, collaboration between the community and council in community development initiatives makes for a more democratic, well-received, and cost-efficient strategy. This section explores participants' expectations of both the Council and the communities involved, and identifies specific roles for each of these stakeholders in building community resilience

\subsubsection{Working Collaboratively}

The main finding was that participants felt responsibility for community resilience building should be shared between both the communities and the Council. One participant took this a step further and highlighted that the Council should be considered as part of the community too. Participants expressed that community 
resilience is a complex process which requires an approach that integrates community participation as well as structural changes that need to be orchestrated by governing bodies.

"I think a mixture, I think having the right policy settings to make the environment conducive. The Council or people at the top can't make it happen. You can lead a horse to water but you can't make it drink. But I know as a teacher, a really important part of teaching is creating the right environment for people to communicate and talk" - Participant G

"Every level. I think any kind of change, we can't put it to one thing. I mean say you want to make a political change, say you want Wellington to be more environmental, you can't just say politically we need to make rules, we have to shift people's consciousness to make people want to do it. [...] I think grassroots definitely works but it's good to have the support [on all levels]" - Participant E

This appetite for collaboration is one which is also held by the Council as discussed in "Wellington Towards 2040: A Smart Capital". Some participants highlighted that collaboration between some communities and the Council had already been established. This collaboration had been successful for a number of projects within the communities i.e. community gardens, residents associations, etc. Many of these participants who had experience working with the Council in these projects held past and current interactions with the Council in a positive light.

"[Community Garden Member] in particular has a really good relationship and there's a chap [from the parks and reserves department] there and if there's something they will ring each other up and have a conversation and work things out, it seems to work out really well" - Participant G

These participants claimed Council representatives were often supportive of community led initiatives. The Councils support of community garden groups was looked upon especially favourably, with positive feedback focused on the role of the 
Community and Neighbourhood Advisor, who works within the Council with a focus on facilitating urban agriculture and community garden groups (Wellington City Council, 2013).

"I know that [the Community and Neighbourhood Advisor] works for the council and she started off at Innermost Gardens, and that's brilliant, I'm delighted that [she] is in there, because she knows what it's like to be on the other side, always looking for the funds and struggling to keep the garden going and so forth. I personally am not involved in having chats with [her] from time to time in the same way that some of the guys are in Kai o te Aro with the Council but they always seem to be responsive and supportive" Participant $C$

The Community and Neighbourhood Advisor, identified by participants, is a recent addition to the Wellington City Council. This role focuses on enhancing urban agriculture. Participants identified that the Community and Neighbourhood Advisor was originally involved with the Innermost Gardens in Mt Victoria, and had built up a relationship of understanding and trust within community gardens communities. The advisor's pre-existing relationship and experience within community gardens allowed for community garden members to work with someone from the Council who understands both the wants and needs of community gardening groups. In having this link between the Council and community garden groups, participants indicated that they felt more at ease when trying to access support and funding as the advisor could empathise with these struggles.

Although most people interviewed highlighted positive relationships with the Council, and the Council's involvement with the communities, some participants felt as though their interactions with the Council were undervalued. Some participants expressed that they perceived the Council's attempts at consultation to be tokenistic at times and felt their ideas or attitudes were brushed off as being insignificant.

"I would like to think that the intention is there, I think in some aspects it feels like it is tokenistic and tick-boxed and people aren't 
realising the reason behind what they are doing. It's like "oh yeah we have got to do this because it's the correct procedure", it's like no, you consult with us because we might have a diverse opinion that's really beneficial in your city planning so you should be asking us because we think differently to you and that's really important" - Participant $F$

This quote from Participant $F$ highlights the sense of dissatisfaction felt by some participants. Participants who expressed their frustration felt that they could identify important weaknesses within their community that the Council could not. In taking a tokenistic approach to consultation, these participants felt that Council's actions would not adequately address the issues raised. This dissatisfaction showed trepidation in participant's expectations of the Council as leaders for resilience building.

\subsubsection{A Role for the Council}

Interviews with participants revealed that negotiating a role for the Council to play in building community resilience was a difficult task. Council responsibility was identified by all participants as integral to the successful functioning of community resilience initiatives.

\section{"Yeah they should definitely play a part, I can't say what part that would be" - Participant I}

Despite this initial alignment of views, the details of the Councils responsibilities were less easily identified or agreed upon by participants. This was in part a reflection of a lack of knowledge of what the Council was expected to provide for communities, but was also evidence of the diversity of participant's expectations of the Council. A common trend amongst younger participants and those who weren't directly involved in the core workings of their community garden, highlighted that their understanding of the Council's role within the community was very limited. 
"I just don't know much about what the City Council do as a role. Like basically the only interaction I have with the City Council is at the Community Garden because I know that land is owned by the Council. But I don't even know how that has come about. I'm quite clueless" - Participant D.

Participants who were already considered leaders within their communities felt more confident in attributing specific roles and responsibilities to the Council with regard to community resilience building. Participants expressed a variety of responsibilities for the Council such as providing space, funds and resources, as well as more active involvement such as organising events, education seminars and workshops.

"Just providing the space really and having someone who was motivating events or sharing knowledge or workshops or something" - Participant J

"So in terms of what Council's role is, facilitating with funding, providing the resources to communities that they aren't able to get" - Participant $K$

These quotes highlight a supportive role for the council, characterised by resource and service provision. Most participants expressed that although they felt the Council had an important role to play, it was not a leadership role. Instead, participants identified the Council as being supporters and enhancers of community led resilience building initiatives.

"I think, if you look at the role of the City Council, that role is to provide platforms for different groups or different people or people with different experiences to voice those experiences and to work with that to create solutions. Rather than having a few people who aren't necessarily really connected trying to make a decision, it's about finding out who the [relevant] groups of people are and giving them the resources and the space to develop their own projects and solutions" - Participant D 
"So I think that the role of Council is skills that they can provide to empower the communities in ways that they can't themselves. Also just providing recognition to communities, even sort of symbolic recognition is great. The fact that our garden got \$2000 worth of funding, that's tiny in terms of what the Councils budgets are but that's huge in terms of the smalls communities sense of recognition from the Council that they matter and that they are part of the city. Just things that our communities can't provide themselves and also as you say those different programmes of connecting communities and other cities" - Participant $K$

Participants identified that communities were restricted in both skills and resources to develop in ways they desired within their communities. In order to build community resilience, the participants stated the Council should take a secondary role that focused on resource provision and aiding communities in developing networks required for building community resilience. As identified by Participant $\mathrm{K}$, recognition is an important resource for communities. This resource was highlighted by other participants as being vital for successful collaboration between the Council and the communities.

"I know doing all the soil tests, the council paid for them. But even though it may well [have] been a world first, it's not recognised because we couldn't get funding to do enough tests so it wasn't scientific enough. So cleaning up the environment could be a lot cheaper and easier" - Participant I

As identified by Participant I, a lack of recognition from the Council can stifle the ability of communities to continue with resilience building initiatives. Participant $\mathrm{K}$ highlights that recognition is an important motivator for communities to take part in resilience building initiatives within the community as it instils community groups with a sense of importance and acknowledges that their efforts have significance. 


\subsubsection{A Role for Communities}

All participants agreed that drive and support from the community was necessary in order to successfully build community resilience. Participants expressed that without enterprise stemming from the community, initiatives would fail as a sense of ownership and self-preservation would not be felt by community members. This was highlighted by some members as a democratic issue, suggesting that absence of community leadership was disrespectful and unrepresentative. Without community consultation and support, initiatives faced the risk of being met with resistance from communities who feel powerless. Participants felt that through instilling a sense of ownership in local projects, community members were more likely to be invested in seeing the project become a success.

"But it's our idea and it's in the Valley and we are quite protective of it. We don't want the Council hijacking it and taking control of it because it is our thing and I think that is really important." Participant $B$

Grassroots approaches to community development reframe the role of the community from consumers into active citizens who have the capacity and agency to exact change in their lives (Dreier, 1996). A grassroots approach to community initiatives is idealised by participants as it allows for communities to take ownership of the process in identifying what could be improved locally, and then putting these ideas into action. Participants felt as though they were more respected and represented when they were involved in the Council's plans. Participants also highlighted the importance of local knowledge and/or lack of local knowledge. For example, one participant from Aro Valley highlighted that many within Aro Valley were not aware that the local water source was heavily polluted and not potable for use in the event of an emergency. The participant expressed that this lack of community knowledge was perhaps not recognised by the Council.

Although perceptions of community motivations for grassroots led resilience building varied from suburb to suburb, most participants had faith in their community's appetite for grass-roots led development. Newtown and Aro Valley, in particular, 
were looked upon favourably not just by those from those communities but also by participants from other suburbs.

"Thorndon probably doesn't have such a strong community sense as Newtown or Aro Valley." - Participant E

These two areas play host to already actively engaged communities that are made up of many smaller civil society groups i.e. the Community Council, the Residents Association and the frequently used community centres. Shared spaces and projects such as these nourish the construction of both bonding and bridging social capital (Eicher \& Kawachi, 2011). The Aro Valley Community Council plays a strong leadership role in fostering community led development focused on both community and environmental welfare, and governance issues (Aro Valley Community Council, n.d). Participants from these communities expressed confidence in their community's ability to provide the skills and leadership necessary for driving a grassroots approach to community resilience.

"Here I think there is some strong leadership or good strong motivated people who are sort of plugging away and driving certain aspects of it, so I think here it's quite well established. Like the community council has been strong for decades now, it's there and the people are there and the structure is place to make decisions and I think that's really important and there's good communication and there's people doing the gardens and people doing restoration so there is lots of different aspects being looked at. Yeah I think there is good connections between people and I think if you have a good idea you could get it up and running relatively quickly and with the help and support of the structures that are in place." Participant $B$

Participants identified that there was a strong presence of small community led initiatives and events across Wellington City suburbs that are currently in progress. These community led initiatives and events contribute to the suburbs grass-roots 
development, as witnessed in native plantings, communal newsletters, workshops, clean-up groups, and local festivals.

"There's people, like the social lab girls, who are making waste wood into furniture and you go along and you learn how to build out of the waste wood and then you have a beer together and then that's kind of a social thing but also constructive and skill building". - Participant $J$

Initiatives, such as these increase community member's frequency of interactions (Alaimo, Reischl, \& Allen, 2010). Lewicka (2005) states that the enhancement of neighbourhood ties also enhances residents place attachment. These initiatives, although not necessarily targeted at creating community resilience, aid in developing socially connected, engaged and resilient communities (Alaimo, Reischl, \& Allen, 2010)

\subsubsection{Barriers to Community Buy In}

As highlighted earlier in this chapter, a lack of familiarity of the Council by younger or less involved participants was mentioned by some participants as a significant barrier which prevents these individuals from taking on leadership roles within their communities.

"But I don't really know what the Council does. I've never really looked into it so I can't really answer that question in a strong enough sense. Yeah I never really thought what the Council's doing" - Participant E

A lack of knowledge surrounding the Council's role acted as a barrier for these individuals to advocate for their communities and access resources (for example grants). This lack of awareness may mean that individuals don't think that they have the power to stimulate change within their community. Chavis and Wandersman (1990) identify one of the main components which encourages civic participation in community affair as the perception that the individual can exact power over the situation in a way that stimulates change. Thus, a lack of perceived power stifles their 
ability to contribute to developing resilience in their communities (Chavis \& Wandersman, 1990).

Time constraints and financial constraints were cited as two of the greatest barriers for communities in developing self-led community improvements. Participants expressed that voluntary community work was considered time consuming and although perhaps rewarding for mental and social wellbeing and fulfilment, it does not provide direct economic benefits to individuals.

"It does come down to time and money and the people who are involved are also working and we to actually get stuff going we need to volunteer our own time. So that's with like the community gardens but if the Council comes in it becomes a slightly paid role which makes it a little more doable" - Participant $B$

"I know the Mt Vic Newsletter is totally volunteer based so maybe a small fund for projects like that just to give people a little more initiative" - Participant $H$

Participants identified that these barriers could be minimised with help from the Council. This help could be manifested in the form of financial contributions to community groups or the creation of paid roles for members who take on greater roles of leadership in their communities.

"So a financial input would help and that would allow maybe two or three people to work together in a more educational aspect" Participant I

"If the Council comes in and it becomes a slightly paid role which makes it a little more doable. And if we are doing something which can be sort of important to the rest of the city, something that can be rolled out to other communities that would be really cool and beneficial for the council, it's a win-win if it comes off" - Participant $B$ 
This financial input would alleviate financial burdens and provide some compensation for community members who take on active roles in building community resilience. However, several participants thought that communities could contribute to alleviating financial burdens for community initiatives. Participants also highlighted that not all community resilience building initiatives required financing. For low cost initiatives, some participants suggested fundraising and time banking as two alternate methods for funding provision.

"The time banking movement, that teaches you how to grow your own seeds and that for no charge other than let's do a swap and I'll babysit your kids for two hours if you help me do a permaculture patch in my garden for two hours. So that kind of swapping of the skills. Knowing that you can use other resources, just that creative thinking, you don't have to have Bunnings Garden Mix supply, there is seaweed down at the beach you can use, there's resources all at hand. It's just about asking as well because that consultation stuff. Even using social media like Facebook, like "really needing some brown stuff for my compost" like bark or something then someone else can be like "oh yeah I've got a whole lot". We find firewood like nobody's business, and we haven't had to buy any just because we have mentioned our fire or something and people have been like "oh yeap I have just chopped down a tree", so I think just as long as people keep a dialog with one another they find ways to help each other and be generous" - Participant F

Participant $F$ was the only respondent to mention time banking as grassroots approach to facilitating community resilience, which illustrates that these alternative approaches are still underutilised by community members. The time banking movement in particular draws on the elements inherent to resilient communities: social capital, highly connected networks, and knowledge transfer. Gregory (2014) highlights that community utilisation of time banking enhances community resilience through increasing connectedness in networks, developing skills, and reducing reliance on external providers. 


\subsubsection{Current Initiatives}

Most participants reflected positively on current and past levels of support and action for community resilience building initiatives i.e. Community Gardens, Neighbours Day etc.; however mixed perceptions of the Council's current intentions were expressed. These mixed perceptions were a result of participants being unfamiliar with the Council's current intentions for resilience building or being sceptical of the associations which they were aligning themselves with.

Although no participants were familiar with the Council's current endeavour to enter into the Rockefeller initiative and participate as one of the 100 resilient cities, most participants reflected positively on the Council's attempts to work internationally and collectively.

"It would be valuable for Wellington City Council to be connected otherwise they may be inventing the wheel, it may well be that we can learn from other cities that are further down the line" Participant $C$

"I support it fully, I think it's a great idea to have funding for resilience and to have somebody looking after the resilience of the city" - Participant E

"I think anything that puts a magnifying glass on us and gets us to reflect on our wellbeing is definitely beneficial" - Participant $F$

Participants highlighted various benefits for Wellington as a result of the Council's involvement in these international and collective projects. These included: increased support networks, access to a greater range of information, and the Councils public commitment to improving resilience within the City. Participants expressed an enthusiasm for the new opportunities that these projects would provide for Wellington City and provided ideas on areas within their communities where the Council should target their projects in order to enhance community resilience.

"Making it possible to cycle around the city because I think if people as a community can get around without using their car. Supporting 
community gardens and supporting people to learn about gardening and helping communities to have events and things that draw everyone together so they can talk about the community" Participant $E$

"I think sexual violence stops people functioning on a really basic level, so I think that would be cool if that were acknowledged as an important problem for the community but it's also a possibility to have people who are really well educated and supported and know their rights and are in power. So I think sexual violence prevention and support would be cool" - Participant D

"Obviously, more money for things like community gardens and the parks, more parks or another market" - Participant H

Many participants highlighted opportunities for improving community resilience by targeting issues such as safety, mental and physical wellbeing and community skills and resource development i.e. funding community associations, workshops. Participants felt confident in identifying weaknesses in their communities and provided potential solutions for addressing these weaknesses. This highlights the capacity and appetite of the community to be more involved in leadership roles in community resilience building initiatives.

Although the majority of participants viewed the 100 Resilient Cities project in a positive light, some participants were less enthusiastic about the association with the Rockefeller Foundation.

"Now I would say the first thing is once you get a financial contribution from anybody it means you are dependent on them and the Rockefellers I am very suspicious of in the first place so it doesn't sound very great to me. See this is what I'm saying this overseas thing, we always look overseas. I think you know we have to trust ourselves" - Participant A 
"Well I don't know anything about the Rockefeller project so I don't know if it's good or not. Just because it's got the name Rockefeller, there would be a time when you think oh yes well it must be good" - Participant C

Participant A expressed particular disdain for this association with international organisations. As identified in the previous chapter, participants identify self-reliance and reduced external dependence as a core element of a resilient community. It is understandable that some participants perceived reliance on external programmes and organisations to steer the city's policies as counteractive to resilience building initiatives. However, this perspective was not a view held by the majority of participants.

\subsection{A Role for Community Gardens}

This section will explore how community gardens build resilience within Wellington City suburb communities. Elements of community resilience, discussed in the following section, reflect the facets of community resilience which were identified by participants in the previous chapter. These are: development of social capital and networks, access to human and physical resources. These characteristics are manifested in a range of ways through the activities and relationships occurring within the bounds of community gardens. This section will conclude with participants' identification of barriers which hinder the contribution community gardens can make to community resilience.

\subsubsection{A Model for Resilient Communities}

\subsection{1.a Developing Social Capital}

Social capital has been identified by many authors as a key component of resilient communities (Aldrich \& Meyer, 2015; Gunderson \& Holling, 2002; Lewis \& Conaty, 2013; Norris \& Stevens, 2007; Sherrieb, Norris, \& Galea, 2010). High levels of social capital improve a community's ability to respond to change both physically and emotionally. Social capital also influences other components of resilient communities; resource sharing, information feedback, innovation, and diversity (Aldrich \& Meyer, 2015). Interviews with participants showed that community 
gardens contribute to bonding, bridging and linking social capital (as defined in Chapter Two).

Participants who were involved with communal style plots discussed how the gardens facilitated interactions between members of the community garden. Within these style of gardens, participants had the opportunity to work together in both the planning and organisational process for the garden, as well as working together to implement these plans through physical labour.

"[We work in] groups of 3 so if there's maybe nine of us there at the time on the Saturday, three of us will get stuck into the asparagus bed weeding that, then another three might see the compost really needs doing" - Participant F

Participants described the use of their community gardens as a way for them to meet new people and establish new relationships within their communities.

"I think when you're meeting people and making friends, you kind of need to see or meet or hang out with someone, like 6 times at least before you feel like there's a friendship made. I think the garden kind of enables you to make those friendships as well because every couple of weeks you are meeting these people and you sort of chat about all sorts of stuff and a lot of those people have become my good friends" - Participant B

Participants from communal style community gardens expressed higher levels of group interaction in comparison to the one participant who was involved with individual plot style community gardening. Participant D, who partook in plot gardening conveyed that it was more difficult to interact with other users of the community garden as a lack of a working bee meant that members utilised the garden at different times and tended to work individually. Despite this, Participant D had begun to form a friendship with several other members. These connections enabled her to access advice and learn from more experienced gardeners. 
"Yeah we talk about gardening and I guess kind of sharing knowledge about stuff. I mean I know a bit about gardening from my family and I was always quite interested but it's cool to have other people because people have other techniques and ways of doing things and seeing what other people are doing" - Participant $D$

In comparison with other participants, Participant D had limited encounters with other members from her community garden. Furthermore, her interactions were limited to within the garden. Participants who were involved in communal style gardening demonstrated that the friendships which were formulated within the context of the garden, were more likely to persist outside of this context too.

"We hangout outside of the garden, this kind of core group of people and go for a drink in Newtown or get coffee, we have potluck dinners. We have had two or three of them where we try and eat stuff from the garden" - Participant $K$

"Some of the people are musicians and I will want to support them and go to their gigs and things like that or [Community Garden Member] is part of the Somali sewing group so I have visited that before. So it doesn't just stay as "oh I only see you in this context" and I have hung out at gigs or if I have seen someone at a bar that's from the garden, I will go sit with them and talk to them" Participant $F$

However, the persistence of these relationships outside of the garden was limited to the individuals' existing connections and the amount of time that they had been involved within the gardens. In addition, some participants weren't interested in sustaining these networks outside of the garden.

"Some of them for sure. Yeah I don't know what everybody else gets up to outside of it. But I'm pretty sure that everybody would stop and say hello to each other on the street. Some of us are friends for 
other reasons and make the effort to see each other reasons" Participant $L$

The connections made in the gardens with other members were not necessarily characterised by friendship. Relationships formed were also be more formal and led to opportunities to access alternative networks.

"Not really just with people who are my friends before, anyway. Not yet. But amazingly [Community Garden Member] we found out is my step aunty. So with her I feel like there is an immediate connection. And with [another Community Garden Member], he's a Steiner teacher at the school in [suburb] and they are looking for high school teachers and I'm doing relieving. So I was like "oh yes me please". So it is about, I will feel like l'll see them again outside of the garden but it is quite early days" - Participant J

"So the person I was talking about in the band is part of an anarchy group and they are really based on a community decision making model, they are really inclusive and collaborative and so I have learnt from him talking about how to lead inclusive group discussions and those kind of things just from the conversations we have had in the garden" - Participant $F$

Participant $\mathrm{F}$ was able to draw on her relationship with another community garden member to access new learning networks outside of the garden. Similarly, Participant $\mathrm{J}$ highlighted that her interactions had presented her with an opportunity to access stable employment. This opportunity may have been missed had she not been involved with the garden as this information perhaps would not have been readily available to her.

As described in Chapter Two, bridging social capital refers to the development of networks between different groups within a community (Poortinga, 2012). This enhances diversity and reduces distrust within the community. Participants highlighted that their community gardens aided in developing bridging social capital within their communities. Community gardens enhanced bridging social capital 
within the community in two ways. The first strategy was through impromptu interactions with individuals, while the other was through working with other groups or organisations. Attempts at developing bridging social capital through impromptu encounters was evident during my participation at two working bees. My experience at both gardens exposed the desire of community gardening members to formulate positive relationships with other users of the gardening space. Throughout the day I witnessed members of the public who utilised these public spaces for leisure. Members from the community gardens were consistent in their interactions with other users and attempted to engage with people passing through the grounds or utilising nearby spaces. Interactions ranged from a simple greeting, to an offer of produce, or an opportunity to participate for those who appeared more curious about the activities being conducted. Interviews with participants indicated that impromptu interactions were widespread throughout Wellington City Community Gardens.

"Well you get to meet different sorts of people especially when we are gardening in our plot which is at the top end of Aro Valley and on the edge of the road. People walking past will stop and talk and we will talk with them and that's a very nice way to have an outreach into the community too and that way we have had new members come in just because they have seen, and watched over the years what we are doing and they have thought "I'd like to be part of that'"'- Participant C

The second incidence of bridging capital was through community garden participants working with or alongside other groups within the community. Participants from nearly all gardens were aware of inter-group interactions. Interactions included coutilisation of space, teaching skills, redistribution of resources, and supporting or receiving support from neighbourhood groups, businesses, schools, residents associations and community centres.

"There's the Mt Vic's resident association that we have connections with. Different people have different connections. We have 
reasonable relationship with the Mt Vic bowling club next door and we have this one old fellow who keeps wandering up and he'll have a few drinks after the game and he'll come up and plant some potatoes or something in the garden. [...]. [T]here's also crossways crèche that have a raised bed that they're using as a little garden now. So as appropriate. I suppose one of the things that I am really aware of is that Chalkle we have had a relationship, with the Sustainability Trust we have had interactions with" - Participant G "Often we get a lot of seedlings from Commonsense organics, they give us the stuff that's about to die" - Participant $L$

Participants from both Innermost Gardens and the Mt Crawford Community Garden stated that their on-site facilities were shared with other non-community garden users. Innermost Gardens leases a community house which is rented out to other local community groups. The participant from the Mt Crawford Community Garden revealed that their garden shed was also used by a local native tree planting group as a plant nursery. Inter-group interactions develop bridging social capital; allowing for the development of networks and resource pools (Poortinga, 2012). This enhances community resilience.

Linking social capital, although a more recent addition to the literature, is central to the development of resilient communities (Poortinga, 2012). For example, the development of links between the community and a city council is crucial for community support during times of disaster. Strong links between a council and community allow for ease of information transfer, efficient distribution of both physical and human resources, and access to community volunteers. Participants thought that community gardens help to bridge the link between them and the Wellington City Council.

"We have had a very productive relationship with the council. With them offering us the space in the park to use. The stereotypes of relationships with bureaucracy are certainly nowhere to be seen in our relationship with the council" - Participant $K$ 
"Yes [the Council] are actually very supportive of Kai o te Aro, they bring us mulch and different things like that. I think [Community Garden Member] has fairly regular contact with people in the Council, and mentioned that we get supplies that we need [because of this relationship]" - Participant $C$

Participants highlighted that interactions with the Council have not only been beneficial for developing their relationship with the Council, but also facilitated in establishing working relationships with other local community gardens. This helped to develop networks and distribute information on different processes and skills.

"...the Council who have these meetings once a month and they've [recently started] bringing people from all different gardens together for a chit-chat once a month. So that's been useful, sharing knowledge and information because all these gardens are at different stages of development, some of them have been round quite a while. And so that's been helpful, to learn from what other people have done and also to try to inform them about our process" - Participant A

As identified by Participant $A$, this was particularly useful for recently established community gardens. At meetings representatives had the opportunity to discover what projects are currently being developed by other community gardens, learn what past projects had been successful or unsuccessful, and why. This enhances the efficiency of community gardens and improves their ability to contribute to their community's resilience.

\subsection{1.b Access to human and physical resources}

As discussed in the first section of this chapter, participants identified access to human and physical resources as being an important component of a resilient community. In this context human resources refers to the skills and knowledge held by individuals. Interviews with participants showed the range of learning opportunities presented within community gardens. This ranged from more structured opportunities, such as workshops or skills days, through to more informal 
and accidental opportunities such as the transfer of knowledge through working together.

"We don't want an individual plot we have got our own gardens at home and that's where we can do our individual stuff. We want to be learning from each other. We want to be contributing to each other and collaborating" - Participant F

"Because by helping you then I am learning how to do it. I did start pulling out weeds that were really quite beneficial when I first went there because [Community Garden Member] approach for new people is like "trial and error, go for your life and then learn from that"'" - Participant F

Within community gardens, members are able to experiment with new techniques and learn for themselves by watching and doing. Part of this process, as explained by Participant $F$, is learning from failure. Participants discussed failure as a learning opportunity rather than as a defeat. Furthermore, participants often expressed their own lack of understanding or skills without negative connotations. Instead, participants perceived all community garden members as having something to contribute to the collaborative learning process. Thus, learning was not framed as a hierarchical process.

"There's a bit of a range [of people involved]. One of them is a very experienced gardener who is a permaculture teacher so she knows a lot about all aspects of gardening, others just do it as a hobby, some of us are doing courses and I think others just come along for the fun of it. There's a real variety of knowledge but a similar kind of keenness from everybody and don't think there is ever a feeling of one person leading the whole thing. I think there's quite an equal contribution to what's going on and an equal-ness of fumbling around of "do we put this here" and "yeah go for it" type of thing" - Participant $L$ 
This collaborative style of learning, which emphasises openness, inclusivity, and creativity allowed for members to use their knowledge to explore alternative techniques in the gardens.

"[Community Garden Member] wanted a space where she could experiment with [...] Hügelkultur ${ }^{5}$ so she had developed a little area [for] that. So I learnt a bit from her about that and began broadening that process out to a couple of other areas and building these little Hügelkultur mounds" - Participant A

Experimental learning was also present at the Innermost Garden in Mt Victoria, where the community gardening group researched, developed and implemented their own bio-remediation project to convert a chemical heavy field into a space for growing organic produce. As stated by one participant involved, the method developed by this group has been highly successful and has been implemented at a much lower cost rate than similar methods used elsewhere.

Community Gardens act as hubs for informal and non-formal learning processes through the practice of gardening. Teaching and learning new theories, techniques and skills, increases an individual's knowledge base. Schugurensky and Mündel (2005) highlight that informal and non-formal learning styles contribute to both individual and community development through providing community members with a range of diverse and transferrable skills which can be utilised not only for civic volunteerism but also for employment within the workforce.

In addition to human resources, participants highlighted that access to physical resources were key to resilient communities. As discussed in in previous sections of this chapter, the community's ability to be self-supporting is central to participants' constructions of community resilience. Interviews and observations conducted during this research identified community gardens as having limited physical resource development. Physical resources identified by participants included fresh produce, buildings and access to tools.

\footnotetext{
${ }^{5}$ Hügelkultur mounds are similar to raised garden beds which can be formed out of logs, grass clippings, cardboard, straw, compost, manure, and other bio-mass.
} 
Innermost Garden in Mt Victoria provides tools and a storage space for community garden members. A tour of the facilities while I was at Innermost Gardens exhibited a comprehensive range of tools that were kept in good working condition. These tools were donated over the years and were provided to individuals working within the garden. Despite this participants identified that access to physical resources required further development. Resources such as power are not yet developed within Wellington City Community Gardens. Power generation was identified by some participants as being central to self-sufficiency.

\subsubsection{Barriers}

Participants cited land tenure as being one of the most important barriers to developing community gardens. This was an issue for community gardens on Council land as well as community gardens on privately owned land. With the exception of Commonground Gardens in Island Bay and a Kai o te Aro site, all community garden spaces are on Council land and have limited tenancy dates. Although tenancy lengths differ from case to case, all Council owned spaces are limited to less than a 10 year period. Members of community garden groups are aware of how a lack of permanency impacts their ability to develop their community gardens in the way they wish. Participant $\mathrm{K}$ highlighted how a lack of land ownership had recently influenced a shift in their gardens location.

"We moved because it's quite nice, Carrara Park is lovely and it was more permanent. We know that the people who own the [previous] section are keen to sell it to housing corp who own a lot of property around there. They own the building right next door and they want housing corp to buy it and develop it. So [it's] a permanency thing" - Participant $K$

The previous location of the Newtown Community Garden was located on private land; however the landowner's indication to sell encouraged the relocation of the garden to Council owned land. A similar process is currently under operation with Commonground Community Garden. The Home of Compassion has informed the group that they need to relocate as the space previously used by the community 
garden is now needed for the development of the organisation. During my attendance at the Commonground Annual General Meeting, members were in the process of negotiating whether to retain or disband the group and how resources should be redistributed. Part of this process involves digging out fruit trees to rehome them as well as deconstructing sheds and raised beds. Built structures and permanent crops have required heavy time and monetary investments. Those present expressed that they were emotionally attached to the developments made in the garden and were upset to see their destruction. Participants who were involved with Community Gardens which were not currently under threat of losing their tenancy also expressed concerns over how a lack of permanency impacts their ability to implement plans.

"I think our lease is for another 7 years. Legally we can only look 7 years ahead but we are planting trees that will be there in 100 years. We are planning long term but you don't know what politics and all that goes on. They could sell it for a housing development or something like that" - Participant I

Participant I highlights how vulnerable community gardens are to the inclinations of the Council, and the influence other community users have on the longevity of the gardens. Other participants highlighted the influence the Council or lease holders have on the activities within the garden.

"the areas that have been selected by Wellington City Council as areas to be used so we are kind of restricted on what we can do in terms of that but it's kind of as long as you're not getting in anybody's way you can grow what you want." - Participant $L$

As demonstrated by Participant I's statements, community garden members are cautious with how they proceed with projects and activities within the garden. They are aware of their tenancy's limitations and act with the intention to avoid straining their relationships with the Council and other community groups because of this.

As identified in the previous chapter, time and financial obligations are barriers which prevent participants from participating in community gardens. Although all 
participants interviewed stated that they were actively involved in their community garden, many stated that the time commitment meant that often they were unable to participate.

"I have always really liked the idea, last year I lived in Brooklyn and I always wanted to go to their days but I was just never free, because they have working bee and it's more like everyone does it together" - Participant D

Participant D's experience in a previous community urban agriculture project exposes the reality for many participants of having to negotiate personal time commitments in order to participate in groups that had set working bee times. Although all groups allow open access to the gardens, and working bees are not mandatory, participants expressed that communal labouring is a driver for their involvement in the gardens. Time pressures were noticed in the management, organisation and administration side of the community gardening groups. In particular, the opportunity to have a paid role for a coordinator was cited as being needed.

"...things happened a lot quicker. There was a lot more going on.

There are people taking over that coordinators role now but they are doing it part time and when they have time, so not as much gets done because they aren't paid" - Participant I

Another barrier participants highlighted was that involvement in the gardens is seasonal and often numbers drop off during the cooler seasons and pick back up again when the growing seasons begin.

"Over the winter period there is a die down in numbers because we don't have classes and things in winter" - Participant I

As stated by Participant I there are fewer initiatives run during the winter seasons, which quells community members' interest and interactions within the garden. Other participants found that often community members who were not involved in the gardens were not aware of the gardens or of how they could become involved with their local community garden. 
"We were just saying people don't pick the food enough. I think that because we are new, people don't know enough about it and don't know they can just come and help themselves" - Participant $L$

\subsection{Summary}

Section 4.1 was composed to answer the question "How do participants from Wellington City Community Gardens, understand the terms resilience and community resilience"? Participants in this study defined resilience using very general and conventional terms. Fitting with the literature, the term was defined differently by almost all participants however most definitions included an aspect of "responding to a disturbance" in a constructive way.

In defining community resilience participants focused on the theme of a group collectively responding to, or preparing for unwanted change in a positive way. Participants identified that the capacity to do this was tied up in both a community's social capital as well as the physical resources they have in place to support themselves.

However, the issue was raised over which community participants actually identified with. Some participants struggled to identify a community which was relevant to their identity; some participants identified with geographical communities which were where they no longer resided; most participants identified that they were a part of more than one community; and many participants identified with communities that were characterised by common interests or activities i.e. cycling communities, spiritual communities, networks formed through university attendance, etc. This raises the question of what kind of communities do we need to be focusing on while trying to build community resilience. If participants are hesitant or struggle to find a sense of community within their geographical communities, is this an indicator of poor geographical community resilience or has the idea of space and how we interact both with it and within it evolved in a way that means that they are no longer relevant?

Section 4.2 addressed the second research question, exploring participant's expectations of roles and responsibilities in the resilience building process. 
Overwhelmingly, participants identified that the process of building community resilience required input from both communities involved and Council. Although participants held past Council interactions and initiatives in a primarily positive light, they did not advocate a leadership role for Council. Instead, participants imagined a supportive role for the Council characterised by resource and service provision. Participants expressed that leadership needed to come from the communities themselves as they were more in tune to their needs. Within the communities, there was an appetite for community led resilience building; however, an individual's ability to participate in civic participation could also be hindered by time and financial constraints.

Very few participants were aware of the Council's current intentions and involvement in resilience building initiatives. Despite some concerns regarding process ownership and reliance on external sources, most participants were enthusiastic about the Council's involvement with projects such as the 100 Resilient Cities programme run by the Rockefeller Foundation. Participants saw these larger projects as a way for Wellington City to learn from others and be supported in transitioning to a more resilient city. Participants were quick to identify local weaknesses within their community and solutions to target these. This indicated some participants' desire to be given the opportunity to work in a leadership role in building community resilience.

Finally, section 4.3 examined the contribution of community gardens to community resilience. As identified in the earlier sections of this chapter, participants' perceptions of a resilient community is derived through two main facets: social capital, and access to human and physical resources this echoes lessons learnt in existing literature (Gunderson \& Holling, 2002; Lewis \& Conaty, 2013; Norris \& Stevens, 2007; Sherrieb et al., 2010). Participants provided evidence which confirms community gardens contribute to these facets of community resilience. Despite this, the development of social capital is more complex than the development of resource access and knowledge sharing. Although community gardens provided the opportunity for members to develop networks within the garden (bonding social capital) not all participants were interested in building social capital. Linking social 
capital, although present, was not a heavily discussed topic by participants. Bridging social capital appeared to be the most successful form of network building.

Participants also identified several barriers which impeded the potential of community gardens to contribute to local community resilience: tenancy length, relationship management with landlords, time and financial constraints, lack of formal and paid coordination, seasonal activity, and visibility within the community. Tenancy length, relationships with landlords, and financial and time recompense were cited as being the greatest barriers by participants. Participants felt these constraints impacted long-term planning and were responsible for inconsistent development of the gardens. 


\section{Chapter 5: Discussion}

The purpose of this research was to examine how community garden members understand and build community resilience within their communities. This chapter incorporates the lessons learned from the literature alongside the findings produced from this research to address the three research questions posed in chapter one.

1) How are the terms "resilience" and "community resilience" used and understood by community garden members from Wellington City?

2) Who do participants from community gardens identify as being responsible for driving community resilience initiatives?

3) How do members of Wellington City community gardens use these gardens to enhance local community resilience?

The first section of this chapter corroborates findings from the literature surrounding the overuse of the term resilience, relating to a lack of cohesive understanding across participant conceptions. This section draws on findings which suggest that a lack of defined parameters surrounding the term may be an asset for encouraging community participation in the resilience building process.

Following this I address the second component of research question one, focusing on participants' understanding of community resilience. This section highlights that community resilience is more widely understood and agreed upon by users. Differences remain however, in determining both the "threats" to the community, as well as what aspects of community identity need to be maintained and how to achieve this.

The third section of this chapter addresses research question two and explores participant expectations and desires regarding roles of responsibility in building community resilience. The key finding within this section is that participants, despite having a generally positive perception of the Wellington City Council, would like to see the communities themselves driving the process of building community resilience, with the Council playing a supportive role. 
The final section explores how community gardens contribute to a participants' understandings of community resilience. The findings here indicate that Wellington City community gardens contribute to the development of bridging and linking social capital, and the acquisition and transferral of knowledge and skills. Physical resources such as produce, water storage, power generation etc. require development, however these short falls do not outweigh the benefits which community gardens provide for enhancing Wellington City's communities resilience.

\subsection{Understanding Resilience}

This section addresses the first research question:

How are the terms "resilience" and "community resilience" perceived by community garden members from Wellington City communities?

Recent documents produced by the Wellington City Council show that in-line with global trends, the Council have become enamoured with the concept of resilience. Planning documents have exposed the Council's determination to build resilience within the city. Resilience is now considered as a 'buzzword'. Critiques by Welsh (2014) state that the overuse of words such as resilience convolute the terms and may make them redundant. Duit, Galaz, Eckerberg, and Ebbesson (2010) highlight the complexity of resilience within social systems bringing light to the issue that resilience is socially framed, and its interpretation differs in response to its users' needs and expectations.

When considering the Council's intentions to build resilience, it is important to identify how resilience is framed by different stakeholders and what it is that these different groups are actually interested in retaining. The question when discussing Council plans for building resilience are, whose interpretation of resilience is being utilised? As well as whose expectations need to be addressed?

Wellington City Council frames resilience building as a collective effort with input needed from the community, Council and businesses alike. While the Council notes that there are different stakeholders involved in this process (Wellington City Council, 2011c), it does not consider that these stakeholders may have different interpretations or interests in the term. Without engaging in this dialogue the Council 
are opening themselves up to potential conflict and failure of their resilience initiatives if their interpretations diverge from other users.

A key finding from this research corroborates Strunz' argument that the absence of an agreed upon definition results in the term being applied loosely by users which further convolutes the term and reduces its credibility. Participants defined the term resilience loosely with diverging explanations. The findings from Chapter Four corroborate the lessons learned from the literature regarding confusion surrounding resilience. Participants' understandings of resilience varied between individuals, and were influenced by the different discourses participants encounter in their lives. Drawing from the conventional definitions of engineering and ecological resilience to help them define the term, participants used varied and at times conflicting connotations to describe resilience. Participants often used a combination of terms from ecological and engineering resilience discourses to explain the term resilience which led to contradictory definitions i.e. using terms which promoted dynamism with terms which promoted rigidity. This inconsistency highlights how poorly defined parameters have left users with a poor grasp of the definition of resilience.

Upon further exploration, many participants stated that they weren't certain of the exact definition of the word and highlighted the complexities of the term. Many asked for a context or sought reassurance in their answers. Despite this, all participants felt comfortable using the term in conversation. As discussed by Strunz (2012) the lack of precision surrounding the term resilience may be a contributing factor of participants willingness to engage with the concept.

Despite this, the lack of cohesion between participant's conceptualisations reiterates the need for the development of common lexicon or the development of defined parameters and uses for the term as discussed in Welsh (2014). The absence of an agreed upon working definition between the Council and community members involved in the resilience building process may lead to a mismatch in expectations and plans of action to be taken. If an agreed upon definition of the term is negotiated, stakeholders contributing to the process are more likely to understand and agree upon the plans which increases efficiency. 


\subsection{Understanding Community Resilience}

Although some differences in understandings of community resilience were found, participants' were more confident in their definitions of the term community resilience than they were defining the term resilience. This may have been a result of having a context in which to ground their understanding. Most participants defined community resilience in relation to the community's capacity to support community members in all areas of their lives.

Support was discussed by participants in two main ways which spoke to Sherrieb et al. (2010) discussions on social capital. These were compartmentalised as either structural social capital or cognitive social capital. The first of these, structural social capital, referred to services, skills and institutional structures which allow communities to reduce reliance on external providers in conjunction with the presence and availability of physical resources. Examples of structural social capital support include community power generation, service provision, community based productions of food, a heterogeneous population with a variety of skills or occupations, empowered community groups (i.e. residents associations), etc. In comparison support in the form of cognitive social capital referred to the ability of community members to build networks, work together, support emotional wellbeing and feel safe within their neighbourhoods.

The main issues of difference within the conceptualisation of community resilience was the difference identifying what constitutes a disturbance, or what events people should be concerned about. From this study it was clear that there were at least three different "threats" participants identified as being of concern for Wellington City. The first, and most immediate and traditional form, was natural hazards such as earthquakes. The second "threat" surrounds long-term changes to society such as climate change, peak oil, and economic crises. Unlike the first two "threats" which are seen as more external disturbances, the third "threat" was more internal, this threat referred to the social change towards insularity whereby connection between individuals within the community is lost. 
The third type of difference within defining community resilience was the issue of defining what it is that needs to be maintained and how. This finding reflects the concerns of Brown (2014) who argued that a key issue in resilience planning is defining a 'desired state' and recognising that there may in fact be multiple 'desired states'. For example, this research illuminated a range of components which participants identified as being at the core of community resilience. Here participants identified human based features such as social inclusion, social trust, social cohesion, and more physical features i.e. community generated power systems, potable water sources. Despite similar understandings of the term, community resilience, as discussed by participants, is a by-product of improvements made in multiple areas of the community. This requires a diverse and holistic approach to building community resilience.

An interesting finding that emerged from interviews was the issue of how "community" is defined. Commonly participants did not identify their geographical community as being their most significant community. Communities of interest were more commonly cited as being significant to participant's identity. One participant in particular completed the interview speaking primarily from her position within the Wellington Cycling community. Her affiliation within this community was stronger than her ties to her geographical community. This brings attention to the issue that individual's ideas of community are evolving and asks the question of whether geographical communities are still relevant to individual's identity and well-being.

If the locus of community has shifted so significantly a decision needs to be made in community resilience planning as to whether or not planning adapts to follow this change or whether it tries to resist this shift. However, this shift may be challenging as identifying which communities of interest are of significance within the public may be difficult. Another challenge with this is that if communities of interest have dispersed populations, individuals involved may not experience the same disturbance i.e. localised threats such as flooding etc. It may be more difficult to coordinate support amongst communities of interest which have dispersed populations. Despite this, reframing the locus of community resilience to be situated within communities of interest may be beneficial for enhancing diversity (for example in economically 
homogenous geographical communities), strengthening pre-existing networks, and benefitting from pre-existing elements of social cohesion.

This draws the argument back to how community resilience is being framed. What do communities need to be building resilience against? For example community resilience against localised natural disaster suggests that geographical community resilience would play a beneficial role. Due to the localised and immediate nature of natural disasters, having people, resources and networks to rely on these situations close at hand is important. However, abstract interpretations of disturbance (economic downturn, food security, etc.) may be equally successful applying a geographical approach to community resilience as a community of interest approach to community resilience. These events are more widespread and enduring which means that the support given from communities of interest may be as effective as immediate response, close at hand, is less significant.

\subsection{Negotiating Responsibility}

Within the Wellington City Council's "Wellington Towards 2040: A Smart Capital" report, the Council discusses resilience building as a collaborative process. They identify themselves as just one player in the process, also looking to business and the community to shoulder some of the responsibility. This section seeks to answer the question:

Who do participants from community gardens identify as being responsible for driving community resilience initiatives?

In-line with the Wellington City Council, participants also presented a collaborative approach to building community resilience. Central to their conception of this process, they identified a role for both the Council and communities within Wellington City. Participants expressed that the communities should be driving the process of building community resilience with the Council acting in a supportive role only.

As introduced in Chapter Two, the idea of resilience has been picked up by the governmentality literature. The aspect of governmentality that is relevant to this research is the idea of reducing the responsibility of governing institutions by 
encouraging the public to govern themselves. Despite an appearance of freedom and autonomy, because of structures and social norms within society, the public become self-governing within a conventional trajectory which maintains the status quo (Pudap, 2008). Critics such as Welsh (2014) argue that resilience building is framed by government institutions as a way for communities to become empowered when in reality it allows governing bodies to encourage communities to "maintain the status quo rather than conceive of challenging it" (p. 21). Empowerment is seen as desirable by community members who take this role upon themselves to be active agents within the community resilience building process. This minimises the role and responsibility of the governmental institution and puts more responsibility onto the community to identify and drive resilience building initiatives i.e. formation and running of community gardens, residents associations etc.

This approach has been critiqued in the literature as being exploitative and serving to reinforce existing relations of power (Joseph, 2013). However, Rogers (2013) argues that community resilience framed within governmentality narratives are not inherently negative. Rogers (2013) states that governmentality is framed within two competing narratives: responsibility versus empowerment. Discussions involving community resilience and its links with governmentality often focus on responsibility and inaccurate conceptions of empowerment. Rogers (2013) argues that community resilience does provide space for community empowerment, however in practise empowerment is often perceived, but not actually experienced i.e. community engagement although positive, is not necessarily empowering. One way in which community members can experience empowerment is through communities' involvement making decisions in the community resilience building process. Therefore, this framing of community resilience as a form of governmentality is only negative if the communities are perceiving their empowerment, but not actually experiencing it. A way in which community members involved in this process could experience actual empowerment is through having the opportunity to contribute to the identification of what is important to maintain or protect against 'threats' to their community and the ways in which this could be achieved. 
Most participants in this study sought empowerment through trying to be involved in the decision making process of community resilience building initiatives, for example contributing to identifying what aspects of the community required attention. It is important to note here that community members need to be given the opportunity to be active decision makers in their communities, and not simply actors who complete predetermined projects set by governing bodies. Participants also wanted to be involved in defining what their community's desired state is. As discussed in Chapter Four, current attempts by the Council at including communities in the planning process for their communities, leaves much to be desired. Inclusion of community members in the decision making process was perceived by participants as tokenistic. Participants perceived that the Council viewed consultation as a step that must be completed in order to formalise the process. Respondents felt that their ideas were often neglected from discussions regarding community based improvements with the Council and that the Council often had a pre-formulated plan which was presented. Consultations appeared to be more reminiscent of a presentation on what the plans were rather than a space for collaborative decision making where community perceptions and needs were taken into account. The participants reflections highlight that community members who participate in these consultations with the Council are not currently experiencing empowerment as their contributions in these situations are disregarded.

As discussed in Chapter Four, participants felt that community resilience building required collaboration between the communities and the Council; communities needed to be the drivers of community resilience building processes, while stating that the Council needed to take on a role characterised by support or facilitation. Active agency was identified by Magis (2010) as being a crucial feature of a resilient community. Welsh (2014) states that grassroots approaches to community resilience have the greatest potential to be transformative. These initiatives challenge the status quo through allowing community members to identify what the 'desired state' is and how it should be achieved.

\subsection{Community Gardens - A Vector for Community Resilience?}

This section aims to address the question: 
How do members from Wellington City Community Gardens use these gardens to enhance community resilience?

As discussed in Chapter Two, community gardens have previously been identified in the literature as conducive to the efforts of building community resilience. Community gardens allow for the development of social capital, knowledge and skill production, access to greater resources and improvement of mental and physical health (Glover, Parry \& Shinew, 2005; Kingsley \& Townsend, 2006). This section explores how community gardens contribute to resilience in Wellington City communities. This section will end with a discussion about areas where community gardens could benefit from further development in order to enhance community resilience.

Community gardens in Wellington City communities enhance community resilience in two key ways. The first is through the development of social capital and the second is through the development of human based resources i.e. skills and knowledge. To a lesser extent community gardens produce physical resources i.e. food. This study also revealed that physical resources are underdeveloped in Wellington City Community Gardens i.e. water collection, power generation, which are also contributors to community resilience.

\subsubsection{Social Capital}

The development of social capital has been cited as an important component of community resilience. As introduced in Chapter Two, social capital is comprised of bonding, bridging and linking social capital. Bonding social capital refers to close-knit relationships between people within a defined homogenous group (Coffé \& Geys, 2007; Hawkins \& Maurer, 2010; Poortinga, 2012). Bridging social capital refers to building relationships between defined groups, and linking social capital refers to the relationships between groups and institutions of power or government (Poortinga, 2012).

This study has found that Wellington City community gardens are contributors to the development of bridging and linking social capital. This finding reflects lessons learnt from Krasny and Tidball (2009). Of the three types of social capital, Wellington City 
community gardens contributed the most to the development of bridging social capital. Bridging social capital was developed through three main streams: incidentalindividual, intra-group work and inter-group interaction. Here I use incidentalindividual interactions to describe unplanned, one-on-one interactions which community garden members shared with non-community garden members in or around their community garden. Bridging social capital can be formed through intragroup work, and refers to the interactions that community garden members made with one another while participating in the garden. Inter-group interactions refers to the planned networks the community garden groups actively developed with other local community groups i.e. community centres, timebanking operations, schools, etc.

Many participants throughout our discussions emphasised that they were driven to taking part in their local community garden as a way to enhance their personal relationships within the community and to meet their neighbours. Community gardens, as a communal use space, theoretically provide an excellent forum for the development of bridging social capital as they provide a communal space and activity to attract a diverse group of people to come together. Emerging from this research, it was clear that the development of intra-group bridging social capital was much more evident in cases of communal gardening rather than individual plot gardening. Central to this was the presence of working bees. Working bees required collective labour and allowed for collaborative decision making within the garden. Working in this space provided the opportunity for individuals to ask for help, learn new techniques as a group or to offer their own skills as a resource. The irregularity of attendance within the plot style gardens resulted in individuals not building up familiarity with one another. Although this does not mean that bridging social capital cannot be developed, the process appeared to be much slower as individuals were not in a situation that encouraged collaborative work or interaction.

Despite community gardens providing a forum for encouraging the development of intra-group bridging social capital, the relationships formed within the garden did not necessarily transcend the boundaries of the garden. Some participants highlighted that although they enjoyed meeting new people within the garden, often they did 
not develop these connections in their personal lives. This finding echoes Kingsley and Townsend's (2006) work, who discovered that the formation of relationships within a community garden did not extend outside of the garden which prevented groups from developing bonding social capital. Kingsley and Townsend (2006) expressed that this may have been a reflection of the length of time the garden had been in operation (for only 2 years).

Within this study, it was clear that relationships sustained outside of the garden were often a result of prior friendships or networks, other common interests, or formal relationships i.e. through work or other organisations. The potential for individual connections to transcend the bounds of the gardens were based on individual preference, length of time in the garden, and prior motivations for joining the garden. For example, one participant expressed they had joined the garden as a way to access and distribute knowledge, but identified that he was not overly social. His passion within the garden therefore, was not linked to the development of social capital, reducing his interest in engaging socially outside of the boundary of the garden.

Increased duration of experience working within the garden appeared to positively correlate with stronger relationships between members as expressed by participants. As highlighted within this research, participants are often mobile, moving from one suburb to another regularly, or with plans to reside in Wellington City for only a defined period of time. A transient population could be an issue for the transition of bridging social capital into bonding social capital as individuals have less time or commitment to develop strong relationships which provide for more emotional based forms of support. Despite this, as discussed in the literature, the development of bonding social capital is not always positive and can result in exclusionary groups which may develop negative characteristics over time (Helliwell \& Putnam, 2004; Coffé \& Geys, 2007; Steinfield, Ellison, \& Lampe, 2008; Poortinga, 2012). Although bonding social capital leads to increased social cohesion, all three types are important for the development of social trust. Bridging social capital inspires social trust between diverse groups of people. The use of community gardens enhances bridging social capital which in turn enhances social trust. The use of community gardens for this may be particularly useful for Wellington City communities, where Wellington 
has a highly transient and diverse population. The community gardens act as a vector for individuals to build up networks in the community, while pre-existing community members may use the space to establish a sense of trust with welcoming new people into their community. In response to the literature, the absence of bonding social capital development here is not necessarily disadvantageous as highly homogenised groups may create barriers for individuals to enter Wellington communities with ease.

In addition to intra-group bridging social capital, community gardens also contributed to bridging social capital with community members who were not involved the community garden. Participants often cited that the open area, as well as mixed purpose space allowed for greater interactions between community garden members and non-community garden community members. Interactions such as these were more frequently cited by participants who took part in community gardens which were situated within the community i.e. Newtown Community Garden in Carrara Park, Innermost Gardens, Kai o te Aro. In comparison, gardens such as Mt Crawford, Commonground and Tanera Park are further removed, either in a space separate to the hub of the community or with physical restrictions i.e. gates that create a barrier which may prevent community members from exploring this space.

In gardens which were integrated into the community rather than removed from the community, participants discussed a drive to engage with non-community garden members and cited frequent incidental interactions with non-members. In these situations the garden acted as an opening topic for members and non-members to engage in conversation. These interactions may build familiarity within communities which in turn may lead to a greater sense of security and community as individuals become more aware of other people within the community.

Unlike bridging social capital which contributed more to cognitive social capital, linking social capital was the greater contributor to structural social capital support as ties between community and governing institutions ease the transferral of resources and knowledge. Incidences of linking social capital development were present in community gardens; however, the occurrence of this social capital was less widespread than that of bridging social capital. Linking social capital was forged more 
acutely with specific members of the community garden, specifically with members who took on roles of leadership within the garden. Despite this, the interactions between community garden 'leaders' and Council members generally fostered positive working relationships. Despite this, members who were not involved in roles of leadership within the garden were unaware of what support the Council already provided for the gardens, or what resources could be accessed in the future.

Many participants expressed that they felt the Council supported them in their efforts within the garden, however still felt they must tread with caution and not invest in actions or activities that may be seen as too radical. This response may be linked to characteristics of governmentality, as discussed earlier in this chapter. Participants were also aware of how their relationships with other more "powerful" groups within the community could impact their ability to access funds or future tenancy agreements with the land owners.

\subsubsection{Resources}

Participants highlighted resource development and accessibility as being another key feature of community resilience, this section looks at the presence of resources within community gardens represented. Lewis and Conaty (2013) and Sherrieb et al. (2010) identify that access to resources improve the capacity of communities to respond to change. Despite both participants and the literature citing physical resource development as important features of resilience, most participants did not refer to the presence of physical resources within the community garden in our discussions. Of those who did, they highlighted the presence of some resources i.e. land, produce, gardening tools, composting systems, or physical structures within the community gardens, it was clear that there is still scope to improve physical resource development. In addition, despite the importance of food security within the literature on community gardens, several participants highlighted the underdevelopment of produce available to support the community in response to an emergency. This displays that community gardens are not currently an effective response to community food security, however their potential to supplement groceries for individuals within the community is still beneficial on an individual basis. The limited development of these resources may impede the ability of communities 
linked to these community gardens to cope with and respond to unexpected disturbances.

Human based resources i.e. networks, skills and knowledge, were highlighted in the literature as being contributors to community resilience. The presence of these resources within the gardens were discussed much more frequently than the presence of physical resources by participants. People centred resources such as these, speak to the alternative conceptualisations of resilience such as unemployment, climate change, and economic downturn. The development of these networks within the garden often provided opportunities for individuals outside of the garden. Examples given were; potential employment, access to housing, and skill development in other areas. In addition, access to land allowed individuals to come together and share techniques and knowledge with the group. This facilitated not only the transferral of knowledge and skills, but also provided the opportunity for experiential learning. Experiential learning led to the modification or development of new and innovative gardening techniques. An example of this was the development of a bio-remediation programme at Innermost Gardens in Mt Victoria. The bioremediation programme developed by members at Innermost Garden produced a technique which is more cost effective than other techniques which are currently widely used.

Schugurensky and Mündel (2005) argue that unpaid work such as that conducted in community gardens is often undervalued for the potential to contribute to both individuals' and collective groups skills and knowledge. The development of these resources can have a positive impact on individuals employability, which can decrease unemployment within the community reducing negatively perceived community attributes. Although skills and knowledge development are considered to be important aspects of resilient communities, the community resilience literature covered in this research does not discuss in-depth the influence this may have on employment options within communities. 


\section{Summary}

The findings from this research indicate that community gardens provide the opportunity to develop both bridging and linking forms of social capital. However in practice, the development of these relationships is dependent on the individuals' actions, expectations and motivations for joining their local community garden. Building bridging social capital was more easily accessed by participants than linking social capital. Although linking social capital ties the community and governing institutions closer together, enhancing knowledge and resource transferral, few members were able to access these relationships.

Although community gardens contribute to physical and human centred resources which enhances community resilience, there remains space to further improve this contribution. Access to physical resources are important for communities' ability to cope with sudden disturbance. A weak presence of physical resources within Wellington City community gardens reduces the resilience of communities involved with their respective gardens. Despite this, there is a stronger presence of human centred resources within the community. The development of these resources could have follow on contributions to community resilience, for example through reducing unemployment. 


\section{Chapter 6: Conclusions}

To conclude, this chapter will summarise the main findings of this research and comment on the limitations. Finally, I will provide recommendations on going forward for mediating issues of different understandings of the community resilience building process in collaborative work between community members and the Council.

Through this research I set out to explore community understandings of the terms resilience and community resilience. The interest for exploring community members' perceptions of these terms came from the lack of a cohesive definition in the literature, the literatures' identification of the terms use as a buzzword, and the Wellington City Council's intention to collaborate with communities in order to build resilience. To further explore how community resilience may be built this research examined how community gardens in Wellington City contribute to the development of community resilience.

This research set out to answer three primary questions:

1) How are the terms "resilience" and "community resilience" used by community garden members from Wellington City?

2) Who do participants from community gardens identify as being responsible for driving community resilience initiatives?

3) How do members from Wellington City Community Gardens use these gardens to enhance community resilience?

Wellington City Council, like many governing institutions, have found utility in the term resilience. However, in their use of the word, they have not provided a definition for the term. With boundary objects such as these, this can either be beneficial or create confusion. As discussed in "Wellington Towards 2040: A Smart Capital", the Council is planning to engage with the community and encourage their participation in the resilience building process, the use of this boundary object may be simultaneously a barrier and a facilitator of collaborative work. Although the convolution of the term may lead to some confusion, the widespread familiarity with 
the term may make individuals feel more comfortable participating in collaborative community resilience building as the term is one they are likely to have encountered before. This familiarity with the term make participating much more accessible than if the Council were to use technical jargon that is unfamiliar to the public. In response to research question one, this research has found that participants drew from a range of discourses to define the term resilience and at times used contradictory connotations or struggled to define the term. However despite a lack of confidence and clarity in defining the term, participants felt comfortable using the term and linked it to positive synonyms. The widespread use of this term may mean that community members are more familiar with the term and are less likely to be put off from participating in resilience building initiative as a result of technical language.

However, interviews conducted with participants highlighted that individuals understand resilience differently and therefore have different expectations of what the resilience building process should address and what the outcome of enhancing resilience will be. Differences in approach, can in part, be explained by the way in which individuals approach the concept of resilience i.e. as a precautionary measure, as an affect or as a response. The second issue is derived from a lack of specificity in the contextual setting. The lack of a context and linking resilience building to any tangible or specific focus allows for individuals to be creative and draw out what aspects are most relevant to their lives. Although this increases creativity, locating resilience within a specific context allows for more meaningful and directed engagement. Within this research, this has been achieved by further exploring community resilience as it is a context within which participants are already (knowingly or unknowingly) engaged with enhancing through the use of community gardens.

In contrast, participants came up with similar ways of defining community resilience, with participants citing community resilience as the community's capacity to support community members in all areas of their lives, whether through physical resources or through social and emotional forms of support. However, within this there were still differences in what aspects participants saw as being important to protect within the community; what type of threats community resilience needed to be built 
against; and how community resilience would be built. These findings highlight the diversity of issues that community members may identify within their own communities, but also the resourcefulness which communities bring to the table as contributors to collaborative community resilience development. By addressing community members understanding of the term and allowing them to contribute to identifying important features of resilience within their communities, a wider scope of planning is achievable. These contributions help to identify weaknesses within communities which may have otherwise gone unnoticed or unaddressed and allows for further development of linking social capital between community members and the Council which further enhances resilience.

Research question two examined participants' expectations of responsibility in driving the process of building resilience, and explored how participants thought responsibilities between the community and Council should be divided. Participants expressed an appetite for driving community resilience building initiatives and identified a primarily supportive role for the Council to play in the process. Participants' desire to be involved in the early stages of the community resilience building process would allow for them to not only identify both problems and solutions within their locale, but also to have a tangible influence in the decision making process. However, despite these desires, in practice participants have had a history engaging with Council through consultation processes that at times made participants feel as though their values and opinions were not seriously addressed. Rather consultation was used as a tool to appease community members rather than include community members in genuine decision-making. Actively engaging with community members in the early stages of the process and allowing them to express their agency within their communities helps to reduce some of the more negative elements of resilience which has been linked to theories of governmentality.

Despite participants' reluctance to let the Council take the lead, upon hearing about current initiatives the Council are pursuing i.e. 100 Resilient Cities programme, most were pleased to see the Council being proactive and building international networks to help enhance local resilience. This was however met with some unease about the involvement of the Rockefeller Foundation or other similar, multi-national 
institutions. Several participants felt that this conflicted with their understanding of resilience which required reducing dependency on external parties to support the city.

The final focus of this thesis was to explore how community gardens contribute to community resilience in Wellington City in order to further understand the practical applications of community led community resilience initiatives. The findings here show that community gardens primarily enhance aspects of bridging and linking social capital within the community. Bridging social capital is most frequently experienced, whereas linking social capital is weaker with only participants who are involved in leadership roles within the gardens experiencing these ties. Bridging social capital increased participants' social trust, access to support networks and resources, and ability to learn new skills or information. Some of the positive ramifications for participants were potential employment, development of new skills, and the ability to teach and share knowledge. Although these opportunities benefit the individual, these attributes enhance the community as a whole too i.e. lowering unemployment, improving ability to respond to challenges in the community.

Participants also identified access to both physical and human resources as an important feature of community resilience. Although participants highlighted the presence of access to human resources i.e. skills and knowledge, less frequently mentioned was access to physical resources i.e. power generation, water storage etc. Access to physical resources enhances community resilience however currently this area is under-developed in Wellington City community gardens. Despite this, access to other physical resources such as land and, in some gardens, buildings, provides the potential to further develop other physical resources within the community garden. A barrier to improving resource development may be the lack of long-term, secure tenancies of community gardens. A lack of permanency may discourage community garden members from investing in expensive or permanent fixtures.

\subsection{Limitations and Further Research}

There are several limitations to this research. As with the time and resource constraints of a Master's thesis, this research was produced with a limited number of 
respondents, with not all of Wellington City's Community Gardens being represented. To get a clearer understanding of the ways in which Wellington City Community Gardens contribute to resilience, it would be advisable to increase the participation pool to include representatives from all gardens.

In addition, a focus on community gardens restricted the exploration of alternative grassroots approaches to community resilience. Interviews with participants highlighted a range of other community based initiatives that are currently in practise, which may be contributing to the development of resilient communities i.e. Residents Associations, Community Centres, Youth Groups, Community Dinners, etc. Another limitation was that due to time constraints, more formal and in-depth analysis of Wellington City Council's role and perspectives could not be carried out. As this thesis only briefly touches on the role of the Council, a more in-depth exploration of the council's perspective(s) is needed, requiring interviews with council members and project coordinators as well as a discourse analysis of documents published by the WCC. This exploration would allow for a more formal comparative study of community members and Council's understandings and expectations of the community resilience building process.

\subsection{Recommendations}

Currently, it seems that community gardens participants do not have enough exposure to Wellington City Council's resilience plans. Although these documents are available freely online, community gardens members are unaware of current initiatives and therefore do not know there is more information to be sought out. There is space here to develop a stronger link between the Council and Wellington community gardens members and their larger communities to increase knowledge transfer between these two stakeholders. Community members need to not only be presented with the opportunity to access this information but also need to be actively encouraged to engage with this information. This opportunity is particularly important for individuals within the community who are interested in taking upon stronger leadership roles within their community. 
In the Wellington City Councils formation of resilience building initiatives, greater care also needs to be taken in defining both the term and the central focus. As discussed earlier in the chapter, defining the term resilience is a challenging process and an agreed upon definition which transcends disciplines is unlikely due to its already widespread use. However, this can be mitigated by ensuring use of the concept is defined within its context i.e. within each resilience planning initiative or institution. This removes uncertainty when communicating ideas between stakeholders. Although the term community resilience is understood in more similar ways between individuals, differences still exist in individuals framing of threats, 'desired state', and how to achieve resilience. Having an agreed upon understanding, or at least realising the differences between these understandings is necessary for collaborative work to ensure success. It is not within the scope of this research to suggest a working definition that would be appropriate for the Council; however, it is recommended that such a definition also incorporates community conceptions.

Community gardens provide a space for communities to build community resilience, specifically aspects of social capital and human resource development. Enhancing the transfer and dispersal of skills and knowledge, as well as the development of social capital, go hand in hand. Despite this there is scope to further develop community resilience through enhancing physical resources available to the community within community garden spaces. The development of resources such as water storage tanks, alternative power generation and further enhancement of food security would enhance community resilience through providing immediate necessities in the event of a disturbance such as an earthquake. These resources would reduce reliance on external service providers and provide immediate relief to the local community. 


\title{
Appendices
}

\author{
Appendix 1: Participant Information Sheet \\ SCHOOL OF GEOGRAPHY, ENVIRONMENT AND EARTH SCIENCES \\ 춘 \\ Te Kura Tatai Aro Whenua \\ VICTORIA UNIVERSTYY OF WELUNGTON, PO Box 600, Welington 6140, New Zealand

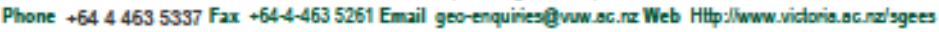

Participant Information Sheet for a Study on Community Resilience

Researcher: Tui Arona, School of Geography, Environment and Earth Sciences, Victoria University of Wellington

\begin{abstract}
About this project
I am a Masters student in Environmental Studies at Victoria University of Wellington. As part of this degree I am undertaking a research project leading to a thesis. The project I am undertaking is examining how ideas of community resilience are constructed by both communities and by councils. I am also looking at issues of responsibility and control of direction in creating resilience building initiatives. This research project has received approval from the Victoria University Human Ethics Committee.
\end{abstract}

\section{What is involved}

I am inviting participants, of ages 18 and over who are actively involved in community garden projects, to take part in this research. One to one interviews, of approximately one hour length, will form the basis of my research project. Interviews will be conducted in Wellington City at a time and place which is suitable for participants, a room will be provided on the Kelburn Campus of Victoria University, however if this location is unsuitable for the participant, an alternative agreed upon location will be arranged. The information you provide will be treated confidentially, however reference may be made to the location of the research i.e. Wellington City or the name of the Community Garden. You will not be individually identified in my research project or in any other presentation or publication. You will have the opportunity to review a transcript of our interview at your request, to ensure your thoughts have been correctly presented before they are used in analysis. All material collected will be kept confidential. No other person besides myself and my supervisors, Bethany Haalboom and Wokje Abrahamse will see the primary material collected from interviews. All interview material will be kept safe, locked in a filing drawer and all interview material will be destroyed within one year following the submission of the thesis.

What will happen with information you provide

The thesis produced using this material will be submitted for marking to the School of Geography, Environment and Earth Sciences and deposited in the University Library. The information retrieved from these interviews may also be used to contribute to articles intended for publication in scholarly journals, or for the construction of conference papers and presentations. Should you feel the need to withdraw from the project, you may do so without question at any time before 10/11/2014. Please contact me if this is the case so I am able to comply with your wishes. At the request of the participant a summary of findings will be provided following the conclusion of the research project.

\section{How to contact us}


If you have any further questions or would like to receive further information about the project, please contact me at, Tui.Arona@vuw.ac.nz, 044635233 ext. 8054 or my supervisor, Wokje Abrahamse, at the School of Geography, Environment and Earth Sciences at Victoria University, wokje.abrahamse@vuw.ac.nz, 044635217.

If you have any ethical concerns about the research please contact Dr Allison Kirkman (Allison.Kirkman@vuw.ac.nz), ph: 04463 5676, Chair of the Human Ethics Committee, Victoria University of Wellington.

Tui Arona 


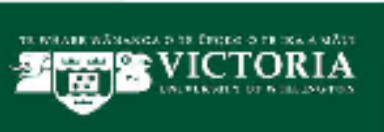

SCHOOL OF GEOGRAPHY, ENVIRONMENT AND EARTH SCIENCES Te Kura Tatai Aro Whenua

VICTORIA UNIVERSTY OF WELINGTON, PO Box 600, Welington 6140, New Zealand

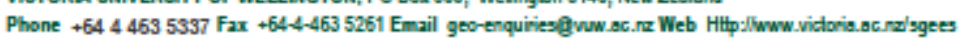

Participant Consent Form for a Study on Community Resilience

Researcher: Tui Arona, School of Geography, Environment and Earth Sciences, Victoria University of Wellington

I have been given and have understood the explanation of this research project. I have had an opportunity to ask questions and have them answered to my satisfaction. I understand that I may withdraw myself (or any information I have provided) from this project before 10/11/2014 without having to give reasons.

I understand that any information I provide will be kept confidential to the researcher, the supervisor. I understand the published results will not use my name, and that no opinions will be attributed to me in any way that will identify me. I understand that the tape recording of interviews will be wiped within one year following the submission of the project unless I indicate that I would like them returned to me.

Please tick this box if you would like to receive a summary of the results of the research when it is completed.

Please tick this box if you would like to receive a transcript of our interview.

If you have indicated that you would like to be sent either of these documents, please provide your contact details below. If you do not have an email address or would prefer a posted copy please input your postal address instead.

Email Address:

I fully understand the information presented on this document and agree to take part in this research

Signed:

Name of participant:

Date: 
Participant Interview Guide for a Study on Community Resilience Researcher. Tui Arona, School of Geography, Environment and Earth Sciences, Victoria University of Wellington

Interview Guide: Community Members

* Age, gender

$\diamond$ How long have you been involved in this community garden?

- Did you participate in any gardens before this one-Details?

$\diamond$ Why do you choose to participate in this garden?

$\diamond$ What benefits do you think this brings to both yourself and the wider community?

* What knowledge do you have of the term "resilience"? (If they are not aware of the word a generalised explanation of the term will be given i.e. Resilience is traditionally viewed as a systems ability to absorb shocks from an external source without effecting the systems identity or function. The term may also be substituted with words such as vulnerability, stability, instability, protection, etc. to allow for participant to grasp a better understanding of the term)

- What connotations do you associate with this term?

Do you view the term in a positive or negative light?

How do you think resilience is created?

What outcomes do you believe building resilience can achieve?

Have you heard of "community resilience"? What do you think "community resilience" might mean/refer to?

- Is this in-line with your local community's current situation? l.e. do you see your community as vulnerable, stable, unstable etc?

- If not: would you like to see it change in order to become more resilient? What actions need to happen in order to achieve this?

- If yes: What do you think has been the reason behind this? What action has you community taken in order to become resilient?

$\downarrow$ How do you think resilience should be manifested in our communities and day to day lives?

$\diamond$ Where do you believe responsibility for actions, payments and decisions such as these lies?

$\downarrow$ What role do you think communities or individuals should have in creating community resilience?

- Do you think the public are currently fulfilling this role or are interested in fulfilling this role?

$\omega$ What do you think the role of council or government should be in creating community resilience?

- Do you think the council are currently fulfilling this role?

$\downarrow$ Do you perceive a role for community gardens in building community resilience?

* Do you have any thoughts on how the enhancement of resilience may be achieved?

- Prompt for actions both global/large scale, local/small scale. 
Appendix 4: Ethics Approval

MEMORANDUM

Phone $\quad 0-4-4635676$

Fax $\quad 0-4-4635209$

Email Allisonkirkman9vuwac.ne

\begin{tabular}{l|l}
\hline TO & Tui Arona \\
\hline COPY TO & $\begin{array}{l}\text { Bethany Haalboom } \\
\text { Wokje Abrahamse }\end{array}$ \\
\hline FROM & Dr Allison Kirkman, Convener, Human Ethics Committee \\
\hline
\end{tabular}

\begin{tabular}{l|l}
\hline DATE & 2 July 2014 \\
\hline PAGES & 1 \\
\hline
\end{tabular}

\section{SUBJECT $\quad$ Ethics Approval: 21053}

Constructing community resilience: A comparative inquiry of institutional and community conceptualisations

Thank you for your application for ethical approval, which has now been considered by the Standing Committee of the Human Ethics Committee.

Your application has been approved from the above date and this approval continues until 1 March 2015. If your data collection is not completed by this date you should apply to the Human Ethics Committee for an extension to this approval.

Best wishes with the research.

Allison Kirkman

Human Ethics Committee

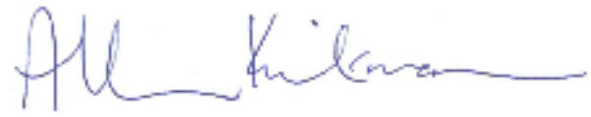


Appendix 5: Recruitment Flyer

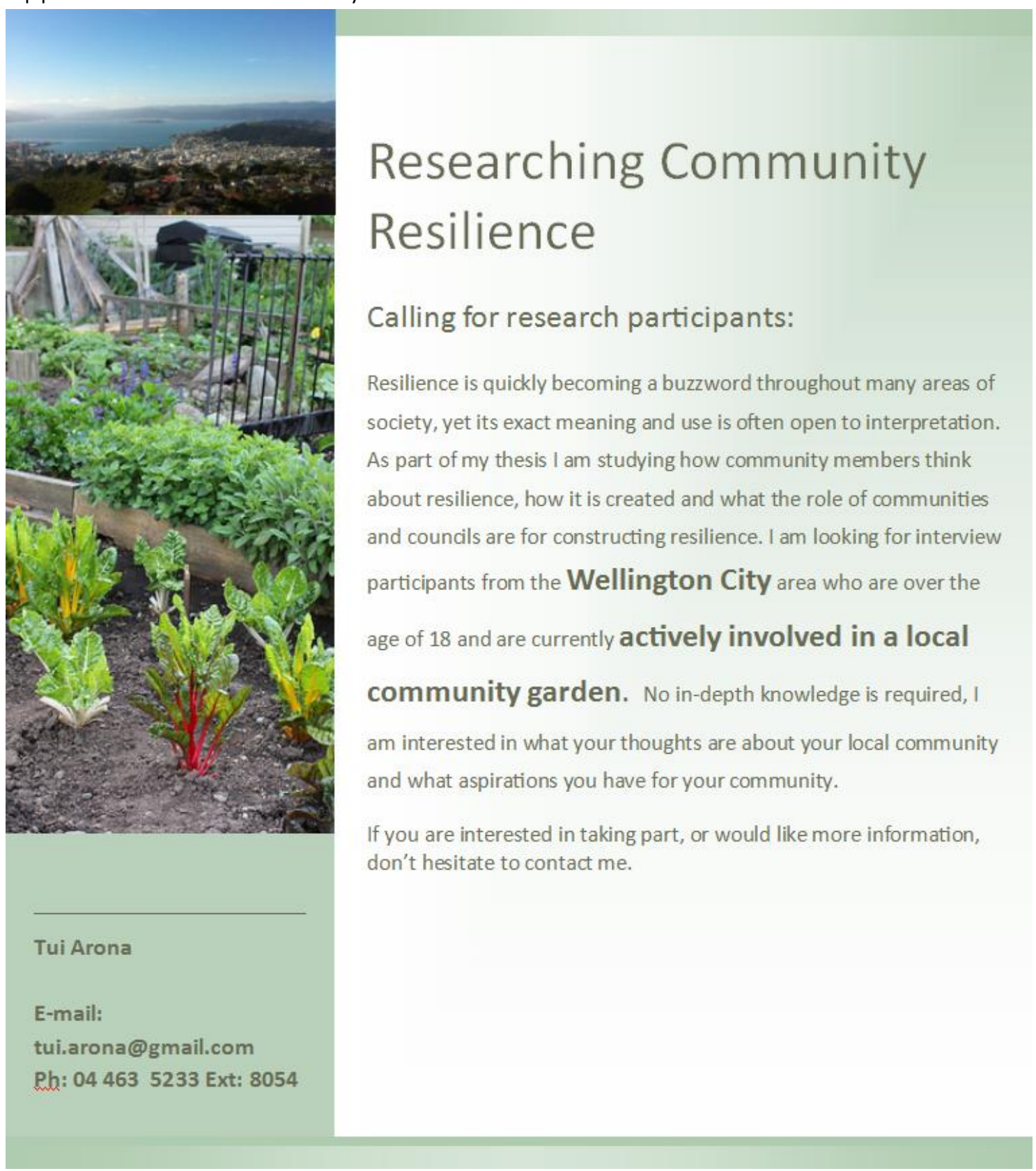




\section{References}

100 Resilient Cities. (2014). 100 Resilient Cities. Retrieved 29/07/2014, from http://www.100resilientcities.org/

Adger, W. N. (2000). Social and ecological resilience: are they related? Progress in Human Geography, 24(3), 347-364.

Alaimo, K., Reischl, T. M., \& Allen, J. O. (2010). Community gardening, neighborhood meetings, and social capital. Journal of Community Psychology, 38(4), 497-514.

Aldrich, D. P., \& Meyer, M. A. (2015). Social Capital and Community Resilience. American Behavioral Scientist, 59(2), 254-269.

Allen, P., FitzSimmons, M., Goodman, M., \& Warner, K. (2003). Shifting plates in the agrifood landscape: the tectonics of alternative agrifood initiatives in California. Journal of Rural Studies, 19(1), 61-75.

Armar-Klemesu, M. (2000). Urban agriculture and food security, nutrition and health. Growing cities, growing food. Urban agriculture on the policy agenda, 99-118.

Barrie, C. (2013). Kai o te Aro, Valley Voice. Retrieved from http://www.arovalley.org.nz/uploads/4/7/0/9/4709585/valley_voice_201308_november.pdf

Berkes, F., \& Folke, C. (1998). Linking social and ecological systems for resilience and sustainability. In F. Berkes, C. Folke \& J. Colding (Eds.), Linking social and ecological systems: management practices and social mechanisms for building resilience (pp. 1-26). Cambridge UK: Cambridge University Press.

Berkes, F., \& Ross, H. (2013). Community resilience: Toward an integrated approach. Society \& Natural Resources, 26(1), 5-20.

Bhattarya, S. (2005). Strategy for Identifying and evaluating sites for urban agriculture: $A$ case study of Gainesville, Florida. (Doctoral Dissertation ), University of Florida.

Braun, V., \& Clarke, V. (2006). Using thematic analysis in psychology. Qualitative research in psychology, 3(2), 77-101.

Brook, I. (2003). Making Here Like There: Place Attachment, Displacement and the Urge to Garden. Ethics, Place \& Environment, 6(3), 227-234.

Brown, K. (2014). Global environmental change I: A social turn for resilience? Progress in Human Geography, 38(1), 107-117.

Chaplowe, S. (1998). Havana's popular gardens:sustainable prospects for urban agriculture. Environmentalist, 18(1), 47-57.

Chavis, D., \& Wandersman, A. (1990). Sense of community in the urban environment: A catalyst for participation and community development. American Journal of Community Psychology, 18(1), 55-81. doi: 10.1007/BF00922689

Coffé, H., \& Geys, B. (2007). Toward an Empirical Characterization of Bridging and Bonding Social Capital. Nonprofit and Voluntary Sector Quarterly, 36(1), 121-139.

Common Ground Community Garden (09/08/2014). [Annual General Meeting].

Common Ground Community Garden. (n.d). About Common Ground Community Gardens. Retrieved 02/04/2015, from https://www.facebook.com/pages/Common-GroundCommunity-Gardens/341554588023?sk=info\&tab=page_info

Creswell, J. W. (2012). Qualitative inquiry and research design: Choosing among five approaches. Thousand Oaks, California: Sage.

Cretney, R. M. (2013). Ongoing Community Resilience from the Ground Up: A Relational Place Based Approach to Grassroots Community Resilience. Victoria University.

Davoudi, S., Shaw, K., Haider, L. J., Quinlan, A. E., Peterson, G. D., Wilkinson, C., . . Davoudi, S. (2012). Resilience: A Bridging Concept or a Dead End? "Reframing" Resilience: Challenges for Planning Theory and Practice Interacting Traps: Resilience Assessment of a Pasture Management System in Northern Afghanistan Urban 
Resilience: What Does it Mean in Planning Practice? Resilience as a Useful Concept for Climate Change Adaptation? The Politics of Resilience for Planning: A Cautionary Note. Planning Theory \& Practice, 13(2), 299-333.

Department of Internal Affairs. (2011). About local government. Local Council. Retrieved 16/03/2015, from http://www.localcouncils.govt.nz/

DeWalt, K. M., \& DeWalt, B. R. (2001). Participant observation: a guide for fieldworkers. Walnut Creek, CA: AltaMira Press.

Di Domenico, M., \& Phillips, N. (2010). Participant Observation. In A. Mills, G. Durepos \& E. Wiebe (Eds.), Encyclopedia of Case Study Research (pp. 653-656). Thousand Oaks, CA: Sage Publications, Inc.

Dreier, P. (1996). Community Empowerment Strategies: The Limits and Potential of Community Organizing in Urban Neighborhoods. Cityscape, 2(2), 121-159.

Easton, P. (2013). Protesters want prison site for public use. Retrieved 03/04/2015, from http://www.stuff.co.nz/dominion-post/news/wellington/8801895/Protesterswant-prison-site-for-public-use

Elwood, S. A., \& Martin, D. G. (2000). "Placing" Interviews: Location and Scales of Power in Qualitative Research. The Professional Geographer, 52(4), 649-657.

Fereday, J., \& Muir-Cochrane, E. (2006). Demonstrating Rigor Using Thematic Analysis: A Hybrid Approach of Inductive and Deductive Coding and Theme Development. International Journal of Qualitative Methods, 5(1), 1-11.

Ferguson, B. C., Brown, R. R., \& Deletic, A. (2013). A Diagnostic Procedure for Transformative Change Based on Transitions, Resilience, and Institutional Thinking. Ecology and Society, 18(4), 57.

Ferris, J., Norman, C., \& Sempik, J. (2001). People, Land and Sustainability: Community Gardens and the Social Dimension of Sustainable Development. Social Policy \& Administration, 35(5), 559-568.

Gecko Representative, (2/09/2014). [Meeting]. Wellington, New Zealand

Geels, F. W., \& Kemp, R. (2006). Transitions, transformations and reproduction: dynamics in socio-technical systems. In M. McKelvey \& M. Holmén (Eds.), Flexibility and stability in the innovating economy (pp. 227-256): Oxford.

Gerlach, L. P., \& Hine, V. H. (1970). People, power, change: Movements of social transformation. Indianapolis: Bobbs-Merril Company.

Glover, T. D., Parry, D. C., \& Shinew, K. J. (2005). Building Relationships, Accessing Resources: Mobilizing Social Capital in Community Garden Contexts. Journal of Leisure Research, 37(4), 450-474.

Gottlieb, R., \& Fisher, A. (1996). Community food security and environmental justice: Searching for a common discourse. Agriculture and Human Values, 13(3), 23-32.

Graedel, T. E., \& Klee, R. J. (2002). Getting serious about sustainability. Environmental science \& technology, 36(4), 523-529.

Grandy, G. (2009). Instrumental case study. In A. Mills, G. Eurepos \& E. Wiebe (Eds.), Encyclopedia of case study research (Vol. 1, pp. 473-475). Thousand Oaks, California: Sage.

Gregory, L. (2014). Resilience or Resistance? Time Banking in the Age of Austerity. Journal of Contemporary European Studies, 22(2), 171-183.

Guitart, D., Pickering, C., \& Byrne, J. (2012). Past results and future directions in urban community gardens research. Urban Forestry \& Urban Greening, 11(4), 364-373.

Gunderson, L. H., \& Holling, C. S. (2002). Panarchy: Understanding Transformations in Human and Natural Systems. Washington DC: Island Press.

Hassanein, N. (2003). Practicing food democracy: a pragmatic politics of transformation. Journal of Rural Studies, 19(1), 77-86. 
Hawkins, R. L., \& Maurer, K. (2010). Bonding, Bridging and Linking: How Social Capital Operated in New Orleans following Hurricane Katrina. British Journal of Social Work, 40(6), 1777-1793.

Haxeltine, A., \& Seyfang, G. (2009). Transitions for the People: Theory and Practice of 'Transition'and 'Resilience' in the UK's Transition Movement. Tyndall Centre for Climate-Change research.

Hay, I. (2010). Qualitative Research Methods in Human Geography: Oxford University Press, Incorporated.

Hayward, B. M. (2013). Rethinking Resilience: Reflections on the Earthquakes in Christchurch, New Zealand, 2010 and 2011. Ecology and Society, 18(4), 37.

Helliwell, J. F., \& Putnam, R. D. (2004). The social context of well-being. Philosophical transactions-royal society of London series B biological sciences, 359(1449), 14351446.

Holling, C. S. (1973). Resilience and Stability of Ecological Systems. Annual Review of Ecology and Systematics, 4, 1-23.

Hopkins, P. E. (2007). Positionalities and knowledge: Negotiating ethics in practice. ACME: An International E-Journal for Critical Geographies, 6(3), 386-394.

Innermost Gardens. (n.d). Innermost Gardens Retrieved 03/03/2015, from http://www.innermostgardens.org.nz/

Joseph, J. (2013). Resilience as embedded neoliberalism: a governmentality approach. Resilience, 1(1), 38-52.

King, N., \& Horrocks, C. (2010). Interviews in qualitative research. London: Sage.

Kingsley, J., \& Townsend, M. (2006). 'Dig In' to Social Capital: Community Gardens as Mechanisms for Growing Urban Social Connectedness. Urban Policy and Research, 24(4), 525-537.

Kitchin, R., \& Tate, N. J. (2000). Conducting research into human geography: Theory, Method and Practice. Essex, UK: Pearson Education Ltd.

Krasny, M. E., \& Tidball, K. G. (2009). Applying a resilience systems framework to urban environmental education. Environmental Education Research, 15(4), 465-482.

Leach, M. (2008). Re-framing resilience: trans-disciplinarity, reflexivity and progressive sustainability. Brighton, UK: STEPS.

Lele, S. (1998). Resilience, sustainability, and environmentalism. Ecological Economics, 2, 17.

Lenihan-Ikin, R. (2014). Funding Proposal for Wellbeing Initiative. Victoria University, Wellington: Gecko.

Levkoe, C. Z. (2006). Learning democracy through food justice movements. Agriculture and Human Values, 23(1), 89-98.

Lewicka, M. (2005). Ways to make people active: The role of place attachment, cultural capital, and neighborhood ties. Journal of Environmental Psychology, 25(4), 381395.

Lewis, M., \& Conaty, P. (2013). The Resilience Imperative: Cooperative Transitions to a Steady-state Economy: New Society Publishers.

Limb, M., \& Dwyer, C. (2001). Qualitative methodologies for geographers: Issues and debates. Arnold, London: Routledge.

Lorenz, D. F. (2013). The diversity of resilience: contributions from a social science perspective. Natural Hazards, 67(1), 7-24.

Lubin, D. A., \& Esty, D. C. (2010). The sustainability imperative. Harvard business review, $88(5), 42-50$.

Magis, K. (2010). Community resilience: an indicator of social sustainability. Society and Natural Resources, 23(5), 401-416. 
Manderson, L., Bennett, E., \& Andajani-Sutjahjo, S. (2006). The Social Dynamics of the Interview: Age, Class, and Gender. Qualitative Health Research, 16(10), 1317-1334.

McMichael, A. J., Butler, C. D., \& Folke, C. (2003). New visions for addressing sustainability. Science, 302(5652), 1919-1920.

Melnick, D. (2005). Environment and human well-being: a practical strategy. London, UK: Earthscan.

Mokai Kainga. (n.d). Mokai Kainga: Owhiro Community Gardens. Retrieved 06/03/2015, from http://www.mokaikainga.org.nz/community-gardens.html

Moore, T., Lapan, S., \& Quartaroli, M. (2012). Case study research. In T. Moore, S. Lapan \& M. Quartaroli (Eds.), Qualitative research: An introduction to methods and designs (pp. 243-270). San Francisco: Jossey-Bass.

Morgan, D. L. (2008). Snowball Sampling. In L. M. Given (Ed.), The Sage Encyclopedia of Qualitative Research Methods (pp. 816-817). Thousand Oaks, CA: SAGE Publications, Inc.

New Zealand Council of Christian Social Services. (n.d). Soil, Soul, Sustenance. Common Ground Gardens at the Home of Compassion, Wellington. Retrieved 02/04/2015, from http://www.nzccss.org.nz/site/page.php?page_id=194

Newtown Residents Association. (2014). A message from the Newtown Community Gardens. Retrieved 20/03/15, from http://newtown.org.nz/2014/11/20/amessage-from-the-newtown-community-gardens/

Norris, F. H., \& Stevens, S. P. (2007). Community Resilience and the Principles of Mass Trauma Intervention. Psychiatry: Interpersonal and Biological Processes, 70(4), 320328. doi: 10.1521 psyc.2007.70.4.320

Peterson, G., Allen, C. R., \& Holling, C. S. (1998). Ecological resilience, biodiversity, and scale. Ecosystems, 1(1), 6-18.

Poortinga, W. (2012). Community resilience and health: The role of bonding, bridging, and linking aspects of social capital. Health \& place, 18(2), 286-295.

Poulopoulos, A. (2013). Battle on for prison site. Retrieved 03/04/2015, from http://www.stuff.co.nz/dominion-post/news/local-papers/thewellingtonian/9044087/Battle-on-for-prison-site

Pudup, M. B. (2008). It takes a garden: Cultivating citizen-subjects in organized garden projects. Geoforum, 39(3), 1228-1240.

Radio New Zealand (Writer) \& Radio New Zealand (Director). (2014). Community Gardening (Part 2), The Weekend. Online: Radio New Zealand,.

Rocha, C. (2001). Urban Food Security Policy: The Case of Belo Horizonte, Brazil. Journal for the Study of Food and Society, 5(1), 36-47.

Rotarangi. (2012). Planted forests on ancestral land: the experiences and resilience of Māori land owners. University of Otago.

Schensul, J. J. (2012). Methodology, methods and tools in qualitative research. In S. D. Lapan, M. T. Quartaroli \& F. J. Riemer (Eds.), Qualitative Research: An Introduction to Methods and Designs. San Francisco, CA: Jossey-Bass.

Schugurensky, D., \& Mündel, K. (2005). Volunteer Work and Learning: Hidden Dimensions of Labour Force Training. In N. Bascia, A. Cumming, A. Datnow, K. Leithwood \& D. Livingstone (Eds.), International Handbook of Educational Policy (Vol. 13, pp. 9971022). Dordrecht, Netherlands: Springer.

Scoop Media. (2013). Guerilla gardeners start work on Mt Crawford - growing vegetables, herbs, fruit. Retrieved 03/04/2015, from http://wellington.scoop.co.nz/?p=57807

Scoop Media. (2014). Guerrilla Gardeners Come in From the Cold. Retrieved 03/04/2015, from http://www.scoop.co.nz/stories/AK1404/S00346/guerrilla-gardeners-comein-from-the-cold.htm 
Sherrieb, K., Norris, F. H., \& Galea, S. (2010). Measuring capacities for community resilience. Social Indicators Research, 99(2), 227-247.

Strunz, S. (2012). Is conceptual vagueness an asset? Arguments from philosophy of science applied to the concept of resilience. Ecological Economics, 76(0), 112-118.

Stumpp, E. (2013). New in town? On resilience and "Resilient Cities". Cities, 32(0), 164-166.

Swanborn, P. (2012). Case study research; what, why and how? (Vol. 27). Portland: Book News, Inc.

Tarrant, A. (2013). Negotiating Multiple Positionalities in the Interview Setting: Researching Across Gender and Generational Boundaries. The Professional Geographer, 66(3), 493-500.

Tegg, S. (2010). Motivation, Empowerment, and Cognitive Style in a Community of Practice. (Dissertation/Thesis), Victoria University of Wellington.

UN-Habitat (Producer). (n.d-a). City Resilience Profiling Programme. Retrieved from http://www.preventionweb.net/files/30049_30049finalbrochurecrpp.pdf

UN-Habitat. (n.d-b). City Resilience Profiling Programme. Retrieved 14/08/14, from http://unhabitat.org/initiatives-programmes/city-resilience-profiling-programme/

Wellington City Council. (2011a). Granting of Licence for a Community Garden to Mokai Kainga Maori Centre. (3). Wellington: Wellington City Council Retrieved from http://wellington.govt.nz/ /media/your-council/meetings/Committees/RegulatoryProcesses-

Committee/2011/11/09/files/9_november_2011_report_3_mokai_kainga_commu nity_gardens_at_tanera_park_final.pdf.

Wellington City Council. (2011b). Minutes: Wednesday 9 November. Wellington: Wellington City Council Retrieved from http://wellington.govt.nz/ /media/yourcouncil/meetings/Committees/Regulatory-ProcessesCommittee/2011/11/09/files/9_november_2011_minutes.pdf.

Wellington City Council. (2011c). Wellington Toward 2040: Smart Capital. Wellington: Wellington City Council Retrieved from http://wellington.govt.nz/ /media/yourcouncil/plans-policies-and-bylaws/plans-and-policies/a-toz/wellington2040/files/wgtn2040-brochure.pdf.

Wellington City Council. (2012a). Community Preparedness Grant. Retrieved 08/07/2014, from http://wellington.govt.nz/your-council/news/2012/02/communitypreparedness-grant

Wellington City Council. (2012b). Long Term Plan 2012-2022: Wellington City Council

Wellington City Council. (2013a). Granting of a ground licence to Innermost GardensIncorporated over part of town belt land at 141 Elizabeth St, Mt Victoria. (3). Wellington: Wellington City Council Retrieved from http://wellington.govt.nz/ /media/your-council/meetings/Committees/RegulatoryProcesses-

Committee/2013/04/17\%20April\%202013\%20Report\%203\%20part\%201\%20Inner most\%20Gardens.pdf.

Wellington City Council. (2013b). Minutes: Wednesday 17 April. Wellington: Wellington City Council Retrieved from http://wellington.govt.nz/ /media/yourcouncil/meetings/Committees/Regulatory-ProcessesCommittee/2013/04/17\%20April\%202013\%20minutes.pdf.

Wellington City Council. (2013c). Minutes: Wednesday 18 September. Wellington: Wellington City Council Retrieved from http://wellington.govt.nz/ /media/yourcouncil/meetings/Committees/Regulatory-Processes-Committee/2013/09/18September-2013-minutes.pdf.

Wellington City Council. (2013d). Proposed Community Garden License to the Newtown Residents Association Incorporated: Carrara Park, 107 Daniell Street, Newtown. (6). 
Wellington: Wellington City Council Retrieved from http://wellington.govt.nz/ /media/your-council/meetings/Committees/RegulatoryProcesses-Committee/2013/09/18-September-2013-Report-6-Carrara-ParkCommunity-Garden.pdf.

Wellington City Council. (2013e). Wellington Selected for UN Programme. Retrieved 10/08/2013, from http://wellington.govt.nz/yourcouncil/news/2013/04/wellington-selected-for-un-programme

Wellington City Council. (2014). Our Living City Fund: Past Allocations. Online: Retrieved from http://wellington.govt.nz/ /media/services/community-andculture/funding/files/Our-Living-City-Fund.pdf.

Wellington City Council. (n.d-a). Community Gardens. Retrieved 19/06/2014, from http://wellington.govt.nz/recreation/enjoy-the-outdoors/gardens/communitygardens

Wellington City Council. (n.d-b). Wellington City Council guidelines for community gardens. Retrieved from http://wellington.govt.nz/ /media/recreation/gardens/files/guidelines-communitygardens.pdf.

Wilson, G. A. (2012). Community Resilience and Environmental Transitions. Abingdon, Oxon: Routledge.

Yin, R. K. (2014). Case study research: design and methods. Los Angeles: Sage.

Zautra, A., Hall, J., \& Murray, K. (2008). Community development and community resilience: An integrative approach. Community Development, 39(3), 130-147. 